\title{
Title: Insulin/IGF Signaling Regulates Presynaptic Glutamate Release in Aversive Olfactory Learning
}

Authors: Du Cheng ${ }^{1}$, James Lee ${ }^{1}$, Maximillian Brown ${ }^{1,2}$, Margaret S. Ebert ${ }^{1}$, Masahiro Tomioka $^{3}$, Yuichi Iino ${ }^{3}$, Cornelia I Bargmann ${ }^{1,4, *}$

${ }^{1}$ Lulu and Anthony Wang Laboratory of Neural Circuits and Behavior, The Rockefeller University, 1230 York Avenue, New York, NY 10065, USA

${ }^{2}$ School of Earth and Environmental Sciences, Queens College, Queens, NY 11367

${ }^{3}$ Department of Biological Sciences, Graduate School of Science, The University of Tokyo, Bunkyo-ku, Tokyo, 113-0033, Japan

${ }^{4}$ Chan Zuckerberg Initiative, Redwood City, CA 94063, USA

*Correspondence to: cori@rockefeller.edu

\section{SUMMARY}

Information flow through neural circuits is continuously modified by context-dependent learning. In the nematode Caenorhabditis elegans, pairing specific odors with food deprivation results in aversion to the odor. Here we identify cell-specific mechanisms of insulin/IGF receptor signaling that integrate sensory information with food context during aversive olfactory learning. Using a conditional allele of the insulin/IGF receptor DAF-2, we show that aversive learning to butanone, an odor sensed only by the $\mathrm{AWC}^{\mathrm{ON}}$ olfactory neuron, requires DAF-2 in $\mathrm{AWC}{ }^{\mathrm{ON}}$. Learning requires an axonally-localized DAF-2c isoform and the insulin receptor substrate (IRS) protein IST-1, but is partly independent of the FoxO transcription factor DAF-16. Upon food deprivation, the unconditioned stimulus for learning, DAF-2 expression increases posttranscriptionally through an insulin- and ist-1-dependent process. Aversive learning suppresses odor-regulated glutamate release from $\mathrm{AWC}^{\mathrm{ON}}$ in wild-type animals but not in ist-1 mutants, suggesting that localized insulin signaling drives presynaptic depression to generate an aversive memory. 


\section{INTRODUCTION}

Insulin and Insulin-like Growth Factors (IGFs) are central regulators of glucose uptake, cell and organ growth, cell proliferation, and reproduction (Tokarz, et al., 2018; Yakar \& Adamo, 2012). Mammalian insulin/IGF receptors are transmembrane tyrosine kinases that initiate signaling after ligand binding by cross-phosphorylation and docking of Insulin Receptor Substrate (IRS) proteins (Kavran, et al., 2014). Phosphorylated IRS proteins then recruit PI3K (Phosphatidylinositol-4,5-bisphosphate 3-kinase) to the cell membrane, where it converts the lipid PIP2 (Phosphatidylinositol 4,5-bisphosphate) to PIP3 (Phosphatidylinositol $(3,4,5)$ trisphosphate). PIP3 in turn activates PDK and AKT kinases, resulting in phosphorylation of multiple downstream targets. For IGF receptor signaling, important targets include FoxO, a transcription factor that is phosphorylated and retained in the cytoplasm in an inactive form by Insulin/IGF signaling. For insulin receptor signaling, critical downstream targets include a cytoplasmic signaling pathway that regulates trafficking of the plasma membrane glucose transporter GLUT-4 to support glucose uptake.

Insulin/IGF signaling also functions in learning and memory. In the nematode worm Caenorhabditis elegans, it regulates aversive learning and memory in contexts where food deprivation acts as an unconditioned stimulus that drives learning (Cho, et al., 2016; Tomioka, et al., 2016; Lin, et al., 2010; Tomioka, et al., 2006). In Drosophila, insulin/IGF signaling acts at multiple times and places to promote olfactory associative learning: it supports development of the mushroom bodies, increases learning efficiency, and drives glucose mobilization for longterm memory formation (de Tredern, et al., 2021; Chambers, et al., 2015; Naganos, et al., 2012). Mammalian insulin/IGF signaling has been implicated in CNS plasticity and learning in the hypothalamus, hippocampus, olfactory bulb, nucleus accumbens, ventral tegmental area, and infralimbic cortex (Reviewed in (Ferrario \& Reagan, 2018; Dyera, et al., 2016)). Despite the robust circuit-level effects of insulin/IGF in mammals, the relevant cellular mechanisms of insulin/IGF action are only partly understood.

In C. elegans, pairing odors, salts, or temperature with differing food contexts can result in behavioral changes that are highly specific to the conditioned stimulus. For example, pairing the attractive odor butanone with food deprivation decreases attraction to butanone, without 
suppressing chemotaxis to other attractive odors (Colbert \& Bargmann, 1995), whereas pairing butanone with food increases attraction to butanone (Torayama, et al., 2007). In each case, butanone attraction behavior relies upon a single olfactory neuron, $\mathrm{AWC}^{\mathrm{ON}}$ (Torayama, et al., 2007; Wes \& Bargmann, 2001). Similarly, pairing salt with food deprivation suppresses salt attraction, and pairing salt with food increases salt attraction (Kunitomo, et al., 2013), in both cases through a single sensory neuron, ASER. The insulin-like neuropeptide INS-1 is a candidate to convey the unconditioned stimulus of food deprivation to these sensory neurons during learning. Aversive learning after pairing food deprivation with odors or salt is lost in ins-1 mutants (Tomioka, et al., 2016; Lin, et al., 2010; Tomioka, et al., 2006), but their appetitive learning after pairing butanone with food is normal (Lin, et al., 2010). INS-1 is released from AIA integrating neurons, and possibly other cells, and acts on sensory neurons to support aversive learning and memory. Both INS-1 and AIA are required in adults near the time of memory formation and retrieval (Cho, et al., 2016; Lin, et al., 2010; Tomioka, et al., 2006).

In addition to learning, C. elegans insulin/IGF signaling regulates development, metabolism, fertility, and lifespan (Murphy \& Hu, 2013). Its function has been best characterized in dauer formation, a stress-induced developmental arrest. A single gene, daf-2, is the ortholog of both insulin receptor and IGF receptors in mammals. Like those receptors, it is predicted to be a receptor tyrosine kinase that is regulated by insulin-like peptides, which can be either agonists or antagonists of $d a f-2$. daf-2 acts through age-1, which encodes a PI3K homolog, and the protein kinase homologs encoded by $p d k-1$, akt-1, and akt-2. The primary target of this signaling pathway is the forkhead FoxO transcription factor encoded by $d a f-16$, which is sequestered in the cytoplasm by daf-2 signaling, preventing access to its transcriptional targets. Surprisingly, the daf-2/daf-16 pathway is only modestly affected by inactivating the sole C. elegans IRS homolog, ist-1 (Wolkow, et al., 2002).

Studies of salt chemotaxis learning in ASER have revealed a second $d a f-2$ signaling pathway that is different from the daf-2/daf-16 transcriptional pathway (Tomioka, et al., 2016; Ohno, et al., 2014). $d a f-2$ encodes at least seven alternative protein isoforms, with DAF-2a being the most widely expressed and best characterized. In ASER, however, aversive learning requires a DAF2c isoform that includes 82 additional amino acids encoded by an alternative exon (Ohno, et al., 
2014). While the canonical DAF-2a protein is limited to the ASER cell body, the DAF-2c isoform required for learning is also present in the ASER axon, where its expression is increased by food deprivation (Ohno, et al., 2014). This localization suggests that axonal DAF-2c signaling may contribute to learning, and indeed, acute local activation of PI3K in the ASER axon can suppress salt attraction.

The insulin/IGF receptor $d a f-2$ is broadly expressed in neurons and non-neuronal tissues (Kimura, et al., 2011; Hunt-Newbury, et al., 2007). Null mutants in daf-2 are developmentally arrested or sterile, with widespread metabolic changes, creating challenges for studying the insulin receptor pathway at cellular resolution (Murphy \& Hu, 2013). Here we demonstrate that C. elegans ist-1 mutants lacking Insulin Receptor Substrate (IRS) activity are defective in aversive olfactory learning. By characterizing ist-1, which is expressed only in a small number of neurons, along with single-cell knockouts of the endogenous daf-2 locus, we identify an insulin/IGF signaling pathway required for aversive learning and show that it is acutely modulated by food deprivation, ins-1, and ist-1. The insulin/IGF receptor pathway suppresses odor-regulated glutamate release at olfactory synapses, providing a cellular mechanism for aversive memory. 


\section{RESULTS}

\section{The insulin receptor substrate mutant ist-1 is defective in aversive learning.}

During a targeted mutant screen, we made the serendipitous finding that an ist- 1 mutation caused profound defects in aversive olfactory learning (see Methods). As learning and memory can engage different molecular mechanisms depending on training and testing protocols, we characterized behavioral responses across a range of conditions designed to distinguish between aversive learning, appetitive learning, and non-associative desensitization. In aversive learning, an Unconditional Stimulus (US), food deprivation, is paired with a Conditional Stimulus (CS), butanone exposure, resulting in reduced chemotaxis to butanone (tested at a 1:1000 dilution) (Figure 1A-B). In appetitive learning, the US is bacterial food, paired with the same CS of butanone exposure; this training results in enhanced attraction to butanone (tested at a 1:10 dilution) (Arey, et al., 2018; Torayama, et al., 2007). Finally, after exposure to very high butanone concentrations, the $\mathrm{AWC}^{\mathrm{ON}}$ neuron becomes desensitized, regardless of food context, also resulting in reduced chemotaxis to 1:1000 butanone (Figure 1A-B) (Cho, et al., 2016; Pereira \& Van der Kooy, 2012). By varying the amount of butanone used in training, we found that desensitization required 100-fold higher butanone training concentrations than aversive learning, and $>1000$-fold higher butanone training concentrations than appetitive learning (Figure 1A-B).

Using these assays, we found that ist-1 null mutants had normal chemotaxis to butanone at baseline, but were highly defective in aversive learning across a 100-fold range of butanone training conditions (Figure 1C). They had a partial defect in desensitization and were normal in appetitive learning. We further examined their behavior by using computational video tracking to examine wild-type and mutant chemotaxis in butanone gradients. C. elegans approaches attractants using a biased random walk, in which it makes sustained forward runs when odor increases, but reorients its movement when odor decreases (Figure S1A) (Levy \& Bargmann, 2020; Pierce-Shimomura, et al., 1999). These reorientation behaviors were similar in naïve wildtype and ist-1 animals (Figure S1B). After training, reorientations were no longer correlated with the direction of the odor source in wild-type animals, but ist-1 mutants retained a substantial odor-oriented reorientation bias consistent with chemotaxis (Figure S1B-C). 


\section{ist-1 is required in the $\mathrm{AWC} \mathrm{CN}^{\mathrm{N}}$ neuron for aversive learning}

The ist-1 gene encodes a protein related to mammalian IRS proteins, with predicted phospholipid-binding pleckstrin homology (PH), phosphotyrosine binding (PTB), and Phosphatidyl Inositol 3-kinase (PI3K) binding domains (Wolkow, et al., 2002). Four ist-1 mRNAs differ based on their initiation sites and 5' exons (ist-1b/e versus ist-1c/d) and alternative splicing of two internal exons (ist-1b/c versus ist-1d/e) (Figure 2A). We observed significant defects in aversive learning in a newly-generated CRISPR-Cas9 allele predicted to affect only the ist-1b/e (long) isoforms, $k y 1074$, and stronger aversive learning defects in three alleles that disrupted all isoforms, $k y 1071, k y 1075$, and $o k 2706$ (Figure 2B).

Expression of an ist-1b cDNA under a $14.8 \mathrm{~kb}$ genomic fragment encompassing $9.3 \mathrm{~kb}$ upstream of the first initiation site, the first exon, and the $5.3 \mathrm{~kb}$ intron before the second initiation site resulted in full rescue of learning (Figure 2C). The same $14.8 \mathrm{~kb}$ fragment drove reliable GFP expression in eight pairs of head neurons (AWC, ASE, ASG, ASI, and BAG sensory neurons and RIM, AIM, and RIG interneurons (Figure 2D) and in some tail neurons (Figure S2C), overlapping the ist-1 expression pattern obtained from single-cell RNA sequencing data (Taylor, et al., 2021). Notably, ist-1 expression is absent in many neuronal and non-neuronal cells that express the insulin receptor daf-2 (Kimura, et al., 2011; Hunt-Newbury, et al., 2007). To define cells in which ist- 1 acts in aversive learning, ist-1b was expressed under shorter regions of the endogenous ist-1 promoter and under cell-specific promoters that overlapped with its expression pattern (Figure 2C, Figure S2). Expression of ist-1 in the $\mathrm{AWC}^{\mathrm{ON}}$ neuron, which is the primary butanone-sensing neuron, fully rescued aversive learning in ist-1 null mutants, whereas expression in other neurons or in the intestine did not (Figure 2C, Figure S2). A GFP-tagged IST-1 protein that rescued the ist- 1 aversive learning defect was broadly distributed in the axon, dendrite and cell body of $\mathrm{AWC} \mathrm{CN}^{\mathrm{ON}}$ and appeared to be excluded from the nucleus (Figure 2E). These results suggest that ist- 1 functions autonomously in the $\mathrm{AWC}^{\mathrm{ON}}$ sensory neuron to drive aversive learning. 


\section{ist-1 interacts with insulin pathway genes in aversive learning}

Aversive learning to butanone requires the insulin-related gene ins-1, which is expressed in the AIA interneurons, other neurons, and intestine, and the daf-2-regulated PI3 kinase age-1, which is required in $\mathrm{AWC}^{\mathrm{ON}}$ neurons (Takeishi, et al., 2020; Cho, et al., 2016) (Figure 3A-B). We found that several additional genes in the insulin pathway had either butanone chemotaxis defects or aversive learning defects. Loss of function mutants in the akt- 1 kinase had a deficit in aversive learning comparable to that of ins-1, ist-1 and age-1 mutants (Figure 3B). Insulin/IGF signaling in both vertebrates and invertebrates is negatively regulated by PTEN, a phosphatase that dephosphorylates PIP3 to form PIP2; daf-18 PTEN phosphatase mutants failed to chemotax to butanone before or after conditioning (Figure 3A-B).

To further determine the relationship between ist-1 and other genes in the pathway, we examined double mutants. Double mutants between ist-1 and the PTEN phosphatase daf-18 had mixed phenotypes: the daf-18 butanone chemotaxis defect was partially restored in daf-18; ist-1 double mutants, and aversive learning was restored as well (Figure 3C). These results are consistent with a model based on the mammalian insulin pathway, in which the insulin receptor DAF-2 activates the PI3 kinase AGE-1, the adaptor protein IST-1 potentiates the DAF-2/AGE-1 interaction, the DAF-18 phosphatase antagonizes AGE-1, and simultaneous loss of both IST-1 and DAF-18 permits residual AGE-1 activation by DAF-2 (Figure 3A). In agreement with this model focused on AGE-1 activation, age-1; daf-18 double mutants resembled age-1, with robust chemotaxis and no aversive learning (Figure $3 \mathrm{C}$ ). However, the daf-18 mutation used in this experiment is not a null allele, which limits the interpretation of these results.

daf-16 FoxO mutants do not chemotax to butanone (Daniels, et al., 2000). In addition, their behavior was not modified by aversive conditioning (Figure 3C). daf-16; ist-1 double mutants had a mixed phenotype: they had intermediate levels of chemotaxis to butanone, with diminished levels of aversive learning (Figure 3C). Since both ist-1 and daf-16 alleles were null alleles, this epistasis analysis indicates that each of these genes has some functions that are independent of the other. The daf-16 null phenotype was also partly suppressed in daf-16; age-1 double mutants (Figure 3C). 
The role of ist-1 in dauer development, the target of the canonical C. elegans insulin/IGF pathway, has been studied only through RNA interference (Wolkow, et al., 2002). Using the ist-1 deletion mutant ok2706, we confirmed that ist-1 mutants did not form dauers under well-fed conditions (data not shown). They were also similar to wild-type in mildly dauer-inducing conditions with limited food at high temperatures (Figure 3D), and were only slightly more likely than wild-type to form dauers when exposed to synthetic pheromones that resulted in substantial dauer formation (Figure 3D).

In summary, ist-1 (insulin receptor substrate), ins-1 (an insulin), age-1 (PI3K), and akt-1 (AKT) are all required for aversive butanone learning, and daf-18 (PTEN) antagonizes ist-1 in a way that is consistent with ist-1 and daf-18 action upstream of age-1. However, there are distinctions between the aversive learning pathway and the canonical C. elegans insulin/IGF pathway (Murphy \& Hu, 2013). ins-1 acts as an inhibitor of insulin signaling in dauer formation, but apparently as an activator (with a similar phenotype to age-1) in learning. ist-1 and akt-1 are essential for aversive learning, but not for dauer formation, where akt-1 is redundant with akt-2. $d a f-16$ is the final output of the $d a f-2$ pathway in dauer formation, and is epistatic to all other genes, but ist-1 function in aversive learning is partially independent of daf-16.

\section{The DAF-2c insulin receptor isoform supports aversive learning in $\mathrm{AWC}^{\mathrm{ON}}$}

One concern in studying insulin pathway mutants, particularly the essential gene daf-2, is that systemic physiological abnormalities in mutants might indirectly affect learning. To begin to address this point, we examined two daf-2 mutants that do not have overt developmental defects, but have taste avoidance defects when salt is paired with food deprivation (Nagashima, et al., 2019; Ohno, et al., 2014) (Figure 4A). The daf-2(pe1230) missense mutation affecting the extracellular domain was highly defective for butanone aversive learning (Figure 4B). A partial aversive learning defect was caused by the DAF-2c-specific allele $d a f-2 c(p e 2722)$ (Figure 4B), which selectively disrupts isoform-specific exon 11.5 that adds 82 amino acids to DAF-2c (Nagashima, et al., 2019; Ohno, et al., 2014). 
Next, we tested full-length $d a f-2 a$ and $d a f-2 c$ cDNAs expressed under the AWC ${ }^{\mathrm{ON}}$-selective str-2 promoter for rescue of $d a f-2$ mutant phenotypes. $d a f-2 c$ fully rescued the aversive learning defects of both $d a f-2(p e 1230)$ and $d a f-2 c($ pe2722) mutants. daf-2a did not significantly rescue aversive learning in $d a f-2 c(p e 2722)$ or $d a f-2$ (pe1230) mutants, although there was a trend toward rescue in daf-2(pe1230) (Figure 4C). The mutant and cell-specific rescue results suggest that the $d a f-2 c$ isoform has a primary role in aversive learning in $\mathrm{AWC}^{\mathrm{ON}}$, although other isoforms such as daf-2a may also contribute.

To further refine the site of $d a f-2$ action, we generated a conditional allele of the endogenous daf-2 locus susceptible to flippase-FRT inactivation. Two FRT sites flanking the second half of the $d a f-2$ gene were inserted by CRISPR-Cas9 recombination, and flippase was expressed under cell-selective promoters to inactivate $d a f-2$ only in selected cells (Figure 4A). Expression of flippase under an $\mathrm{AWC}^{\mathrm{ON}}$-selective promoter resulted in a partial aversive learning defect after butanone conditioning (Figure 4D). As a flippase activity reporter indicated that this transgene was also active in ASI neurons, and occasionally in other cells (Muñoz-Jiménez, et al., 2017) (Figure 4D and Methods), we used other promoters to confirm AWC ${ }^{\mathrm{ON}}$ as a relevant site of $d a f-2$ action. An ASI-specific daf-2 knockout did not affect aversive learning, while a sensory-specific daf-2 knockout that affected $\mathrm{AWC}^{\mathrm{ON}}$ and other sensory neurons disrupted aversive learning. Together, these results support a role for $d a f-2$ in $\mathrm{AWC}^{\mathrm{ON}}$ in aversive learning. The incomplete effect of $d a f-2$ inactivation in $\mathrm{AWC}^{\mathrm{ON}}$ in may be due to daf-2 activity in other cells, incomplete flippase recombination (see Methods), or pre-existing daf-2 mRNA or protein that persists in $\mathrm{AWC}^{\mathrm{ON}}$ after recombination.

\section{IST-1 has a minor role in the DAF-2c pathway for taste avoidance learning}

The involvement of the $d a f-2 c$ isoform in aversive olfactory learning suggested an analogy with taste avoidance learning, the associative learning behavior in which daf-2c was first characterized (Ohno, et al., 2014). Taste avoidance learning has similar properties to olfactory avoidance learning: when high salt is paired with food deprivation, animals lose their attraction to high salt (Figure 5A). ist-1 mutants had a partial decrease in taste avoidance learning (Figure 5B), while retaining normal preferences when high or low salt was paired with food (Figure S3). This defect was rescued by expressing ist-1 in ASER, the sensory neuron required for taste 
avoidance learning (Figure 5B). The ist-1 mutant defect in taste avoidance learning was milder than the defect in $d a f-2 c(p e 2722)$ mutants. daf-2c; ist-1 double mutants had strong defects resembling those of $d a f-2 c$ (Figure 5B).

daf-16 mutants are also defective in taste avoidance learning, resembling daf-2c(pe2722) (Figure 5B). Double mutants between the daf-16 and ist-1 mutants had a stronger defect than either single mutant (Figure 5B). A similar enhanced defect was observed in daf-16; daf-2c double mutants (Nagashima, et al., 2019) and in daf-16; daf-2c; ist-1 triple mutants (Figure 5B). These results are consistent with overlapping functions for $d a f-2 c$ and ist-1, and distinct functions for $d a f-16$, in taste avoidance learning.

In summary, ist-1, daf-2c, and daf-16 all affect both aversive olfactory learning and taste avoidance learning. For salt chemotaxis learning, the daf-2c(pe2722) mutant defect was more severe than that of ist-1, whereas for aversive olfactory learning the $i s t-1$ defect was more severe than that of $d a f-2 c($ pe2722). For both olfactory learning and taste learning, daf-16; ist-1 double mutants were different from either single mutant, indicating that daf-16 and ist-1 function at least partly in parallel (Figure 3B, 5B).

\section{Food deprivation and insulin signaling regulate DAF-2 levels in $\mathrm{AWC}^{\mathrm{ON}}$}

In the ASER neurons that mediate taste avoidance learning, mVenus-tagged DAF-2a protein is restricted to the cell body, while mVenus-tagged DAF-2c protein is present in the cell body, axons, and synaptic regions (Ohno, et al., 2014). We observed similar subcellular localization patterns of mVenus-tagged DAF-2a and DAF-2c in AWC ${ }^{\mathrm{ON}}$. DAF-2a was present in the AWC dendrite and cell body, with a somatic pattern suggesting nuclear exclusion, but was undetectable in the $\mathrm{AWC} \mathrm{ON}^{\mathrm{N}}$ axon (Figure 6A-C), whereas DAF-2c was present in the dendrite, cell body and axon of $\mathrm{AWC}^{\mathrm{ON}}$ (Figure 6D-F).

The levels of tagged DAF-2a and DAF-2c protein in AWC ${ }^{\mathrm{ON}}$ increased after 90 minutes of food deprivation, the unconditioned stimulus used for aversive conditioning, but their subcellular localization patterns were unchanged (Figure 6A-F). In control experiments, expression of GFP under the same $\mathrm{AWC}^{\mathrm{ON}}$-selective str-2 promoter was not affected by food deprivation, 
suggesting that DAF-2 translation, trafficking, or stability is altered post-transcriptionally (Figure 6G).

In mammals, insulin signaling results in internalization of insulin receptors, which may subsequently return to the cell surface or be degraded (Chen, et al., 2019). With that in mind, we asked whether insulin signaling itself might contribute to the observed changes in DAF-2 protein expression. Indeed, food deprivation did not affect AWC ${ }^{\mathrm{ON}}$ DAF-2 levels in ist-1 or ins- 1 mutants (Figure 6B-C, Figure 6E-F). Since ist- 1 has a minor role in salt learning, we asked whether ist-1 also plays a role in the localization of DAF-2c in the salt-sensing ASER neuron. The levels of mVenus-tagged DAF-2c in the ASER axon increased after 90 minutes of food deprivation in wild-type animals, but not in ist-1 mutants (Figure 6H). These results suggest that food regulates DAF-2 protein in sensory neurons via ins-1 and ist-1.

\section{Aversive learning suppresses odor-dependent glutamate release from $\mathrm{AWC}^{\mathrm{ON}}$}

To ask how ist-1-dependent insulin signaling affects $\mathrm{AWC}^{\mathrm{ON}}$ responses to odor in naïve and trained animals, we employed the genetically-encoded calcium indicator GCaMP5. AWC ${ }^{\text {ON }}$ calcium responses to butanone pulses were normal in ist- 1 mutants across a 100,000-fold range of butanone concentrations, consistent with their normal chemotaxis (Figure 7A-B). Sustained exposure to high butanone, with or without food, causes a ten-fold reduction in $\mathrm{AWC}^{\mathrm{ON}}$ butanone sensitivity across its dynamic range that persists for at least 30 minutes (Cho, et al., 2016). This nonassociative $\mathrm{AWC}^{\mathrm{ON}}$ desensitization was similar in wild-type and ist-1 animals (Figure 7B). We conclude that the aversive learning defect in ist- 1 mutants arises downstream of the AWC ${ }^{\mathrm{ON}}$ calcium signal, as previously proposed for ins-1 and age-1 insulin/IGF pathway genes (Cho, et al., 2016).

The AWC ${ }^{\mathrm{ON}}$ neuron releases the classical neurotransmitter glutamate and a number of neuropeptides (Chalasani, et al., 2010; Chalasani, et al., 2007). An AWC-selective knockout of eat-4, the vesicular glutamate transporter, was generated using FLP::FRT recombination targeted to the endogenous eat-4 locus (López-Cruz, et al., 2019). AWC knockout of eat-4 resulted in a butanone chemotaxis defect comparable to that of the eat-4 null mutant (Figure 7C). These 
animals had a slight reduction in chemotaxis after pairing butanone and food deprivation, as did eat-4 null mutants. Thus, AWC glutamate release is important for butanone chemotaxis, but likely functions together with additional AWC neurotransmitters.

To investigate the synaptic properties of $\mathrm{AWC}^{\mathrm{ON}}$, we used a reporter strain in which the EAT-4 transporter was fused to $\mathrm{pHluorin}$, a $\mathrm{pH}$-sensitive version of GFP whose fluorescence increases when acidic glutamatergic synaptic vesicles fuse with the plasma membrane (Ventimiglia \& Bargmann, 2017). Naïve wild-type animals and ist-1(ok2706) mutants had similar AWC responses to butanone addition and removal using this synaptic reporter (Figure 7D, E). After pairing butanone with food deprivation, EAT-4::pHluorin responses to odor pulses were reduced in wild-type $\mathrm{AWC}^{\mathrm{ON}}$ neurons for at least 30 minutes, consistent with a dampened synaptic response to odor (Figure 7D, E). Importantly, this synaptic effect was observed at butanone concentrations that elicited strong GCaMP responses in both naïve and trained animals (Figure 7B). By contrast, $\mathrm{AWC}^{\mathrm{ON}}$ neurons in ist-1 mutants retained substantial odor-regulated glutamate release after training, providing a synaptic correlate of their defect in aversive learning (Figure $7 \mathrm{D}, \mathrm{E})$. These results suggest that aversive learning reduces odor-regulated glutamate release from $\mathrm{AWC}^{\mathrm{ON}}$ via ist-1-dependent insulin/IGF signaling.

To further explore the relationship between synaptic transmission and aversive learning, we examined PKC-1, a presynaptic protein kinase $\mathrm{C}$ homolog that stimulates glutamate release from $\mathrm{AWC}^{\mathrm{ON}}$ neurons (Figure 3A) (Ventimiglia \& Bargmann, 2017) and neuropeptide secretion (Sieburth, et al., 2007). PKC-1 is activated by Gq-PLC signaling; in AWC ${ }^{\mathrm{ON}}$, pkc-1 and Gq are key effectors of appetitive learning after pairing butanone with food (Arey, et al., 2018). pkc-1 mutants were repelled by butanone, and only slightly affected by pairing butanone with food deprivation (Figure 7F). Their chemotaxis defect was rescued by expressing $p k c-1$ in AWC ${ }^{\mathrm{ON}}$, and interestingly, the rescued strain was defective in aversive learning (Figure 7F). The learning defect might be due to $p k c-1$ overexpression in $\mathrm{AWC}^{\mathrm{ON}}$ or the absence of $p k c-1$ in another cell type, so we next examined a strain in which a $p k c-1(g f)$ cDNA was specifically expressed in $\mathrm{AWC}^{\mathrm{ON}}$ in wild-type animals. The AWC ${ }^{\mathrm{ON}}:$ :pkc- $1(g f)$ strain was highly defective in aversive learning, consistent with a role for $\mathrm{AWC}^{\mathrm{ON}}$ presynaptic regulation in learning and memory (Figure 7F). 


\section{DISCUSSION}

These results provide three new insights into insulin/IGF signaling in olfactory learning. First, aversive learning in $\mathrm{AWC}^{\mathrm{ON}}$ engages a cell type-specific insulin-daf-2 signaling pathway that includes the adaptor protein IST-1. Second, insulin/IGF signaling causes DAF-2c insulin receptor levels to rise during food deprivation, suggesting an acute function that sets the stage for learning. Third, aversive training inhibits odor-regulated glutamate release from $\mathrm{AWC}^{\mathrm{ON}}$ via the insulin/IGF signaling pathway. Through cell-specific inactivation of the endogenous daf-2 locus, and through the analysis of $i s t-1$ mutants that have restricted defects in insulin/IGF signaling, we were able to localize ist- 1 and $d a f-2$ functions in aversive learning to $\mathrm{AWC}^{\mathrm{ON}}$ sensory neurons. These genetic tools allowed us to avoid systemic developmental and metabolic effects of this critical endocrine pathway.

\section{Aversive learning uses a cell type-specific insulin/IGF signaling pathway}

The insulin-related molecule encoded by ins- 1 and the insulin receptor encoded by daf-2 are both required for aversive learning. By contrast, ins -1 and $d a f-2$ have opposite effects on dauer formation (Kodama, et al., 2006). C. elegans has 40 genes that encode insulin-like peptides, and the $d a f-2$ gene encodes at least seven different protein isoforms with different functions (Ohno, et al., 2014; Martinez, et al., 2020). Structural studies of mammalian insulin and IGF-1 receptors predict that the DAF-2c-specific exon is adjacent to the primary ligand-receptor interface, and therefore could alter interactions between DAF-2 and insulin ligands (Gutmann, et al., 2019; Li, et al., 2019; Scapin, et al., 2018). We speculate that INS-1 activates DAF-2c, the isoform implicated in aversive learning, but inhibits the DAF-2a isoform used in dauer development.

In alternative models, INS-1 might not act directly on $\mathrm{AWC}^{\mathrm{ON}}$, but indirectly via other cells. Insulin-to-insulin relays have been observed in several settings in C. elegans: for example, in pathogen-related learning, INS-7 from the URX sensory neuron antagonizes the insulin/IGF receptor DAF-2 in RIA interneurons, to prevent learning, while INS-6 secreted from the ASI sensory neurons suppresses INS-7 production from URX neurons, thereby disinhibiting RIA and 
allowing learning (Chen, et al., 2013). Several other neuronal insulins participate in long-term activity-dependent regulation that results in compensation across circuits (Yeon, et al., 2021). Results like these underscore the value of the cell type-specific daf-2 knockout used here, which demonstrates a direct requirement for $d a f-2$ in $\mathrm{AWC}^{\mathrm{ON}}$, although it leaves open the possibility that $d a f-2$ acts in other cell types as well.

Insulin and insulin-like signaling are usually associated with nutrients and growth in both vertebrates and invertebrates. However, the aversive learning paradigms for odor and salt in $C$. elegans require ins-1, daf-2c, and insulin signaling in the opposite context, food deprivation. ins1 signaling from the intestine drives food deprivation-induced thermosensory plasticity, consistent with a role for ins-1 in encoding the low-food context (Takeishi, et al., 2020). Moreover, ins- 1 expression is upregulated by starvation both in the intestine and in the AIA neurons that regulate AWC plasticity (Takeishi, et al., 2020). We observed that DAF-2 levels in $\mathrm{AWC}^{\mathrm{ON}}$ increase upon food deprivation through a post-transcriptional mechanism that requires ist-1 and ins-1. These results suggest that acute insulin signaling during food deprivation results in altered translation, stabilization, or trafficking of DAF-2 receptors, and sets the stage for learning. There is precedent for such post-transcriptional regulation in mammals, where insulin/IGF receptors are internalized and may be degraded after ligand binding (Chen, et al., 2019), but IRS (IST-1) can promote retention of IGF-IR complexes on the plasma membrane instead of degradation by blocking an AP2 binding site (Yoneyama, et al., 2018).

IRS proteins are required for insulin/IGF signaling in mammals and in Drosophila, but were not previously thought to be important in C. elegans (Wolkow, et al., 2002). We found that ist-1 has a prominent role in aversive olfactory learning. Expression of ist-1 is highly enriched in AWC, ASE, AFD, and BAG sensory neurons, all of which show robust plasticity upon food deprivation. One possibility is that ist- 1 preferentially contributes to neuronal and behavioral daf2 signaling, and less to endocrine and developmental daf-2 signaling in C. elegans; a second possibility is that IST-1 potentiates INS-1/DAF-2c interactions through inside-out signaling. Olfactory learning also has a strict requirement for the AKT-related kinase akt-1, whereas in development akt-1 is largely redundant with akt-2. akt-1 expression is enriched in many of the same neurons that express ist-1, including AWC, ASE, and BAG (Taylor, et al., 2021). Whether 
akt-1 and akt-2 differ only in their expression, or also in function, remains to be determined. Mammalian Akt1, Akt2, and Akt3 have different cellular and subcellular distributions (Santi \& Lee, 2010), and distinct roles in synaptic plasticity in the hippocampus (Levenga, et al., 2017).

The analysis of double mutants suggests that insulin/IGF receptor signaling has two targets in $\mathrm{AWC}^{\mathrm{ON}}$ : one that depends on the $d a f-16$ transcriptional regulatory pathway, and one that does not. Similarly, in salt chemotaxis, insulin signaling occurs through one pathway that requires daf$2 a$ and $d a f-16$, and a second pathway that is $d a f-2 c$-dependent and $d a f-16$-independent (Nagashima, et al., 2019). Using temperature-sensitive mutations in daf-2, Lin et al. (2010) showed that insulin/IGF signaling is required both for the formation and for the retrieval of an aversive olfactory memory. It is possible that these temporally distinct functions are associated with molecularly distinct insulin/IGF signaling pathways.

\section{Aversive learning suppresses presynaptic glutamate release from AWC ${ }^{\text {ON }}$}

Odor responses in $\mathrm{AWC}^{\mathrm{ON}}$ are regulated by olfactory experience and/or insulin/IGF signaling across multiple timescales. Sustained butanone exposure with food results in non-associative desensitization of $\mathrm{AWC}^{\mathrm{ON}}$ calcium responses to butanone, but this is insufficient for aversive learning (Cho, et al., 2016). Insulin/IGF signaling transiently suppresses AWC ${ }^{\mathrm{ON}}$ calcium responses through a rapid feedback loop, but this functional plasticity is short-lived compared to aversive learning (Cho, et al., 2016; Chalasani, et al., 2010). Here, we show that sustained pairing of butanone odor with food deprivation results in suppression of odor-regulated glutamate release from $\mathrm{AWC}^{\mathrm{ON}}$. This presynaptic depression requires association of food deprivation with odor, as expected for aversive learning, and is retained for at least 30 minutes, consistent with the hour-long chemotaxis assay. As glutamate release from AWC is required for efficient chemotaxis and the odor-regulated turning behavior used in chemotaxis, this functional change is likely to contribute to behavioral changes after learning (Tsunozaki, et al., 2008; Chalasani, et al., 2007). A similar mechanism has been proposed to play a role in aversive taste learning, where calcium responses to salt in ASER sensory neurons are preserved but synaptic pHluorin signals are decreased after training (Oda, et al., 2011). The detailed mechanism by which insulin signaling suppresses glutamate release remains to be determined, and might 
involve AGE-1 mobilization of lipids that regulate synaptic proteins such as protein kinase C (PKC-1) (Ohno et al., 2014), AKT-1-dependent protein phosphorylation, or regulation of gene expression.

How is food deprivation associated with odor cues? Olfactory signal transduction in $\mathrm{AWC}^{\mathrm{ON}}$ is mediated by cGMP, and one site of odor-food convergence is the cGMP-dependent protein kinase EGL-4. When butanone is present for an hour or more, and DAF-2/AGE-1 signaling is active, EGL-4 translocates from the AWC ${ }^{\mathrm{ON}}$ cytoplasm to the nucleus (Cho, et al., 2016; Lee, et al., 2010; O'Halloran, et al., 2009; Torayama, et al., 2007; L'Etoile, et al., 2002). Like INS-1, EGL-4 is required for aversive but not appetitive learning (Cho, et al., 2016; Torayama, et al., 2007). The sustained coincidence of EGL-4 and insulin/IGF activity when odor is paired with food deprivation could represent a signal for associative learning. Proteomic studies indicate that EGL-4 is enriched in presynaptic regions (Artan, et al., 2021), where it could interact with DAF2 signaling components. As mammalian EGL-4 homologs potentiate synaptic release in nociceptive neurons (Luo, et al., 2012), it is possible that depletion of presynaptic EGL-4 could contribute to synaptic depression in $\mathrm{AWC}^{\mathrm{ON}}$, along with EGL-4-dependent transcriptional changes in the nucleus.

Olfactory neurons in all animals consist of many classes with distinct odor responses. Recent results have shown that mouse olfactory sensory neurons regulate dozens of activity-sensitive genes within a few hours in a novel olfactory environment, in a cell type-specific fashion, resulting in altered odor responses (Tsukahara, et al., 2021). Food deprivation is a powerful motivating stimulus in all animals (Smith \& Grueter, 2021), and insulin receptors are prominently expressed in the rodent olfactory bulb (Kuboki, et al., 2021; Aimé, et al., 2012). It will be interesting to ask whether insulin signaling can modify mammalian olfactory neurons to provide associative input to an odor context. More broadly, insulin resistance in type-2 diabetes is associated with increased risk of Alzheimer's disease, whose early symptoms include defects in olfactory processing (Talbot, et al., 2012). We speculate that exploring the relationship between insulin/IGF and learning in mammals could lead to a deeper understanding of these clinical findings. 


\section{AUTHOR CONTRIBUTIONS}

D.C. and C.I.B. designed experiments. D.C. conducted molecular, cellular, and behavioral analyses of olfactory learning. J.L. conducted dauer formation experiments. M.T. and Y.I. conducted salt learning experiments. D.C., M.B. and M.E. generated the CRISPR daf-2 conditional knockout line. D.C. and C.I.B. analyzed and interpreted results and wrote the paper with input from all authors.

\section{DECLARATION OF INTERESTS}

D.C. is the owner of iDu Optics LLC, a company that manufactures the LabCam device used in microscopy imaging, including C. elegans research. LabCam was not used in this study.

\section{ACKNOWLEDGEMENTS}

We thank the Caenorhabditis Genetics Center (NIH P40 OD010440) for strains, Patrick McGrath for sequence analysis of ist-1 (ky1071), Rebecca Butcher for synthetic ascarosides, Christine Cho, Alejandro Lopez, Elias Scheer, Navin Pokala, May Dobosiewicz, Aylesse Sordillo, and Donovan Ventimiglia, for advice and discussion, and Aylesse Sordillo, Elias Scheer, Yoav Printz, and Audrey Harnagel for comments on the manuscript. Du Cheng was supported by the Paul and Daisy Soros Fellowship for New Americans and by a Medical Scientist Training Program grant from the National Institute of General Medical Sciences of the NIH (T32GM007739) to the Weill Cornel1/Rockefeller/Sloan Kettering Tri-Institutional MD$\mathrm{PhD}$ Program. This work was supported by the Howard Hughes Medical Institute, of which Cori Bargmann was an investigator, and by the Chan Zuckerberg Initiative. 


\section{REFERENCES}

Aimé, P., Hegoburu, C., Jaillard, T., Degletagne, C., Garcia, S., Messaoudi, B., Thevenet, M., Lorsignol, A., Duchamp, C., Mouly, A., and Julliard, A. K. (2012). A physiological increase of insulin in the olfactory bulb decreases detection of a learned aversive odor and abolishes food odor-induced sniffing behavior in rats. PLoS One 7, e51227. 10.1371/journal.pone.0051227.

Arey, R. N., Stein, G. M., Kaletsky, R., Kauffman, A., \& Murphy, C. T. (2018). Activation of Gaq signaling enhances memory consolidation and slows cognitive decline. Neuron 98, 562-574. 10.1016/j.neuron.2018.03.039.

Arribere, J. A., Bell, R. T., Fu, B. X., Artiles, K. L., Hartman, P. S., \& Fire, A. Z. (2014).

Efficient marker-free recovery of custom genetic modifications with CRISPR/Cas9 in Caenorhabditis elegans. Genetics 198, 837-846. 10.1534/genetics.114.169730.

Artan, M., Barratt, S., Flynn, S. M., Skehel, M., Nicolas, A., \& de Bono, M. (2021). Interactome analysis of Caenorhabditis elegans synapses by TurboID-based proximity labeling. J Biol Chem. 297, 101094. 10.1016/j.jbc.2021.101094.

Bloemer, J., Bhattacharya, S., Amin, R., \& Suppiramaniam, V. (2014). Impaired insulin signaling and mechanisms of memory loss. Progress in molecular biology and translational science, 121, 413-449. 10.1016/B978-0-12-800101-1.00013-2.

Brenner, S. (1974). The Genetics of Caenorhabditis elegans. Genetics 77, 71-94.

Butcher, R.A., Ragains, J.R., Kim, E. \& Clardy, J., 2008. A potent dauer pheromone component in Caenorhabditis elegans that acts synergistically with other components. Proc Natl Acad Sci USA. 105:14288-14292. 10.1073/pnas.0806676105.

Chalasani, S. H., Chronis, N., Tsunozaki, M., Gray, J. M., Ramot, D., Goodman, M. B., \& Bargmann, C. I. (2007). Dissecting a circuit for olfactory behaviour in Caenorhabditis elegans. Nature 450, 63-70. 10.1038/nature06292.

Chalasani, S. H., Kato, S., Albrecht, D. R., Nakagawa, T., Abbott, L. F., \& Bargmann, C. I. (2010). Neuropeptide feedback modifies odor-evoked dynamics in Caenorhabditis elegans olfactory neurons. Nature Neuroscience 13, 615-621. 10.1038/nn.2526.

Chambers, D. B., Androschuk, A., Rosenfelt, C., Langer, S., Harding, M., \& Bolduc, F. V. (2015). Insulin signaling is acutely required for long-term memory in Drosophila. Front Neural Circuits. Front Neural Circuits. 9, 8. 10.3389/fncir.2015.00008.

Chen, Y., Huang, L., Qi, X., \& Chen, C. (2019). Insulin receptor trafficking: consequences for insulin sensitivity and diabetes. Int J Mol Sci. 20, 5007. 10.3390/ijms20205007.

Chen, Z., Hendricks, M., Cornils, A., Maier, W., Alcedo, J., \& Zhang, Y. (2013). Two insulinlike peptides antagonistically regulate aversive olfactory learning in C. elegans. Neuron, 77, 578585. 10.1016/j.neuron.2012.11.025.

Cho, C. E., Brueggemann, C., L'Etoile, N. D., \& Bargmann, C. I. (2016). Parallel encoding of sensory history and behavioral preference during Caenorhabditis elegans olfactory learning. eLIFE 5, e14000. doi: 10.7554/eLife.14000. 
Chronis, N., Zimmer, M., \& Bargmann, C. I. (2007). Microfluidics for in vivo imaging of neuronal and behavioral activity in Caenorhabditis elegans. Nature Methods 4, 727-731. $10.1038 /$ nmeth1075.

Colbert, H. A., \& Bargmann, C. I. (1995). Odorant-specific adaptation pathways generate olfactory plasticity in C. elegans. Neuron 14, 803-812. 10.1016/0896-6273(95)90224-4.

Daniels, S. A., Ailion, M., Thomas, J. H., \& Sengupta, P. (2000). egl-4 acts through a transforming growth factor-beta/SMAD pathway in Caenorhabditis elegans to regulate multiple neuronal circuits in response to sensory cues. Genetics 156, 123-141.

10.1093/genetics/156.1.123.

de Tredern, E., Rabah, Y., Pasquer, L., Minatchy, J., Plaçais, P.-Y., \& Preat, T. (2021). Glial glucose fuels the neuronal pentose phosphate pathway for long-term memory. Cell Rep. 36, 109620. 10.1016/j.celrep.2021.109620.

Dokshin, G. A., Ghanta, K. S., Piscopo, K. M., \& Mello, C. C. (2018). Robust genome editing with short single-stranded and long, partially single-stranded DNA donors in Caenorhabditis elegans. Genetics 210, 781-787. 10.1534/genetics.118.301532.

Dyera, A. H., Vahdatpoura, C., Sanfeliub, A., \& Tropeab, D. (2016). The role of Insulin-Like Growth Factor 1 (IGF-1) in brain development, maturation and neuroplasticity. Neuroscience 325, 89-99. 10.1016/j.neuroscience.2016.03.056.

Ferrario, C. R., \& Reagan, L. (2018). Insulin-mediated synaptic plasticity in the CNS: Anatomical, functional and temporal contexts. Neuropharmacology 136, 182-191. 10.1016/j.neuropharm.2017.12.001.

Gutmann, T., Schäfer, I. B., Poojari, C., Brankatschk, B., Vattulainen, I., Strauss, M., \& Coskun, Ü. (2019). Cryo-EM structure of the complete and ligand-saturated insulin receptor ectodomain. Journal of Cell Biology 219, e201907210. 10.1083/jcb.201907210.

Hunt-Newbury, R., Viveiros, R., Johnsen, R., Mah, A., Anastas, D., Fang, L., Halfnight, E., Lee, D., Lin, J., Lorch, J., et al. (2007). High-throughput in vivo analysis of gene expression in Caenorhabditis elegans. Plos Biology 5, e237. 10.1371/journal.pbio.0050237.

Kamal, A., Biessels, G. J., Urban, I. J., \& Gispen, W. H. (1999). Hippocampal synaptic plasticity in streptozotocin-diabetic rats: impairment of long-term potentiation and facilitation of long-term depression. Neuroscience, 90, 737-745. 10.1016/s0306-4522(98)00485-0.

Kavran, J. M., McCabe, J. M., Byrne, P. O., Connacher, M. K., Wang, Z., Ramek, A., Sarabipour, S., Shan, Y., Shaw, D., et al., Leahy, D. J. (2014). How IGF-1 activates its receptor. eLife 3, e03772. 10.7554/eLife.03772.

Kimura, K. D., Riddle, D. L., \& Ruvkun, G. (2011). The C. elegans DAF-2 insulin-like receptor is abundantly expressed in the nervous system and regulated by nutritional status. Cold Spring Harb Symp Quant Biol 76, 113-120. 10.1101/sqb.2011.76.010660.

Kodama, E., Kuhara, A., Mohri-Shiomi, A., Kimura, K. D., Okumura, M., Tomioka, M., Iino, Y., Mori, I. (2006). Insulin-like signaling and the neural circuit for integrative behavior in $C$. elegans. Genes Dev 20, 2955-2960. 10.1101/gad.1479906. 
Kuboki, A., Kikuta, S., Otori, N., Kojima, H., Matsumoto, I., Reisert, J., \& Yamasoba, T. (2021). Insulin-dependent maturation of newly generated olfactory sensory neurons after injury. eNeuro, 8(3), eNeuro 8, 0168-21. 10.1523/ENEURO.0168-21.2021.

Kunitomo, H., Sato, H., Iwata, R., Satoh, Y., Ohno, H., Yamada, K., \& Iino, Y. (2013).

Concentration memory-dependent synaptic plasticity of a taste circuit regulates salt concentration chemotaxis in Caenorhabditis elegans. Nat Commun. 4, 2210. $10.1038 /$ ncomms 3210 .

Larsch, J., Ventimiglia, D., Bargmann, C. I., \& Albrecht, D. R. (2013). High-throughput imaging of neuronal activity in Caenorhabditis elegans. Proc Natl Acad Sci U S A 110, E4266-4273. 10.1073/pnas.1318325110.

Lee, J., O'Halloran, D., Kaye, J., Juang, B., Goga, A., \& L'Etoile, N. (2010). Nuclear accumulation of the cGMP-dependent kinase EGL-4 instructs olfactory adaptation in the AWC neurons of C. elegans. Proc Natl Acad Sci U S A 107, 6016-6021. 10.1073/pnas.1000866107.

L'Etoile, N., Coburn, C., Eastham, J., Kistler, A., Gallegos, G., \& Bargmann, C. (2002). The cyclic GMP-dependent protein kinase EGL-4 regulates olfactory adaptation in C. elegans. Neuron 36, 1079-1089. 10.1016/s0896-6273(02)01066-8.

Levenga, J., Wong, H., Milstead, R. A., Keller, B. N., LaPlante, L. E., \& Hoeffer, C. A. (2017). AKT isoforms have distinct hippocampal expression and roles in synaptic plasticity. Elife 6 , e30640. 10.7554/eLife.30640.

Levy, S., \& Bargmann, C. I. (2020). An adaptive-threshold mechanism for odor sensation and animal navigation. Neuron 105, 534-548.e13. 10.1016/j.neuron.2019.10.034.

Li, J., Choi, E., Yu, H., \& Bai, X.-c. (2019). Structural basis of the activation of type 1 insulinlike growth factor receptor. Nature Communications 10, 4567. 10.1038/s41467-019-12564-0.

Lin, C. H., Tomioka, M., Pereira, S., Sellings, L., Iino, Y., \& Kooy, D. v. (2010). Insulin signaling plays a dual role in Caenorhabditis elegans memory acquisition and memory retrieval. Journal of Neuroscience 30, 8001-8011. 10.1523/JNEUROSCI.4636-09.2010.

Luo, C., Gangadharan, V., Bali, K. K., Xie, R.-G., Agarwal, N., Kurejova, M., Tappe-Theodor, A., Tegeder, I., Feil, S., et al., Robert Feil, T. K. (2012). Presynaptically localized cyclic GMPdependent protein kinase 1 is a key determinant of spinal synaptic potentiation and pain hypersensitivity. PLoS Biol. 10, e1001283. 10.1371/journal.pbio.1001283.

López-Cruz, A., Sordillo, A., Pokala, N., Liu, Q., McGrath, P. T., \& Bargmann, C. I. (2019).

Parallel multimodal circuits control an innate foraging behavior. Neuron 102, 407-419. 10.1016/j.neuron.2019.01.053.

Martinez, B. A., Rodrigues, P. R., Medina, R. M., Mondal, P., Harrison, N. J., Lone, M. A., et al., Gill, M. S. (2020). An alternatively spliced, non-signaling insulin receptor modulates insulin sensitivity via insulin peptide sequestration in C. elegans. Elife 9, e49917. 10.7554/eLife.49917.

Muñoz-Jiménez, C., Ayuso, C., Dobrzynska, A., Torres-Mendéz, A., Ruiz, P. d., \& Askjaer, P. (2017). An efficient FLP-Based toolkit for spatiotemporal control of gene expression in Caenorhabditis elegans. Genetics 206, 1763-1778. 10.1534/genetics.117.201012. 
Murphy, C. T., \& Hu, P. J. (2013). Insulin/insulin-like growth factor signaling in C. elegans. WormBook, ed. The C. elegans Research Community, WormBook. 10.1895/wormbook.1.164.1, http://www.wormbook.org.

Naganos, S., Horiuchi, J., \& Saitoe, M. (2012). Mutations in the Drosophila insulin receptor substrate, CHICO, impair olfactory associative learning. Neurosci Res 73. 49-55. 10.1016/j.neures.2012.02.001.

Nagashima, T., Iino, Y., \& Tomioka, M. (2019). DAF-16/FOXO promotes taste avoidance learning independently of axonal insulin-like signaling. PLoS Genetics 15, e1008297. 10.1083/jcb.201811090.

Neal, S.J., Kim, K. \& Sengupta, P., 2013. Quantitative assessment of pheromone-induced Dauer formation in Caenorhabditis elegans. Methods Mol Biol. 1068, 273-83. 10.1007/978-1-62703619-1_20.

Oda, S., Tomioka, M., \& Iino, Y. (2011). Neuronal plasticity regulated by the insulin-like signaling pathway underlies salt chemotaxis learning in Caenorhabditis elegans. J Neurophysiol. 106, 301-308. 10.1152/jn.01029.2010.

O'Halloran, D. M., Altshuler-Keylin, S., Lee, J. I., \& L'Etoile, N. D. (2009). Regulators of AWCMediated Olfactory Plasticity in Caenorhabditis elegans. PLoS Genetics 5, e1000761. 10.1371/journal.pgen.1000761.

Ohno, H., Kato, S., Naito, Y., Kunitomo, H., Tomioka, M., \& Iino, Y. (2014). Role of synaptic phosphatidylinositol 3-kinase in a behavioral learning response in C. elegans. Science 345, 313317. 10.1371/journal.pgen.1000761.

Pereira, S., \& Van der Kooy, D. (2012). Two forms of learning following training to a single odorant in Caenorhabditis elegans AWC Neurons. Journal of Neuroscience 32, 9035-9044. 10.1523/JNEUROSCI.4221-11.2012.

Pierce-Shimomura, J. T., Morse, T. M., \& Lockery, S. R. (1999). The fundamental role of pirouettes in Caenorhabditis elegans chemotaxis. Journal of Neuroscience 19, 9557-9569. 10.1523/JNEUROSCI.19-21-09557.1999.

Pokala, N., Liu, Q., Gordus, A., \& Bargmann, C. I. (2014). Inducible and titratable silencing of Caenorhabditis elegans neurons in vivo with histamine-gated chloride channels. Proc Natl Acad Sci U S A 111, 2770-2775. 10.1073/pnas.1400615111.

Santi, S. A., \& Lee, H. (2010). The Akt isoforms are present at distinct subcellular locations. Am J Physiol Cell Physiol. 298, C580-591. 10.1152/ajpcell.00375.2009.

Scapin, G., Dandey, V. P., Zhang, Z., Prosise, W., Hruza, A., Kelly, T., Mayhood, T., Strickland, C., Potter, C. S., Carragher, B. (2018). Structure of the insulin receptor-insulin complex by single-particle cryo-EM analysis. Nature 556, 122-125. 10.1038/nature26153.

Sieburth, D., Madison, J. M., \& Kaplan, J. M. (2007). PKC-1 regulates secretion of neuropeptides. Nat Neurosci. 10, 49-57. 10.1038/nn1810.

Smith, N. K., \& Grueter, B. A. (2021). Hunger-driven adaptive prioritization of behavior. FEBS J. doi: $10.1111 /$ febs. 15791 . 
Takeishi, A., Yeon, J., Harris, N., Yang, W., \& Sengupta, P. (2020). Feeding state functionally reconfigures a sensory circuit to drive thermosensory behavioral plasticity. eLife 9, e61167. 10.7554/eLife.61167.

Talbot, K., Wang, H. Y., Kazi, H., Han, L. Y., Bakshi, K. P., Stucky, A., Fuino, R. L., Kawaguchi, K. R., Samoyedny, A. J., Wilson, R. S., et al. (2012). Demonstrated brain insulin resistance in Alzheimer's disease patients is associated with IGF-1 resistance, IRS-1 dysregulation, and cognitive decline. J Clin Invest. 122, 1316-1338. 10.1172/JCI59903.

Taylor, S. R., Santpere, G., Weinreb, A., Barrett, A., Reilly, M. B., Xu, C., et al., Miller 3rd, D. (2021). Molecular topography of an entire nervous system. Cell 184, 4329-4347.e23. 10.1016/j.cell.2021.06.023.

Tokarz, V. L., MacDonald, P. E., \& Klip, A. (2018). The cell biology of systemic insulin function. J Cell Biol. 217, 2273-2289. 10.1083/jcb.201802095.

Tomioka, M., Adachi, T., Suzuki, H., Kunitomo, H., Schafer, W. R., \& Iino, Y. (2006). The insulin/PI 3-kinase pathway regulates salt chemotaxis learning in Caenorhabditis elegans. Neuron 51, 613-25. 10.1016/j.neuron.2006.07.024.

Tomioka, M., Naito, Y., Kuroyanagi, H., \& Iino, Y. (2016). Splicing factors control C. elegans behavioural learning in a single neuron by producing DAF-2c receptor. Nature Communication 7, 11645. 10.1038/ncomms11645.

Torayama, I., Ishihara, T., \& Katsura, I. (2007). Caenorhabditis elegans integrates the signals of butanone and food to enhance chemotaxis to butanone. The Journal of Neuroscience 27, 741750. 10.1523/JNEUROSCI.4312-06.2007.

Tseng, Q., Wang, I., Duchemin-Pelletier, E., Azioune, A., Carpi, N., Gao, J., Fihol, O., Piel, M., Thery, M., Balland, M. (2011). A new micropatterning method of soft substrates reveals that different tumorigenic signals can promote or reduce cell contraction levels. Lab Chip 11, 22312240. 10.1039/c0lc00641f.

Tsukahara, T., Brann, D. H., Pashkovski, S. L., Guitchounts, G., Bozza, T., \& Datta, S. R. (2021). A transcriptional rheostat couples past activity to future sensory responses. Cell 184, 6326-6343.e32. 10.1016/j.cell.2021.11.022.

Tsunozaki, M., Chalasani, S. H., \& Bargmann, C. I. (2008). A behavioral switch: cGMP and PKC signaling in olfactory neurons reverses odor preference in C. elegans. Neuron 59, 959-71. 10.1016/j.neuron.2008.07.038.

Ventimiglia, D., \& Bargmann, C. I. (2017). Diverse modes of synaptic signaling, regulation, and plasticity distinguish two classes of $C$. elegans glutamatergic neurons. Elife 6, e31234, 10.7554/eLife.31234.

Wes, P., \& Bargmann, C. (2001). C. elegans odour discrimination requires asymmetric diversity in olfactory neurons. Nature 401, 698-701. 10.1038/35070581.

Wolkow, C. A., Muñoz, M. J., Riddle, D. L., \& Ruvkun, G. (2002). Insulin receptor substrate and p55 orthologous adaptor proteins function in the Caenorhabditis elegans daf-2/insulin-like signaling pathway. Journal of Biological Chemistry 277, 49591-49597. 10.1074/jbc.M207866200. 
Yakar, S., \& Adamo, M. L. (2012). Insulin-Like Growth Factor 1 physiology. Lessons from mouse models. Endocrinology and Metabolism Clinics of North America 41, 231-247.

10.1016/j.ecl.2012.04.008.

Yeon, J., Takeishi, A., \& Sengupta, P. (2021). Chronic vs acute manipulations reveal degeneracy in a thermosensory neuron network. MicroPubl Biol. 10, 17912. 10.17912/micropub.biology.000355.

Yoneyama, Y., Lanzerstorfer, P., Niwa, H., Umehara, T., Shibano, T., Yokoyama, S., Chida, K., Weghuber, J., Hakuno, F., Takahashi, S.-I. (2018). IRS-1 acts as an endocytic regulator of IGF-I receptor to facilitate sustained IGF signaling. Elife 7, e32893. doi: 10.7554/eLife.32893.

Yoshimura, J., Ichikawa, K., Shoura, M. J., Artiles, K. L., Gabdank, I., Wahba, L., Smith, C. L., Edgley, M. L., Rougvie, A. E., et al., Schwarz, E. M. (2019). Recompleting the Caenorhabditis elegans genome. Genome Research 29, 1009-1022. 10.1101/gr.244830.118. 


\section{FIGURE LEGENDS}

\section{Figure 1. ist-1 mutants are defective in aversive learning}

A) Training and testing conditions distinguish three forms of odor learning. Associative learning to butanone can be aversive, resulting in reduced chemotaxis, or appetitive, resulting in enhanced chemotaxis, depending on whether food is present during training. Non-associative desensitization occurs after exposure to high butanone concentration regardless of the presence of food.

B,C) Chemotaxis index of wild-type (B) and ist-1 mutant (C) animals after training as in panel (A). The chemotaxis index is defined as (\# of animals at odor)-(\# of animals at ethanol control)/ (total \# of animals in assay) after one hour. White bars, Control: animals were either deprived of food or fed for $90 \mathrm{~min}$, without exposing to odor, then tested for chemotaxis to 1:1000 butanone or 1:10 butanone. Pink bars, Aversive learning: animals were deprived of food while exposed to varying concentrations of butanone odor for $90 \mathrm{~min}$, then tested for chemotaxis to 1:1000 butanone. Grey bars, Desensitization: animals were fed while exposed to varying concentrations of butanone odor for $90 \mathrm{~min}$, then tested for chemotaxis to 1:1000 butanone. Blue bars, Appetitive learning: animals were fed while exposed to varying concentrations of butanone odor for $90 \mathrm{~min}$, then tested for chemotaxis to $1: 10$ butanone.

Error bars indicate S.E.M. **, values differ at $\mathrm{p} \leq 0.01$. ***, values differ at $\mathrm{p} \leq 0.001$. ****, values differ at $\mathrm{p} \leq 0.0001$. ns, values are not significantly different. Statistical tests are described in Table S2.

\section{Figure 2. ist-1 is required in $\mathrm{AWC}^{\mathrm{ON}}$ for butanone aversive learning}

A) Genomic structure of the C. elegans insulin receptor substrate-1 (ist-1) gene. Four isoforms of ist- 1 are generated from alternative promoters and alternative splicing. Solid blocks correspond to exons, and locations of mutations are indicated by a red line or a red bar. ky1071 was a background mutation discovered in the flp-20(pk1596) strain. ok2706 was obtained from the Caenorhabditis Genetics Center. ky1074, ky1076 and ky1075 were generated by targeted CRISPR/Cas-9 mutagenesis (see Methods).

B) Chemotaxis and aversive learning in ist-1 mutants. Animals were food-deprived (control, white bars) or food-deprived with $20 \mu$ l butanone odor (trained, pink bars) for 90 min and tested for chemotaxis to 1:1000 butanone. 
C) Transgenic rescue of ist-1 mutants. Animals were trained and tested as above. Left, full rescue of ky1071 mutants with a fosmid covering the entire genomic sequence of $i s t-1$ or a $14.8 \mathrm{~kb}$ promoter fragment driving an ist- $1 b$ cDNA. This strain included the original $f l p-20$ mutation. Right, rescue of ist-1(ok2706) mutants with the ist-1b cDNA under different cell-specific promoters. Only the str-2 promoter that expresses ist-1 in $\mathrm{AWC}^{\mathrm{ON}}$ rescued aversive olfactory learning.

D) Expression of an ist-1::eGFP reporter with $14.8 \mathrm{~kb}$ of genomic DNA encompassing $9.3 \mathrm{~kb}$ upstream of the first ist-1 exon (the initiation site of isoforms ist-1b and ist-1e) and $5.3 \mathrm{~kb}$ upstream of the second exon (the initiation site of isoforms ist-1c and ist-1d).

E) Localization of an eGFP::IST-1 fusion protein expressed under the AWC ${ }^{\mathrm{ON}}$-selective str-2 promoter. Top, diagram of the expression construct. Lower left, transgenic rescue of ist1(ok2706) by str-2::eGFP::IST-1. Animals were trained and tested as above. Lower right, representative maximal intensity projection of of IST-1::eGFP in AWC ${ }^{\mathrm{ON}}$ neuron, showing fluorescence in the dendrite (d), axon (a), and cell soma (s). Aggregated protein in the cell body is likely due to overexpression.

Error bars indicate S.E.M. *, values differ at $\mathrm{p} \leq 0.05$. **, values differ at $\mathrm{p} \leq 0.01$. ***, values differ at $\mathrm{p} \leq 0.001$. $* * * *$, values differ at $\mathrm{p} \leq 0.0001$. ns, values are not significantly different. Statistical tests are described in Table S2.

\section{Figure 3. ist-1 interacts with the insulin/IGF signaling pathway in aversive learning}

A) Summary diagram of $C$. elegans insulin/IGF pathway highlighting genes that affect butanone chemotaxis (pink) or aversive learning (blue).

B,C) Chemotaxis and aversive learning in insulin pathway mutants and double mutants. Animals were food-deprived (control, white bars) or food-deprived with $20 \mu 1$ butanone odor (trained, pink bars) for $90 \mathrm{~min}$ and tested for chemotaxis to 1:1000 butanone. Defects in ins-1, age-1, and daf-16 were as previously reported (Cho, et al., 2016; Daniels, et al., 2000). daf-16(mgDf50) and age-1(m333) are null alleles; daf-18(e1375) and age-1(hx546) are partial loss of function alleles. D) Dauer formation in wild-type and ist-1(ok2706) animals grown in mildly dauer-inducing conditions (limited food at $25^{\circ} \mathrm{C}$ ) or strongly dauer-inducing conditions (limited food at $25^{\circ} \mathrm{C}$ supplemented with $73 \mathrm{nM}$ each of ascarosides C3 and C6). 
Error bars indicate S.E.M. *, values differ at $\mathrm{p} \leq 0.05 . * *$, values differ at $\mathrm{p} \leq 0.01$. ***, values differ at $\mathrm{p} \leq 0.001$. $* * * *$, values differ at $\mathrm{p} \leq 0.0001$. ns, values are not significantly different. Statistical tests are described in Table S2.

\section{Figure 4. The DAF-2 insulin/IGF receptor is required in $A W C^{\mathrm{ON}}$ for aversive learning}

A) Top, genomic structure of $d a f-2$ and mutations used in this study. White boxes denote promoter and 3'UTR regions; black boxes denote exons. The $d a f-2 a$ and $d a f-2 c$ isoforms differ by inclusion of the alternative exon 11.5. The mutations in $d a f-2(p e 1230)$ and $d a f-2 c(p e 2722)$ both affect the extracellular domain of the predicted DAF-2 protein. To generate a conditional daf-2 knockout allele for this study, two FRT sites flanking half of the daf-2 gene were inserted by CRISPR-Cas9 mutagenesis of the endogenous daf-2 gene (see Methods).

B) Chemotaxis and aversive learning in wild-type, ist-1(ok2706), daf-2(pe1230), and daf2c(pe2722) animals. Animals were food-deprived (control, white bars) or food-deprived with 20 $\mu 1$ butanone odor (trained, pink bars) for $90 \mathrm{~min}$ and tested for chemotaxis to 1:1000 butanone.

C) Transgenic rescue of $d a f-2(p e 1230)$ and $d a f-2 c(p e 2722)$ mutants with $d a f-2 a$ or $d a f-2 c$ cDNAs expressed under the $\mathrm{AWC}^{\mathrm{ON}}$-selective str-2 promoter. Animals were trained and tested as above.

D) Chemotaxis and aversive learning in animals with cell-selective flippase transgenes injected into the daf-2frt strain to generate conditional knockouts. In each strain, the site and efficiency of flippase recombination was determined using a reporter transgene (see Methods). Significant learning defects were observed upon flippase expression under the $\mathrm{AWC}^{\mathrm{ON}}$-selective str-2 promoter or the tax-4 promoter that is expressed in AWC and nine other pairs of sensory neurons. Flippase expression under the ASI-specific str-3 promoter did not elicit learning defects. Animals were trained and tested as above.

Error bars indicate S.E.M. *, values differ at $\mathrm{p} \leq 0.05$. **, values differ at $\mathrm{p} \leq 0.01$. ***, values differ at $\mathrm{p} \leq 0.001$. $* * * *$, values differ at $\mathrm{p} \leq 0.0001$. ns, values are not significantly different. Statistical tests are described in Table S2.

Figure 5. ist-1 in ASER interacts with the insulin/IGF pathway in taste avoidance learning A) Taste avoidance learning. Pairing food with $100 \mathrm{mM} \mathrm{NaCl}$ results in chemotaxis to high salt $(95 \mathrm{mM})$ in a salt gradient (trained, white bars). Pairing food deprivation with $100 \mathrm{mM} \mathrm{NaCl}$ 
results in taste avoidance learning, expressed as chemotaxis to low salt (35 $\mathrm{mM})$ in a salt gradient (trained, blue bars). The preference index is defined as (\# of animals at high salt)-(\# of animals at low salt)/ (total \# of animals in assay) after one hour.

B) Taste avoidance learning in insulin pathway mutants including ist-1, daf-2c, and daf-16, and rescue of taste avoidance learning by ist-1 expression under the ASER-specific gcy-5 promoter. Animals were food-deprived with $100 \mathrm{mM} \mathrm{NaCl}$ for 5 hours (trained, blue bars) and tested for chemotaxis in a salt gradient as above.

Error bars indicate S.E.M. *, values differ at $\mathrm{p} \leq 0.05 .^{* *}$, values differ at $\mathrm{p} \leq 0.01$. $^{* * * *}$, values differ at $\mathrm{p} \leq 0.0001$. ns, values are not significantly different. Statistical tests are described in Table S2. Additional salt training and chemotaxis results are in Figure S3.

\section{Figure 6. DAF-2 is regulated by nutritional state, ist-1, and ins-1}

A) and D) Expression of DAF-2a::mVenus and DAF-2c::mVenus in AWC ${ }^{\mathrm{ON}}$ neurons of fed and food-deprived animals. Top, diagrams of expression constructs. Bottom, representative maximal intensity projection of $\mathrm{AWC}^{\mathrm{ON}}$ in well-fed or 90 min-food-deprived animals (d: dendrite, a: axon, s: cell soma). Note axonal expression of DAF-2c::mVenus and axonal exclusion of DAF2a::mVenus.

B) and C) DAF-2a::mVenus, E) and F) DAF-2c::mVenus fluorescence in AWC ${ }^{\mathrm{ON}}$ cell bodies or axons, quantified either immediately after removal from food or 90 minutes after food deprivation on NGM agar plates. Expression of DAF-2a::mVenus (in the cell body) and DAF2c::mVenus (in the cell body and axon) is increased by food deprivation in wild-type animals but not in ins-1 or ist-1 mutants.

G) Quantification of str-2::GFP signals in wild-type animals either immediately after removal from food or 90 minutes after food deprivation on NGM agar plates. Food deprivation does not increase GFP expression in the $\mathrm{AWC}^{\mathrm{ON}}$ axon or cell body.

H) Expression of DAF-2c::mVenus in ASER neurons, quantified either immediately after removal from food or 90 minutes after food deprivation on NGM agar plates. Expression of DAF-2c::mVenus is increased in wild-type animals but not in ist-1 mutants.

In B,C,E,F, and G, Normalized fluorescence represents background-subtracted fluorescence of animals taken under identical imaging conditions across panels. Error bars indicate S.E.M. *, values differ at $\mathrm{p} \leq 0.05$. ns, values are not significantly different. In H, ASER DAF-2c::mVenus 
fluorescence was expressed as a ratio relative to a co-expressed mCherry transgene. Statistical tests are described in Table S2.

\section{Figure 7. Aversive learning suppresses synaptic odor response in $\mathrm{AWC}^{\mathrm{ON}}$}

A) Diagram of $\mathrm{AWC}^{\mathrm{ON}}$ neuron illustrating sites of odor detection in the cilia, the site of calcium imaging in the cell body, and the sites of synaptic EAT-4::pHluorin imaging in the axon. $\mathrm{AWC}^{\mathrm{ON}}$ responds to odor removal with calcium increases that trigger synaptic vesicle release. B) Desensitization of the $\mathrm{AWC}^{\mathrm{ON}}$ calcium response. Animals were exposed to $10 \mathrm{mM}$ butanone for 90 minutes, or incubated in buffer for 90 minutes, followed by monitoring AWC ${ }^{\text {ON }}$ GCaMP5 responses to different odor concentrations. After butanone exposure (red lines), the AWC ${ }^{\mathrm{ON}}$ dose-response curve is shifted $\sim 10$-fold to the right compared to control animals (black lines) across the full range of odor concentrations. ist- 1 mutants showed similar desensitization to wildtype animals. Grey stripes indicate times when butanone stimulus was present (30s pulses, separated by 30 s or 90 s in buffer). Solid lines represent average data of multiple trials (WT control: $n=64$ worms from 7 independent experiments, WT trained: $n=47$ worms from 5 independent experiments, ist-1(ok2706) control: $\mathrm{n}=65$ worms from 7 independent experiments, ist-1(ok2706): $\mathrm{n}=55$ worms from 5 independent experiments). Shading represents S.E.M.

C) Chemotaxis and aversive learning in wild type, eat-4 vesicular glutamate transporter mutants, and animals with AWC-selective knockout of eat-4. Animals were food-deprived (control, white bars) or food-deprived with $20 \mu \mathrm{l}$ butanone odor (trained, pink bars) for 90 min and tested for chemotaxis to $1: 1000$ butanone.

D) AWC ${ }^{\mathrm{ON}}$ EAT-4-pHluorin responses to butanone pulses in wild type (top) and ist-1 mutant (bottom) animals, in control (left, black lines) and trained (right, red lines) groups. Bold line shows average across multiple trials; thin lines show signal from each individual trial. Grey stripes indicate times when butanone stimulus was present $\left(10^{5} \mathrm{M}, 1 \mathrm{~min}\right.$ pulses, separated by 2 $\min )$.

E) Quantification of AWC ${ }^{\mathrm{ON}}$ EAT-4-pHluorin signals from D). To calculate the change in synaptic release, the fluorescence signal during odor stimulation (5-10 s before odor removal) was subtracted from the post-stimulation fluorescence level (5-10 s after odor removal). (WT control: $\mathrm{n}=11$ worms with 2-3 trials each, WT trained: $\mathrm{n}=22$ worms with 2-3 trials each, ist- 
1(ok2706) control: $\mathrm{n}=10$ worms with 2-3 trials each, ist-1(ok2706): $\mathrm{n}=18$ worms with 2-3 trials each).

F) Chemotaxis and aversive learning in $p k c-1$ mutants (see Fig 3A), pkc-1 mutants with $p k c-1$ rescued in $\mathrm{AWC}^{\mathrm{ON}}$, and wild-type animals expressing $p k c-1(g f)$ in $\mathrm{AWC}^{\mathrm{ON}}$. Animals were trained and tested as above.

Error bars indicate S.E.M. *, values differ at $\mathrm{p} \leq 0.05 . * *$, values differ at $\mathrm{p} \leq 0.01$. ***, values differ at $\mathrm{p} \leq 0.001$. $* * * *$, values differ at $\mathrm{p} \leq 0.0001$. ns, values are not significantly different. Statistical tests are described in Table S2. 


\section{KEY RESOURCES TABLE}

Table 1 Strains generated in this study

\begin{tabular}{|c|c|c|}
\hline Strain & Genotype & Description \\
\hline CX17680 & ist-1(ky1071) flp-20(pk1596) X & $\begin{array}{l}\text { 1x backcrossed from } \\
\text { PT505 }\end{array}$ \\
\hline CX17681 & $f l p-20(p k 1596) X$ & $\begin{array}{l}\text { 3x backcrossed from } \\
\text { PT505 }\end{array}$ \\
\hline CX17683 & ist-1(ky1071) flp-20(pk1596) X & $\begin{array}{l}\text { 3x backcrossed from } \\
\text { PT505 }\end{array}$ \\
\hline CX17685 & $f l p-20(p k 1596) X$ & $\begin{array}{l}8 \mathrm{x} \text { backcrossed from } \\
\text { PT505 }\end{array}$ \\
\hline CX17728 & 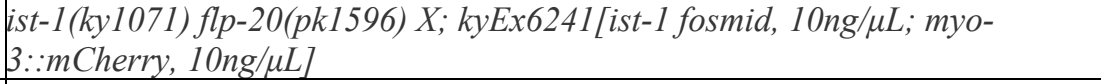 & Fosmid WRM062cC02 \\
\hline CX17910 & 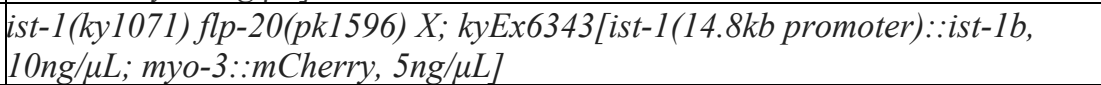 & cDNA rescue \\
\hline CX1074 & ist-1 (ky1074) X & CRISPR generated allele \\
\hline CX1075 & ist-1(ky1075) $X$ & CRISPR generated allele \\
\hline CX1076 & ist-1 (ky1076) X & CRISPR generated allele \\
\hline CX17790 & ist-1(ok2706) X & $\begin{array}{l}\text { 2x backcrossed from } \\
\text { RB2621 }\end{array}$ \\
\hline CX18202 & 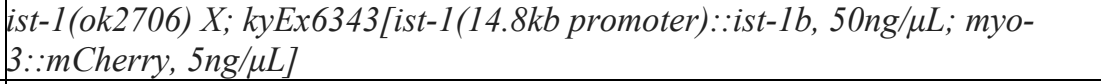 & \\
\hline CX17977 & 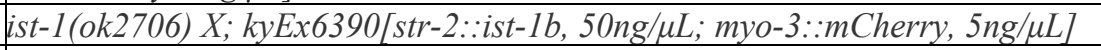 & ist- 1 rescue in $\mathrm{AWC} \mathrm{ON}^{\mathrm{N}}$ \\
\hline CX17969 & 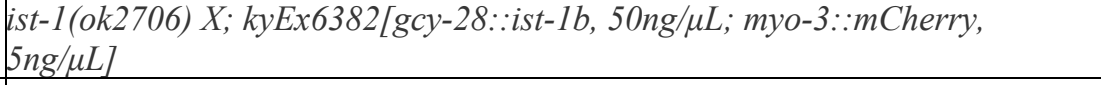 & $\begin{array}{l}\text { ist-1 rescue in AIA, ASI, } \\
\text { AVF }\end{array}$ \\
\hline CX17971 & 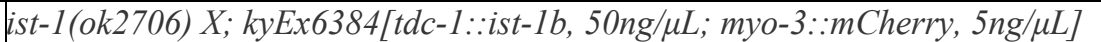 & ist- 1 rescue in RIM \\
\hline CX18183 & 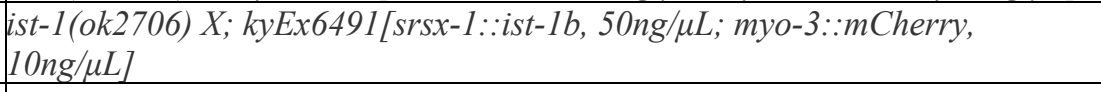 & $\begin{array}{c}\text { ist-1 rescue in } \mathrm{AWC}{ }^{\mathrm{OFF}} \text {, } \\
\mathrm{AWB}\end{array}$ \\
\hline CX18178 & 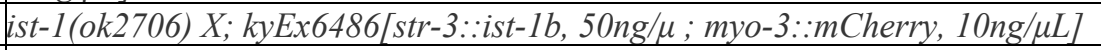 & ist- 1 rescue in ASI \\
\hline CX18182 & ist-1 (ok2706) X; kyEx6490[elt-2::ist-1b, 50ng/ $\mu$; myo-3::mCherry, $10 \mathrm{ng} / \mu \mathrm{L}]$ & ist- 1 rescue in the gut \\
\hline CX18054 & 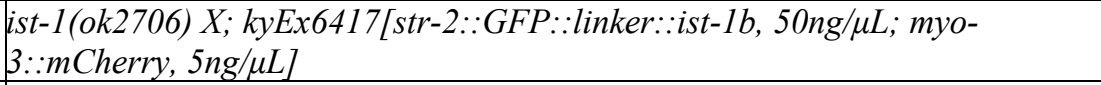 & GFP::IST-1 fusion \\
\hline CX18112 & $\begin{array}{l}\text { ist-1(ok2706) X; gcy-28(tm2411) I; kyEx6417[str-2::GFP::linker::ist-1b, } \\
\text { 50ng/ } \mu \text { L; myo-3::mCherry, 5ng/ } \mathrm{LL}]\end{array}$ & GFP::IST-1 fusion \\
\hline CX18114 & 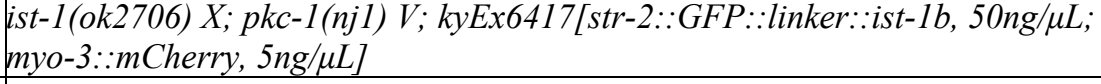 & GFP::IST-1 fusion \\
\hline CX18117 & 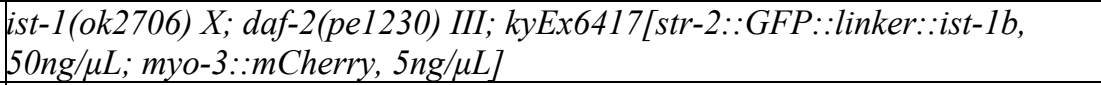 & GFP::IST-1 fusion \\
\hline CX18045 & daf-18(e1375) IV; ist-1(ok2706) X & \\
\hline CX18046 & daf-16(mgDf50) I; ist-1(ok2706) X; & \\
\hline CX18355 & daf-16(mgDf50) I; age-1(hx546) II & \\
\hline IK105 & $p k c-1(n j 1) \mathrm{V}$ & \\
\hline CX15246 & pkc-1(nj1) V; kyEx5125[str-2::pkc-1::sl2::mCherry] & $p k c-1$ rescue in $\mathrm{AWC}^{\mathrm{ON}}$ \\
\hline CX11099 & kyEx2921[str-2::pkc-1(gf)::sl2::GFP; elt-2::GFP] & $\begin{array}{c}p k c-1 \text { over-expression in } \\
\text { AWC }^{\mathrm{ON}}\end{array}$ \\
\hline CX1095 & $\begin{array}{l}\text { daf-2(ky1095) daf-2(ky1087) III; ky1087 = [let- } \\
\text { 858UTR::FRT::mCherry],III:2995919, ky1096=[FRT],III:3010987 }\end{array}$ & $\begin{array}{l}\text { edited } d a f-2 \text { with } 5^{\prime} \text { and } 3 \\
\text { FRT }\end{array}$ \\
\hline CX1087 & daf-2(ky1087) III, ky1087= [let-858UTR::FRT::mCherry],III:2995919 & edited $d a f-2$ with 3 ' FRT \\
\hline CX18084 & 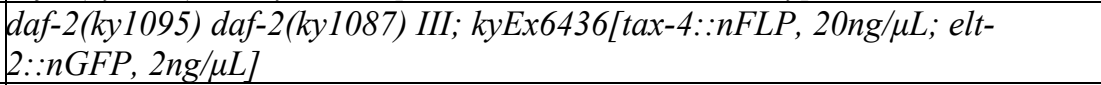 & $\begin{array}{c}\text { daf-2 knockout in sensory } \\
\text { neurons }\end{array}$ \\
\hline CX18086 & $\begin{array}{l}\text { daf-2(ky1095) daf-2(ky1087) III; kyEx6438[str-2::nFLP, 20ng/ } \mu L ; \text { elt- } \\
2:: n G F P, 2 n g / \mu L]\end{array}$ & $\begin{array}{l}\text { daf-2 knockout in } \\
\text { AWC } \\
\text { ON, RIA, ASI }\end{array}$ \\
\hline CX18184 & 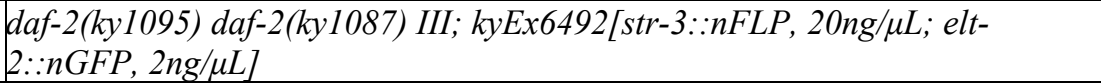 & daf-2 knockout in ASI \\
\hline
\end{tabular}


Table 1 Strains generated in this study, continued

\begin{tabular}{|c|c|c|}
\hline Strain & Genotype & Description \\
\hline CX18084 & $\begin{array}{l}\text { bqSi294[pBN154(unc-119(+) Phsp16.41::FRT::mCh::his-58::FRT::gfp::his- } \\
\text { 58)] II; daf-2(ky1095) daf-2(ky1087) III; kyEx6436; }\end{array}$ & $\begin{array}{l}\text { Flippase activity reporter } \\
\text { in sensory neurons }\end{array}$ \\
\hline CX18086 & $\begin{array}{l}\text { bqSi294[pBN154(unc-119(+) Phsp16.41::FRT::mCh::his-58::FRT::gfp::his- } \\
\text { 58)] I; Idaf-2(ky1095) daf-2(ky1087) III; kyEx6438; }\end{array}$ & $\begin{array}{l}\text { Flippase activity reporter } \\
\text { in AWC }\end{array}$ \\
\hline CX18191 & $\begin{array}{l}\text { bqSi294[pBN154(unc-119(+) Phsp16.41::FRT::mCh::his-58::FRT::gfp::his- } \\
\text { 58)] II; daf-2(ky1095) daf-2(ky1087) III; kyEx6439; }\end{array}$ & $\begin{array}{c}\text { Flippase activity reporter } \\
\text { in ASI }\end{array}$ \\
\hline CX18192 & $\begin{array}{l}\text { ist-1(ok2706) X; kyIs 721 [integrated str-2::GCaMP5 from } 50 \mathrm{ng} / \mu \mathrm{L} ; \text { elt- } \\
2:: \mathrm{m} \text { Cherry } 10 \mathrm{ng} / \mu \mathrm{L}]\end{array}$ & $\begin{array}{l}\text { ist-1 GCaMP imaging } \\
\text { strain }\end{array}$ \\
\hline CX18125 & 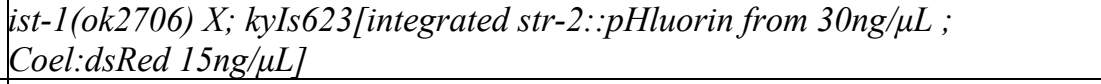 & $\begin{array}{l}\text { ist-1 pHluorin imaging } \\
\text { strain }\end{array}$ \\
\hline CX18187 & kyEx6495[str-2::daf-2a::mVenus, 50ng/ $\mu$ L; myo-3::mCherry, $5 \mathrm{ng} / \mu L]$ & DAF-2a::mVenus \\
\hline CX18190 & kyEx6498[str-2::daf-2c::mVenus, 50ng/ $\mu \mathrm{L} ;$ myo-3::mCherry, $5 \mathrm{ng} / \mu \mathrm{L}]$ & DAF-2c::mVenus \\
\hline CX18203 & 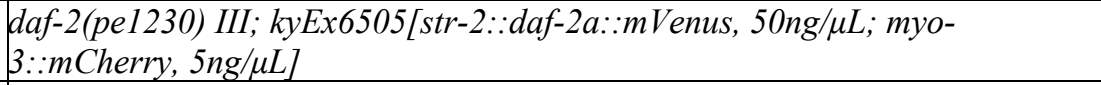 & DAF-2a rescue \\
\hline CX18205 & 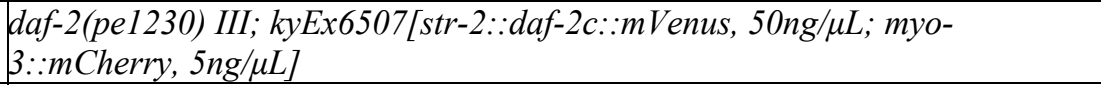 & DAF- $2 \mathrm{c}$ rescue \\
\hline CX18206 & 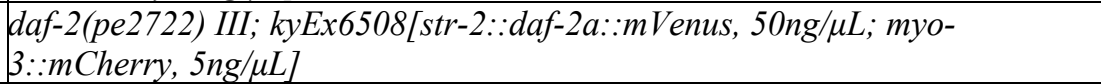 & DAF-2a rescue \\
\hline CX18207 & 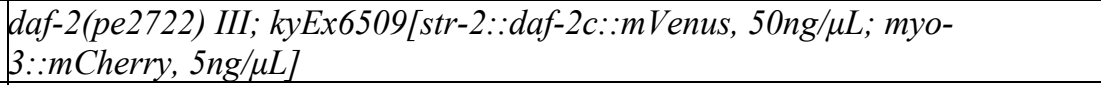 & DAF-2c rescue \\
\hline CX18216 & $\begin{array}{l}\text { ist-1(ok2706) X; kyEx5616[str-2::daf-2a::mVenus, 50ng/ } \mu L ; \text { myo-3::mCherry, } \\
5 n g / \mu L]\end{array}$ & DAF-2a::mVenus \\
\hline CX18217 & $\begin{array}{l}\text { ist-1(ok2706) X; kyEx5614[str-2::daf-2c::mVenus, 50ng/ } \mu \text {; myo-3::mCherry, } \\
5 n g / \mu L]\end{array}$ & DAF-2c::mVenus \\
\hline CX18262 & 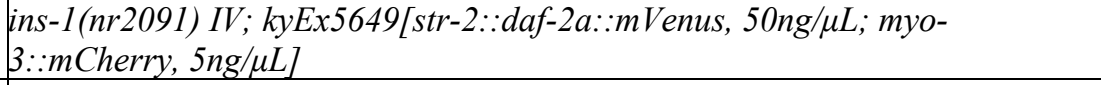 & DAF-2a::mVenus \\
\hline CX18261 & 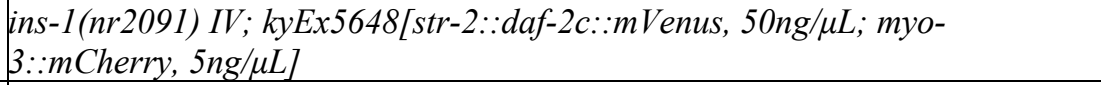 & DAF-2c::mVenus \\
\hline JN4762 & 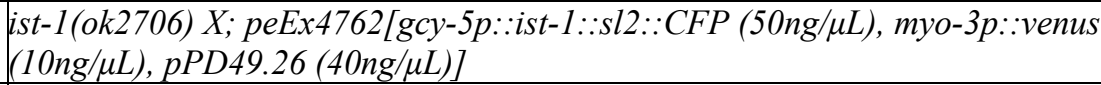 & ist- 1 rescue in ASER \\
\hline JN4785 & daf-2c(pe2722) III; ist-1(ok2706) X. & \\
\hline JN4786 & daf-16(mgDf50) I; daf-2c(pe2722) III; ist-1(ok2706) X. & \\
\hline JN1524 & $\begin{array}{l}\text { Is[Pgcy-5::daf-2c::mVenus; Punc-122::mCherry]; Is [Pgcy-5::mCherry; Plin- } \\
44: \because g f p]\end{array}$ & DAF-2c::mVenus \\
\hline JN3746 & $\begin{array}{l}\text { ist-1(ok2706) X; Is [Pgcy-5::daf-2c::mVenus; Punc-122::mCherry]; Is [Pgcy- } \\
5:: m \text { Cherry; Plin-44::gfp] }\end{array}$ & DAF-2c::mVenus \\
\hline
\end{tabular}

\section{CONTACT FOR REAGENT AND RESOURCES SHARING}

Further information and requests for resources and reagents should be directed to and will be fulfilled by the Lead Contact, Dr. Cornelia Bargmann (cori@rockefeller.edu).

\section{EXPERIMENTAL MODEL AND SUBJECT DETAILS}




\section{C. elegans strains}

All new CRISPR-generated strains and transgenic strains are listed in Table 1.

\section{Nematode maintenance and molecular biology}

All strains were maintained at $20^{\circ} \mathrm{C}$ on Nematode Growth Medium (NGM) plates, seeded with E. coli OP50 bacteria as a food source (Brenner, 1974). Wild-type animals were the genetically defined strain PD1074 derived from the Bristol strain N2 (Yoshimura, et al., 2019).

\section{METHOD DETAILS}

\section{Chemotaxis assays}

Animals were grown at $20^{\circ} \mathrm{C}$ on $10 \mathrm{~cm}$ round NGM plates spotted with $900 \mu \mathrm{l}$ of E. coli OP50. Chemotaxis plates are square plates containing $12 \mathrm{ml}$ of modified NGM agar (without peptone and cholesterol, 1.7\% Granulated, purified agar (Agar-agar, Millipore), $50 \mathrm{mM} \mathrm{NaCl}, 25 \mathrm{mM}$ $\mathrm{KHPO}_{4}$ (pH6), $1 \mathrm{mM} \mathrm{CaCl}, 1 \mathrm{mM} \mathrm{MgSO}_{4}$ ). The chemotaxis plates are allowed to air-dry without lids for 15 minutes before use, or are stored at $4{ }^{\circ} \mathrm{C}$ for up to 2 weeks before use. Fifteen minutes before the start of the assay, one $1 \mu 1$ spot of $\mathrm{NaN}_{3}$ was spotted at the midline of each end of the plate. Adult animals were washed three times with NGM buffer $(50 \mathrm{mM} \mathrm{NaCl}, 25$ $\mathrm{mM} \mathrm{KHPO}_{4}(\mathrm{pH} 6), 1 \mathrm{mM} \mathrm{CaCl}_{2}, 1 \mathrm{mM} \mathrm{MgSO}_{4}$ ) with 15 min of total wash time. 50-100 animals were then placed at the center of the square plate spotted with either one $2 \mu 1$ drop of butanone diluted to $1: 10$ or 1:1000 in ethanol, or an ethanol control. A piece of folded, absorbent paper (Kimwipe) was used to soak up the solution from the droplet before the lid was closed, freeing the animals from the droplet and beginning the assay. The assay was recorded in an imaging apparatus with Streampix software and a 6.6 MP PL-B781F CMOS camera (Pixelink) as described in (López-Cruz, et al., 2019) for 1 hour at 3 frames/second. The chemotaxis index was quantified at the last frame of the recording by counting animals that had left the origin and accumulated on the side closest to the odor (\#Odor), on the side closest to the control (\#Control), and in the intermediate region (\#Middle). Animal positions were also tracked for further analysis. The formula used to calculate the chemotaxis index was: Chemotaxis index $=$ (\#Odor \#Control) / (\#Odor + \#Control + \#Middle) 


\section{Training for aversive learning}

The training protocol for aversive learning is based on the assay developed by (Colbert \& Bargmann, 1995) with modifications. One-day old adults were washed three times with NGM buffer and placed on conditioning plates consisting of NGM agar without peptone and cholesterol (same as chemotaxis plates). For the trained group, $20 \mu 1$ of butanone were distributed on four small pieces of agar on the inside of the lid of the plate, while the control group did not have butanone on the lid. The plates were then sealed with parafilm for 90 minutes before animals were washed 2-3 times with NGM buffer and tested in chemotaxis assays according to the previous section.

\section{Training for desensitization and appetitive learning}

The training protocol for desensitization and appetitive learning (or enhancement) is identical; the two assays are distinguished by test conditions (Torayama, et al., 2007). One-day old adults were washed three times with NGM buffer and placed on conditioning plates consisting of NGM agar seeded with $900 \mathrm{ul}$ of OP50. For the trained group, $20 \mu \mathrm{l}$ of butanone were distributed on four small pieces of agar on the inside of the lid of the plate, while the control did not have butanone on the lid. The plates were then sealed with parafilm and incubated for 90 minutes before animals were washed and tested in chemotaxis assays according to the section “Chemotaxis assays" with 1:1000 butanone for desensitization, and 1:10 butanone for appetitive learning.

\section{Salt concentration learning assay}

Salt concentration learning assays were performed according to our previously reported procedure (Tomioka, et al., 2016). For conditioning on agar plates, adult worms were transferred to NGM plates with 25- or 100-mM NaCl in the absence or presence of a bacterial food (NA22) for 4-5 h. After conditioning, the worms were placed at the center of a test plate with an $\mathrm{NaCl}$ gradient and allowed to crawl for $45 \mathrm{~min}$. A chemotaxis index was determined according to the following equation: $\mathrm{NaCl}$ Preference Index $=(\mathrm{NA}-\mathrm{NB}) /(\mathrm{Nall}-\mathrm{Nc})$, where NA and $\mathrm{NB}$ are the number of worms in the high- and low-salt areas, respectively, Nall is the total number of worms on a test plate, and $\mathrm{Nc}$ is the number of worms in the area around the starting position. 


\section{Chemotaxis recordings and analyses}

40-60 animals were placed on a square plate with modified NGM agar. A 1-hour movie was recorded at 3 frames per second with Streampix software and a 6.6 MP PL-B781F CMOS camera (Pixelink). Animals' trajectories were extracted by a custom MatLab script. A longreversal-omega turn (pirouette) event was defined as a reversal coupled with an omega turn, and identified as a sharp change in angular speed ( $\geq 75$ degree/s), followed by a sharp reorientation (body-enclosing ellipse eccentricity $\leq 0.875$, filtered by an angular speed threshold $\geq 60$ degree/s), as previously described (Pokala, et al., 2014). Long-reversal-omega frequency was calculated by binning the events with respect to the angle between each worm's heading and the direction of the odor source before the reorientation, at $30^{\circ}$ intervals. The normalized long-reversal-omega frequency was calculated by binning the event/worm/minute with respect to angle between each worm's heading and the direction of the odor source before the reorientation, at $90^{\circ}$ intervals.

\section{Dauer formation assays}

Dauer formation assays were performed using synthetic dauer-inducing pheromones with modifications to previously described methods (Neal, et al., 2013; Butcher et al., 2008). Assay plates were prepared 24 hours before each experiment by mixing $1 \mathrm{ml}$ NGM-agar with $100 \mu \mathrm{l}$ synthetic pheromone mixture (ascarosides $\mathrm{C} 3$ and $\mathrm{C} 6,73 \mathrm{nM}$ final concentration each) or ethanol control. On the day of each experiment, $20 \mu \mathrm{l}$ heat-killed OP50 (8 mg/ml in NGM buffer) was added and dried onto each plate. 14 adult animals were picked onto each assay plate and allowed to lay eggs for 3-4 hours before being removed. Plates were sealed with parafilm and incubated at $25^{\circ} \mathrm{C}$ with wet paper towels to prevent desiccation. After 72 hours of incubation, the proportion of dauers (including partial dauers) in each assay plate was counted based on their distinguishing characteristics: radial constriction, posture, gut refraction, locomotion, and cessation of pumping (Neal, et al., 2013).

\section{Calcium imaging in the arena chip}

Multiple animals expressing GCaMP5 in AWC ${ }^{\mathrm{ON}}$ were imaged simultaneously as described (Larsch, et al., 2013; Cho, et al., 2016) with slight modifications. PDMS chips with two arenas were made using a custom mold. The chips were flooded with NGM buffer containing $10 \mathrm{mM}$ tetramisole hydrochloride, and 10-15 adult animals were loaded into each arena. Animals were 
trained in the chip for 90 minutes with $10 \mathrm{mM}$ butanone (or NGM buffer for control groups) followed by a 15-minute wash with NGM buffer, then imaged on a Zeiss AxioObserver A1 microscope with a $2.5 \mathrm{X}$ objective and Metamorph software for synchronized image capture with pulsed illumination. A three-way valve was used to switch between buffer and odor flow into the chip, and a Hamilton valve was used to switch between different concentrations of odor. The stimulation protocol was three 30-second alternations between odor and buffer followed by 90 seconds of buffer, and then the sequence was repeated at 10-fold higher odor concentration for a total of six butanone concentrations, ranging from $10^{-8} \mathrm{M}$ to $10^{-3} \mathrm{M}$, plus a buffer-to-buffer control. Fluorescence was measured using a custom ImageJ script (Larsch, et al., 2013). Calcium imaging data analysis was identical to that used in (Cho, et al., 2016) using custom Matlab scripts to analyze calcium imaging data generated by ImageJ tracking programs.

\section{pHluorin imaging in the single-animal trapped chip}

The pHluorin imaging method is similar to that developed by (Ventimiglia \& Bargmann, 2017). 1-day old adults expressing an $\mathrm{AWC}^{\mathrm{ON}}:$ :EAT-4-pHluorin transgene were picked off food and trained for aversive learning. After training, animals were washed 3 times for a total of 15 minutes with NGM buffer and loaded into the imaging chip. Polydimethylsiloxane (PDMS) imaging chips were fabricated as described in (Chronis, et al., 2007) using a custom-designed silicon mold. PDMS chips were cured and holes were punched in fluid inlets, and chips were then bonded to glass cover slips. Animals were immobilized in the chip by adding $1 \mathrm{mM}$ tetramisole hydrochloride (Sigma) to the worm holding chamber. A time stack of images was captured using a CoolSnap HQ Photometrics camera and a Zeiss Axioscope upright microscope with a 40X objective. Images were motion-corrected using the method developed by (Tseng, et al., 2011). Fluorescence measurements were extracted with custom, semi-automated tracking software in ImageJ script (Ventimiglia \& Bargmann, 2017) that tracked axon position and extracted intensity measurements. pHluorin imaging analysis was similar to that used in (Ventimiglia \& Bargmann, 2017), with slight modifications. Data was smoothed with a moving average of 50 frames before analysis and plotting.

\section{Quantitative analysis of DAF-2::mVenus subcellular localization}


For AWC ${ }^{\mathrm{ON}}$ imaging, one-day old adult animals were either picked directly off plates (fed) or moved to an unseeded NGM plate for 90 minutes for food deprivation. Animals were then mounted and anaesthetized on a $3 \%$ agar pad containing $10 \mathrm{mM}$ sodium azide. Images were taken within 5-30 minutes after mounting. Fluorescent images of live animals were acquired using a Zeiss Axio Imager Z1 Apotome system with an AxioCamMR3 camera through an excitation filter of BP 500/20nm, with a beam splitter at $515 \mathrm{~nm}$ and an emission filter at BP $535 / 30$ with a $20 \%$ attenuator setting on the light source. A Z-Stack of 30 images was taken at 1 $\mu \mathrm{m}$ spacing with a $63 \mathrm{X} / 1.40 \mathrm{NA}$ objective with $500 \mathrm{~ms}$ exposure time per image. DAF-2a or DAF-2c::mVenus fluorescence intensity was measured with ImageJ. An image containing the largest area of the $\mathrm{AWC}^{\mathrm{ON}}$ cell body or axon based on mVenus expression was selected from Zseries for quantification. DAF-2::mVenus quantification was different from that described in (Ohno, et al., 2014), and more similar to that described in (Nagashima, et al., 2019). A rectangular region of interest (ROI) was drawn manually inside the area of the cell body or a piece of axon before using ImageJ to calculate the average intensity of fluorescence in the ROI. Average fluorescence intensity from at least five ROIs was used to quantify axon fluorescence of a given image stack. Background fluorescence intensity was averaged from at least five ROIs adjacent to the cell body or axon. The normalized fluorescence was calculated by subtracting the average fluorescence intensity of the background from the average fluorescence intensity of the cell body or axon.

For ASER imaging, fluorescence ratio was calculated based on the relative signal intensities of DAF-2c::mVenus and mCherry co-expressed in ASER.

\section{Identification of ist-1(ky1071) allele from genomic sequencing of $f l p-20(p k 1596)$}

Genomic DNA was prepared from wild-type and four strains resulting from backcrossing PT505 $f l p-20$ (pk1596) to wild-type. The strain CX17680, a 2X backcross of PT505 flp-20(pk1596), and the strain CX17683, a 6X backcross of PT505 flp-20(pk1596), were both defective in butanone aversive learning. The strain CX17681, a 6X backcross of PT505 flp-20(pk1596) and CX17685, an $8 \mathrm{X}$ backcross of PT505 flp-20(pk1596), were both proficient in butanone aversive learning. Whole genome sequencing of these samples was performed by the Rockefeller Genomic Resource Center using an Illumina HiSeq 2500 System. Sequence reads were analyzed by 
Patrick McGrath (Georgia Tech) by comparing the sequence of the backcrossed strains to the wild-type strains using a custom program. A T->G mutation was found in the splicing motif for $i s t-1$ after the end of the $3^{\text {rd }}$ exon and verified using Sanger sequencing. The ist-1(ky1071) point mutation, which is predicted to disrupt a splice donor, is:

ggaatttcagTATCAATGGCAGCAAGAGAGGAGAGAATACGCGAAAGTAGACAACAAGGGCAAC TGAAAGAAAAAAGGCTGAAAAATCCAGATTCAAAAGGTGATACAAGTCACGATAAGCCGACCAG AGAAACATGGAAGCCGTTAGCCGTTGAAGACTTACCAAAGGATGAAGATCCGGATGAATTTGGA ATTCCAGAAGTCTACAAATGTGGAAATTTTTAGTAGGGTTTGCTCCAGTGgt [g] atgtttatttagaaattatgtgcacaattcaattttttgagcagttgtcgatcaaaaagaaat tctttcagatttatttttaattatgcataaatcttcatattcc (site of point mutation underlined in red, mutation in square bracket, $3^{\text {rd }}$ exon in uppercase, introns in lowercase)

\section{CRISPR/Cas9-generated mutant strains}

New mutations in ist-1 were generated using a co-CRISPR protocol (Arribere, et al., 2014), with a template-guided dominant mutation on the rol-6 gene to induce a roller phenotype to aid selection of the gene-edited progeny. Young hermaphrodites with only a few eggs in the gonad were injected with a mix of plasmids encoding Cas9, a gRNA targeting rol-6, a gRNA targeting the gene of interest (such as ist-1), and a ssDNA repair template that induces the rol-6(su1006) mutation. F1 animals carrying roller phenotypes were isolated onto individual plates, allowed to lay eggs, and then screened for a target mutation by Sanger sequencing. non-Roller F2 animals with frameshift mutations in ist-1 were chosen to generate homozygous strains. The homozygous strains were then backcrossed twice to wild-type strains before being used to test behavior. The sequence of the ist-1(ky1074) mutation (resulting in a frameshift in exon 2 affecting isoforms $1 \mathrm{~b}$ and $1 \mathrm{e})$ is:

AAAACAGTGAGCTTCAGCGCTGCCAACAATAATAAACGGTGTCTGAGCTGATGTTG CCCGCCGAGCC (Deletion underlined).

The sequence of the ist-1(ky1075) mutation (resulting in a frameshift in the third shared exon, affecting all isoforms) is:

GCTAATGTTTGTGACACTCACGGAACGATGTTTAGAACTTCACGAGTCGGAGAAATC CTATCGTGCG (Deletion underlined). 
The sequence of the ist-1(ky1076) mutation (resulting in a frameshift in exon 2 affecting all isoforms) is:

GCGCCAGGAAGAAACAGGAAGAAACTGTAAAGAAATgtaagtgtcgttctgttatggttgttaaatt (Deletion underlined).

\section{Generating a conditional $d a f-2$ allele}

The flippase-FRT-modified daf-2 strain, including an FRT site sequence, the let-858 3'UTR, and the mCherry coding sequence before the 3' UTR of the daf-2 gene, was made using a protocol developed by the Mello lab (Dokshin, et al., 2018). Briefly, S. pyogenes Cas9 protein and synthesized tracrRNA and crRNA were used to generate the cut required for recombination. The let-858 3' UTR-FRT-mCherry insertion sequence was first assembled by standard cloning methods into a plasmid vector. Then oligos were used to generate the repair template by PCR: a pair of $55 \mathrm{nt}$ 5'SP9 (TEG) modified oligos added $35 \mathrm{nt}$ of homology to each side of the insertion site in the genome. The repair template was then heated and cooled with specific downsteps in the thermal cycler $\left(95^{\circ} \mathrm{C}-2: 00 \mathrm{~min} ; 85^{\circ} \mathrm{C}-10 \mathrm{sec}, 75^{\circ} \mathrm{C}-10 \mathrm{sec}, 65^{\circ} \mathrm{C}-10 \mathrm{sec}, 55^{\circ} \mathrm{C}-1: 00 \mathrm{~min}\right.$, $45^{\circ} \mathrm{C}-30 \mathrm{sec}, 35^{\circ} \mathrm{C}-10 \mathrm{sec}, 25^{\circ} \mathrm{C}-10 \mathrm{sec}, 4^{\circ} \mathrm{C}-\mathrm{O} / \mathrm{N}$. Ramp down at $\left.1^{\circ} \mathrm{C} / \mathrm{sec}\right)$. Although the mechanism is unknown, the Mello lab found these heating-cooling steps are critical to achieve high knock-in efficiencies. The repair template, tracrRNA, crRNA and rol-6(su1006) plasmid co-injection marker were then injected into young hermaphrodite gonads, and mutants were selected as described above. (See section “CRISPR/Cas9-generated mutant strains”). The upstream FRT site was inserted in the middle of the daf-2 gene such that excision would delete exons 10 through 17 which encode all intracellular domains including the kinase domain. We note that the $d a f-2 b$ isoform, which encodes a secreted protein that antagonizes insulin signaling, might be expressed in a shortened form (exons 1-9, instead of its normal sequence from exons 111) (Martinez, et al., 2020). For the second site, we inserted a let-858 3'UTR-FRT-mCherry coding sequence between the stop codon and the 3' UTR of $d a f-2$, with the intention that mCherry should be expressed after successful knockout of $d a f-2$ in cells of interest. Due to oversight in design, the mCherry reporter could not be visualized after FRT recombination. Instead, the BN294 bqSi294 strain, which carries an integrated transgene that expresses ubiquitous mCherry and a masked GFP, was used to report cell-specific flippase expression (Muñoz-Jiménez, et al., 2017). Upon flippase recombination between two FRT sites, mCherry is 
excised and GFP expression is unmasked. In the str-2p::flippase bqSi294strain, GFP was present in $\mathrm{AWC}^{\mathrm{ON}}$ in 7/11 animals, in ASI in 4/11 animals, in URX in 4/11 animals, and less frequently in OLQ, CEP, AFD, ASK, RIC, pharyngeal muscle cells, and body wall muscles cells (1/11 to 3/11 animals each).

The sequence surrounding the 5' insertion of the FRT site in daf-2 (CX1095) conditional knockout strain is:

ccgatttgccggaaattccaattccggcaattttccgatttgccggaaatttcaaatccgccaGAAGTTCCTATTCTCTAG

AAAGTATAGGAACTTCacttgccgatttgectgaaatttcatttcetgcgattttccgagttgccggaaatttcaaaaaattttct gaaactctgaaactagaaaagtttcggaaagaagcgcctaaacaggcgcttttaatgctgt

(Black letters: $d a f-2$ genomic sequence. Lower case: introns. Upper case: exons. Bold letters:

\section{FRT site sequence.)}

The sequence surrounding the 3' insertion of the let-858 3' UTR-FRT-mCherry in the daf-2 (CX1095) conditional knockout strain is:

CGAAACGGCAACAGCCGTGACATTTTCAACGGACGTTCGGCTTTCGGTGAAAATGA GCATCTAATCGAGGATAATGAGCATCATCCACTT/GTCTGATAAATTTTCAAATTTTA AATACTGAATATTTGTTTTTTTTCCTATTATTTATTTATTCTCTTTGTGTTTTTTTTCTT GCTTTCTAAAAAATTAATTCAATCCAAATCTAAACATTTTTTTTTCTCTTTCCGTCTCC CAATTCGTATTCCGCTCCTCTCATCTGAACACAATGTGCAAGTTTATTTATCTTCTCG CTTTCATTTCATTAGGACGTGGGGGGAATTGGTGGAAGGGGGAAACACACAAAAGG ATGATGGAAATGAAATAAGGACACACAATATGCAACAACATTCAATTCAGAAATAT GGAGGAAGGTTTAAAAGAAAACATAAAAATATATAGAGGAGGAAGGAAAACTAGT AAAAAATAAGCAAAGAAATTAGGCGAACGATGAGAATTGTCCTCGCTTGGAAGTTC CTATTCTCTAGAAAGTATAGGAACTTCAATGGTCTCAAAGGGTGAAGAAGATAAC ATGGCAATTATTAAAGAGTTTATGCGTTTCAAGGTGCATATGGAGGGATCTGTCAAT GGGCATGAGTTTGAAATTGAAGGTGAAGGAGAAGGCCGACCATATGAGGGAACAC AAACCGCAAAACTAAAGgtaagtttaaacatatatatactaactaaccetgattatttaaattttcagGTAACTAAAG GCGGACCATTACCATTCGCCTGGGACATCCTCTCTCCACAGTTCATGTATGGAAGTA AAGCTTATGTTAAACATCCGGCAGATATACCAGATTATTTGAAACTTTCATTCCCGG AGGGTTTTAAGTGGGAACGCGTAATGAATTTTGAAGACGGAGGAGTTGTTACAGTG ACGCAAGACTCAAGgtaagtttaaacagttcggtactaactaaccatacatatttaaattttcagCCTCCAAGATGGA 
GAATTTATTTATAAAGTCAAACTTCGAGGAACGAATTTCCCCTCGGATGGACCTGTT ATGCAGAAGAAGACTATGGGATGGGAAGCTTCAAGTGAAAGAATGTACCCTGAAGA CGGTGCTCTTAAGGGAGAGATTAAACAACGTCTTAAATTGAAAGATGGAGGACATT ACGATGCTGAGGTGAAGACAACTTACAAAGCCAAAAAACCAGTTCAGCTGCCAGGA GCGTACAATGTTAATATTAAACTGGATATCACCTCCCACAACGAGGATTACACTATC GTTGAGCAATATGAAAGAGCTGAAGGGCGGCACTCGACAGGTGGCATGGATGAATT GTATAAGTAGAACCCCCAAAAAATCCCGCCTCTTAAATTATAAATTATCTCCCACAT TATCATATCTCTACACGAATATCGGATTTTTTTTCAGATTTTTTCTG

(black letters: daf-2 genomic sequence. Lower case: introns. Upper case: exons. Yellow highlight: CRISPR target sequence. Slash: / CRISPR cut site. Blue letters: let-858 3' UTR. Bold: FRT site sequence. Red letters: mCherry sequence.) 
bioRxiv preprint doi: https://doi.org/10.1101/2022.02.14.480437; this version posted March 1, 2022. The copyright holder for this preprint (which was not certified by peer review) is the author/funder, who has granted bioRxiv a license to display the preprint in perpetuity. It is made available under aCC-BY 4.0 International license.

Table 2. Statistical Analyses

\begin{tabular}{|c|c|c|c|c|c|}
\hline Panel & Comparison & Sum & p-value & alpha & Test \\
\hline 1B; left & WT, Control vs Trained; 0.02ul & ns & 0.3282 & 0.05 & Mann-Whitney \\
\hline 1B; left & WT, Control vs Trained; $0.2 \mathrm{ul}$ & $* * *$ & 0.0001 & 0.05 & Mann-Whitney \\
\hline 1B; left & WT, Control vs Trained; 2 ul & $* * * *$ & $<0.0001$ & 0.05 & Mann-Whitney \\
\hline 1B; left & WT, Control vs Trained; $20 u l$ & $* * * *$ & $<0.0001$ & 0.05 & Mann-Whitney \\
\hline 1B; left & WT, Control vs Trained; 200ul & *** & 0.0002 & 0.05 & Mann-Whitney \\
\hline 1B; center & WT, Control vs Trained; 0.02ul & ns & 0.3823 & 0.05 & Mann-Whitney \\
\hline 1B; center & WT, Control vs Trained; $0.2 \mathrm{ul}$ & ns & 0.9329 & 0.05 & Mann-Whitney \\
\hline 1B; center & WT, Control vs Trained; 2 ul & ns & 0.3282 & 0.05 & Mann-Whitney \\
\hline 1B; center & WT, Control vs Trained; 20ul & $* * *$ & 0.0002 & 0.05 & Mann-Whitney \\
\hline 1B; center & WT, Control vs Trained; $200 u$ l & **** & $<0.0001$ & 0.05 & Mann-Whitney \\
\hline 1B; right & WT, Control vs Trained; 0.02ul & * & 0.0286 & 0.05 & Mann-Whitney \\
\hline 1B; right & WT, Control vs Trained; $0.2 \mathrm{ul}$ & * & 0.0286 & 0.05 & Mann-Whitney \\
\hline 1B; right & WT, Control vs Trained; 2 ul & * & 0.0286 & 0.05 & Mann-Whitney \\
\hline 1B; right & WT, Control vs Trained; $20 u$ l & $* * *$ & 0.0002 & 0.05 & Mann-Whitney \\
\hline 1B; right & WT, Control vs Trained; $200 u$ l & * & 0.0286 & 0.05 & Mann-Whitney \\
\hline 1C; left & ist-1, Control vs Trained; 0.02ul & ns & 0.6857 & 0.05 & Mann-Whitney \\
\hline 1C; left & ist-1, Control vs Trained; 0.2ul & ns & 0.6857 & 0.05 & Mann-Whitney \\
\hline 1C; left & ist-1, Control vs Trained; $2 \mathrm{ul}$ & ns & 0.2251 & 0.05 & Mann-Whitney \\
\hline 1C; left & ist-1, Control vs Trained; $20 \mathrm{ul}$ & ** & 0.0030 & 0.05 & Mann-Whitney \\
\hline 1C; left & ist-1, Control vs Trained; $200 u$ l & ** & 0.0022 & 0.05 & Mann-Whitney \\
\hline 1C; center & ist-1, Control vs Trained; $0.02 \mathrm{ul}$ & ns & 0.8857 & 0.05 & Mann-Whitney \\
\hline 1C; center & ist-1, Control vs Trained; $0.2 \mathrm{ul}$ & ns & 0.2000 & 0.05 & Mann-Whitney \\
\hline 1C; center & ist-1, Control vs Trained; $2 \mathrm{ul}$ & ns & 0.1948 & 0.05 & Mann-Whitney \\
\hline 1C; center & ist-1, Control vs Trained; $20 \mathrm{ul}$ & ** & 0.0047 & 0.05 & Mann-Whitney \\
\hline 1C; center & ist-1, Control vs Trained; $200 u$ l & $* * *$ & 0.0002 & 0.05 & Mann-Whitney \\
\hline $1 \mathrm{C}$; right & ist-1, Control vs Trained; $0.02 \mathrm{ul}$ & ** & 0.0022 & 0.05 & Mann-Whitney \\
\hline $1 \mathrm{C}$; right & ist-1, Control vs Trained; $0.2 \mathrm{ul}$ & ** & 0.0022 & 0.05 & Mann-Whitney \\
\hline $1 \mathrm{C}$; right & ist-1, Control vs Trained; $2 \mathrm{ul}$ & ** & 0.0022 & 0.05 & Mann-Whitney \\
\hline $1 \mathrm{C}$; right & ist-1, Control vs Trained; 20ul & $* *$ & 0.0022 & 0.05 & Mann-Whitney \\
\hline $1 \mathrm{C}$; right & ist-1, Control vs Trained; $200 u l$ & ** & 0.0022 & 0.05 & Mann-Whitney \\
\hline 2B & $W T$, Control vs Trained & $* * * *$ & $<0.0001$ & 0.05 & Mann-Whitney \\
\hline $2 \mathrm{~B}$ & ist-1(ky1074), Control vs Trained & * & 0.0104 & 0.05 & Mann-Whitney \\
\hline $2 \mathrm{~B}$ & ist-1(ky1076), Control vs Trained & ** & 0.0043 & 0.05 & Mann-Whitney \\
\hline $2 \mathrm{~B}$ & ist-1(ky1071), Control vs Trained & ns & 0.2403 & 0.05 & Mann-Whitney \\
\hline $2 \mathrm{~B}$ & ist-1(ky1075), Control vs Trained & ns & 0.1212 & 0.05 & Mann-Whitney \\
\hline $2 \mathrm{~B}$ & ist-1(ok2706), Control vs Trained & $* * *$ & 0.0001 & 0.05 & Mann-Whitney \\
\hline $2 \mathrm{C}$ & WT, Control vs Trained & $* * \star *$ & $<0.0001$ & 0.05 & Mann-Whitney \\
\hline $2 \mathrm{C}$ & ist-1(ky1071), Control vs Trained & ns & 0.2403 & 0.05 & Mann-Whitney \\
\hline
\end{tabular}




\begin{tabular}{|c|c|c|c|c|c|}
\hline $2 \mathrm{C}$ & $\begin{array}{l}\text { ist-1(ky1071); ist-1 fosmid, Control } \\
\text { vs Trained }\end{array}$ & $* *$ & 0.0079 & 0.05 & Mann-Whitney \\
\hline $2 \mathrm{C}$ & $\begin{array}{l}\text { ist-1(ky1071); ist-1(14.8kb)p::ist-1b, } \\
\text { Control vs Trained; }\end{array}$ & ** & 0.0079 & 0.05 & Mann-Whitney \\
\hline $2 C$ & ist-1(ok2706), Control vs Trained & $* * *$ & 0.0004 & 0.05 & Mann-Whitney \\
\hline $2 \mathrm{C}$ & $\begin{array}{l}\text { ist-1(ok2706); str-2p::ist-1b, Control } \\
\text { vs Trained }\end{array}$ & $* * * *$ & $<0.0001$ & 0.05 & Mann-Whitney \\
\hline $2 \mathrm{C}$ & $\begin{array}{l}\text { ist-1(ok2706); srsx-3p::ist-1b, Control } \\
\text { vs Trained }\end{array}$ & $* * *$ & 0.0002 & 0.05 & Mann-Whitney \\
\hline $2 \mathrm{C}$ & $\begin{array}{l}\text { ist-1(ok2706); tdc-1p::ist-1b, Control } \\
\text { vs Trained }\end{array}$ & ns & 0.0931 & 0.05 & Mann-Whitney \\
\hline $2 \mathrm{C}$ & $\begin{array}{l}\text { ist-1(ok2706); str-3p::ist-1b, Control } \\
\text { vs Trained }\end{array}$ & $* * *$ & 0.0005 & 0.05 & Mann-Whitney \\
\hline $2 \mathrm{C}$ & $\begin{array}{l}\text { ist-1(ok2706); gcy-28p::ist-1b, } \\
\text { Control vs Trained }\end{array}$ & ** & 0.0043 & 0.05 & Mann-Whitney \\
\hline $2 \mathrm{C}$ & $\begin{array}{l}\text { ist-1(ok2706); elt-2p:::ist-1b, Control } \\
\text { vs Trained }\end{array}$ & ** & 0.0059 & 0.05 & Mann-Whitney \\
\hline $2 \mathrm{C}$ & WT Trained vs ist-1(ky1071) Trained & * & 0.0145 & 0.05 & Kruskal-Wallis; Dunn's correction \\
\hline $2 \mathrm{C}$ & $\begin{array}{l}\text { WT Trained vs ist-1(ky1071); ist-1 } \\
\text { fosmid Trained }\end{array}$ & ns & $>0.9999$ & 0.05 & Kruskal-Wallis; Dunn's correction \\
\hline $2 \mathrm{C}$ & $\begin{array}{l}\text { WT Trained vs ist-1(ky1071); ist- } \\
\text { 1(14.8Kb)p::ist-1b, Trained }\end{array}$ & ns & 0.6461 & 0.05 & Kruskal-Wallis; Dunn's correction \\
\hline $2 \mathrm{C}$ & WT Trained vs ist-1(ok2706) Trained & $* * *$ & 0.0002 & 0.05 & Kruskal-Wallis; Dunn's correction \\
\hline $2 \mathrm{C}$ & $\begin{array}{l}\text { WT Trained vs ist-1(ky1071); str- } \\
2 p:: i s t-1 b \text { Trained }\end{array}$ & ns & 0.3529 & 0.05 & Kruskal-Wallis; Dunn's correction \\
\hline $2 \mathrm{C}$ & $\begin{array}{l}\text { ist-1(ky1071) Trained vs ist- } \\
\text { 1(ky1071); ist-1 fosmid Trained }\end{array}$ & * & 0.0186 & 0.05 & Kruskal-Wallis; Dunn's correction \\
\hline $2 \mathrm{C}$ & $\begin{array}{l}\text { ist-1(ky1071) Trained vs ist- } \\
1(14.8 k b) p:: i s t-1 b, \text { Trained }\end{array}$ & ** & 0.0064 & 0.05 & Kruskal-Wallis; Dunn's correction \\
\hline $2 \mathrm{C}$ & $\begin{array}{l}\text { ist-1(ok2706) Trained vs ist- } \\
\text { 1(ok2706); str-2p::ist-1b Trained }\end{array}$ & $* * * *$ & $<0.0001$ & 0.05 & Kruskal-Wallis; Dunn's correction \\
\hline 2C & $\begin{array}{l}\text { ist-1(ok2706) Trained vs ist- } \\
\text { 1(ok2706); srsx-3p::ist-1b Trained }\end{array}$ & ns & $>0.9999$ & 0.05 & Kruskal-Wallis; Dunn's correction \\
\hline $2 \mathrm{C}$ & $\begin{array}{l}\text { ist-1(ok2706) Trained vs ist- } \\
\text { 1(ok2706); tdc-1p::ist-1b Trained }\end{array}$ & ns & $>0.9999$ & 0.05 & Kruskal-Wallis; Dunn's correction \\
\hline $2 \mathrm{C}$ & $\begin{array}{l}\text { ist-1(ok2706) Trained vs ist- } \\
\text { 1(ok2706); str-3p::ist-1b Trained }\end{array}$ & ns & $>0.9999$ & 0.05 & Kruskal-Wallis; Dunn's correction \\
\hline $2 \mathrm{C}$ & $\begin{array}{l}\text { ist-1(ok2706) Trained vs ist- } \\
\text { 1(ok2706); str-2p::ist-1b Trained }\end{array}$ & ns & 0.8696 & 0.05 & Kruskal-Wallis; Dunn's correction \\
\hline $2 \mathrm{C}$ & $\begin{array}{l}\text { ist-1(ok2706) Trained vs ist- } \\
\text { 1(ok2706); elt-2p::ist-1b Trained }\end{array}$ & ns & $>0.9999$ & & Kruskal-Wallis; Dunn's correction \\
\hline $2 \mathrm{E}$ & $\begin{array}{l}\text { ist-1(ok2706); str- } \\
2 p:: \text { eGFP::linker::ist-1b }\end{array}$ & $* * *$ & 0.0006 & 0.05 & Mann-Whitney \\
\hline $3 B$ & $W T$, Control vs Trained & $* * * *$ & $<0.0001$ & 0.05 & Mann-Whitney \\
\hline 3B & ins-1(nr2091), Control vs Trained & ns & $>0.9999$ & 0.05 & Mann-Whitney \\
\hline 3B & akt-1(mg306)If, Control vs Trained & ns & 0.4848 & 0.05 & Mann-Whitney \\
\hline 3B & akt-1(mg144)gf, Control vs Trained & $* *$ & 0.0022 & 0.05 & Mann-Whitney \\
\hline 3B & daf-18(e1375), Control vs Trained & ns & 0.5929 & 0.05 & Mann-Whitney \\
\hline $3 C$ & ist-1(ok2706), Control vs Trained & ** & 0.0041 & 0.05 & Mann-Whitney \\
\hline $3 C$ & daf-18(e1375), Control vs Trained & ns & 0.5929 & 0.05 & Mann-Whitney \\
\hline $3 C$ & $\begin{array}{l}\text { daf-18(e1375); ist-1(ok2706) Control } \\
\text { vs Trained }\end{array}$ & *** & 0.0002 & 0.05 & Mann-Whitney \\
\hline
\end{tabular}


bioRxiv preprint doi: https://doi.org/10.1101/2022.02.14.480437: this version posted March 1, 2022. The copyright holder for this preprint (which was not certified by peer review) is the author/funder, who has granted bioRxiv a license to display the preprint in perpetuity. It is made available under aCC-BY 4.0 International license.

\begin{tabular}{|c|c|c|c|c|c|}
\hline $3 \mathrm{C}$ & $\begin{array}{l}\text { age- } 1(h \times 546), \text { Control vs Trained } \\
\text { age-1(m333); daf-18(e1375), Control } \\
\text { vs Trained }\end{array}$ & ns & $\begin{array}{l}0.2456 \\
0.1520\end{array}$ & $\begin{array}{l}0.05 \\
0.05\end{array}$ & $\begin{array}{l}\text { Mann-Whitney } \\
\text { Mann-Whitney }\end{array}$ \\
\hline $3 C$ & $\begin{array}{l}\text { daf-18(e1375) Control vs daf- } \\
\text { 18(e1375); ist-1(ok2706) Control } \\
\text { daf-18(e1375) Control vs age- } \\
\text { 1(m333); daf-18(e1375) Control } \\
\text { daf-18(e1375) Trained vs age- } \\
\text { 1(m333); daf-18(e1375) Trained }\end{array}$ & $* * *$ & $\begin{array}{l}0.0002 \\
0.0002 \\
0.0002\end{array}$ & 0.05 & $\begin{array}{l}\text { Mann-Whitney } \\
\text { Mann-Whitney } \\
\text { Mann-Whitney }\end{array}$ \\
\hline $3 \mathrm{C}$ & daf-16(mgDf50), Control vs Trained & ns & 0.8785 & 0.05 & Mann-Whitney \\
\hline $3 C$ & $\begin{array}{l}\text { daf-16(mgDf50); ist-1(ok2706) } \\
\text { Control vs Trained }\end{array}$ & * & 0.0104 & 0.05 & Mann-Whitney \\
\hline $3 C$ & $\begin{array}{l}\text { daf-16(mgDf50); age-1(hx546) } \\
\text { Control vs Trained }\end{array}$ & $* * *$ & 0.0007 & 0.05 & Mann-Whitney \\
\hline $3 C$ & $\begin{array}{l}\text { daf-16(mgDf50) Control vs daf- } \\
\text { 16(mgDf50); ist-1(ok2706) Control }\end{array}$ & **** & & 0.05 & Mann-Whitney \\
\hline $3 \mathrm{C}$ & $\begin{array}{l}\text { daf-16(mgDf50) Trained vs daf- } \\
\text { 16(mgDf50); ist-1(ok2706) Trained }\end{array}$ & * & 0.0222 & 0.05 & Mann-Whitney \\
\hline $3 \mathrm{C}$ & $\begin{array}{l}\text { daf-16(mgDf50) Control vs daf- } \\
\text { 16(mgDf50); age-1(hx546) Control }\end{array}$ & ** & 0.0014 & 0.05 & Mann-Whitney \\
\hline $3 \mathrm{C}$ & $\begin{array}{l}\text { daf-16(mgDf50) Trained vs daf- } \\
\text { 16(mgDf50); age-1(hx546) Trained }\end{array}$ & ns & 0.7618 & 0.05 & Mann-Whitney \\
\hline 3D & WT $25^{\circ} \mathrm{C}$ vs ist- 1 (ok2706) $25^{\circ} \mathrm{C}$ & ns & 0.1429 & 0.05 & Mann-Whitney \\
\hline 3D & $\begin{array}{l}\text { WT } 25^{\circ} \mathrm{C}+\text { ascaroside vs ist- } \\
1(\text { ok2 } 2706) 25^{\circ} \mathrm{C}+\text { ascaroside }\end{array}$ & * & 0.0286 & 0.05 & Mann-Whitney \\
\hline 4B & $W T$, Control vs Trained & $* * * *$ & $<0.0001$ & 0.05 & Mann-Whitney \\
\hline 4B & ist-1(ok2706), Control vs Trained & ** & 0.0041 & 0.05 & Mann-Whitney \\
\hline $4 \mathrm{~B}$ & daf-2(pe1230) Control vs Trained & ns & 0.0556 & 0.05 & Mann-Whitney \\
\hline 4B & daf-2(pe2722) Control vs Trained & $* * * *$ & $<0.0001$ & 0.05 & Mann-Whitney \\
\hline 4B & WT Trained vs ist-1(ok2706) Trained & $* * *$ & 0.0001 & 0.05 & Kruskal-Wallis; Dunn's correction \\
\hline 4B & $\begin{array}{l}\text { WT Trained vs daf-2(pe1230) } \\
\text { Trained }\end{array}$ & $* * *$ & 0.0002 & 0.05 & Kruskal-Wallis; Dunn's correction \\
\hline 4B & $\begin{array}{l}\text { WT Trained vs daf-2c(pe2722) } \\
\text { Trained }\end{array}$ & *** & 0.0003 & 0.05 & Kruskal-Wallis; Dunn's correction \\
\hline $4 \mathrm{C}$ & $\begin{array}{l}\text { WT Trained vs daf-2(pe1230) } \\
\text { Trained }\end{array}$ & *** & 0.0008 & 0.05 & Kruskal-Wallis; Dunn's correction \\
\hline $4 \mathrm{C}$ & $\begin{array}{l}\text { WT Trained vs daf-2c(pe2722) } \\
\text { Trained }\end{array}$ & * & 0.0351 & 0.05 & Kruskal-Wallis; Dunn's correction \\
\hline $4 \mathrm{C}$ & $\begin{array}{l}\text { daf-2(pe1230) Trained vs daf- } \\
\text { 2(pe1230); str-2p::daf-2a Trained }\end{array}$ & ns & 0.3646 & 0.05 & Kruskal-Wallis; Dunn's correction \\
\hline $4 C$ & $\begin{array}{l}\text { daf-2(pe1230) Trained vs daf- } \\
\text { 2(pe1230); str-2p::daf-2c Trained }\end{array}$ & ** & 0.0047 & 0.05 & Kruskal-Wallis; Dunn's correction \\
\hline $4 \mathrm{C}$ & $\begin{array}{l}\text { daf-2(pe2722) Trained vs daf- } \\
\text { 2(pe2722); str-2p::daf-2a Trained }\end{array}$ & ns & $>0.9999$ & 0.05 & Kruskal-Wallis; Dunn's correction \\
\hline $4 \mathrm{C}$ & $\begin{array}{l}\text { daf-2(pe2722) Trained vs daf- } \\
\text { 2(pe2722); str-2p::daf-2c Trained }\end{array}$ & ** & 0.0087 & 0.05 & Kruskal-Wallis; Dunn's correction \\
\hline 4D & $\begin{array}{l}\text { WT Trained vs daf-2(ky1087 ky1095) } \\
\text { Trained }\end{array}$ & ns & 0.7551 & 0.05 & Mann-Whitney \\
\hline 4D & $\begin{array}{l}\text { daf-2(ky1095) Trained vs daf- } \\
\text { 2(ky1087 ky1095); str-2p::flp Trained }\end{array}$ & ** & 0.0039 & 0.05 & Kruskal-Wallis; Dunn's correction \\
\hline
\end{tabular}




\begin{tabular}{|c|c|c|c|c|c|}
\hline 4D & $\begin{array}{l}\text { daf-2(ky1087 ky1095) Trained vs } \\
\text { daf-2(ky1087 ky1095); tax-4p::flp } \\
\text { Trained } \\
\text { daf-2(ky1087 ky1095) Trained vs } \\
\text { daf-2(ky1087 ky1095); str-3p::flp } \\
\text { Trained }\end{array}$ & ns & $\begin{array}{r}0.0031 \\
>0.9999\end{array}$ & 0.05 & $\begin{array}{l}\text { Kruskal-Wallis; Dunn's correction } \\
\text { Kruskal-Wallis; Dunn's correction }\end{array}$ \\
\hline $5 B$ & WT vs ist-1(ok2706) & * & 0.0140 & 0.05 & Kruskal-Wallis; Dunn's correction \\
\hline $5 B$ & WT vs ist-1(ok2706); gcy-5::ist-1b & ns & 0.0679 & 0.05 & Kruskal-Wallis; Dunn's correction \\
\hline $5 B$ & $\begin{array}{l}\text { daf-2c(pe2722) vs daf-2c(pe2722); } \\
\text { ist-1(ok2706) }\end{array}$ & ns & 0.1464 & 0.05 & Mann-Whitney \\
\hline $5 B$ & $\begin{array}{l}\text { daf-16(mgDf50) vs daf-16(mgDf50); } \\
\text { ist-1(ok2706) }\end{array}$ & * & 0.0222 & 0.05 & Kruskal-Wallis; Dunn's correction \\
\hline $5 B$ & $\begin{array}{l}\text { daf-16(mgDf50) vs daf-16(mgDf50); } \\
\text { daf-2c(pe2722) }\end{array}$ & $* * * *$ & $<0.0001$ & 0.05 & Kruskal-Wallis; Dunn's correction \\
\hline $5 B$ & $\begin{array}{l}\text { daf-16(mgDf50) vs daf-16(mgDf50); } \\
\text { daf-2c(pe2722); ist-1(ok2706) }\end{array}$ & ** & 0.0019 & 0.05 & Kruskal-Wallis; Dunn's correction \\
\hline $6 \mathrm{~B}$ & WT fed vs food deprived & ** & 0.0034 & 0.05 & Mann-Whitney \\
\hline $6 \mathrm{~B}$ & ist-1 fed vs food deprived & ns & 0.8818 & 0.05 & Mann-Whitney \\
\hline $6 \mathrm{~B}$ & ins-1 fed vs food deprived & ns & 0.2824 & 0.05 & Mann-Whitney \\
\hline $6 \mathrm{E}$ & WT fed vs food deprived & ** & 0.0032 & 0.05 & Mann-Whitney \\
\hline $6 \mathrm{E}$ & ist-1 fed vs food deprived & ns & 0.9434 & 0.05 & Mann-Whitney \\
\hline $6 \mathrm{E}$ & ins-1 fed vs food deprived & ns & 0.5825 & 0.05 & Mann-Whitney \\
\hline $6 \mathrm{~F}$ & WT fed vs food deprived & *** & 0.0003 & 0.05 & Mann-Whitney \\
\hline $6 \mathrm{~F}$ & ist- 1 fed vs food deprived & ns & 0.8994 & 0.05 & Mann-Whitney \\
\hline $6 \mathrm{~F}$ & ins-1 fed vs food deprived & ns & 0.8596 & 0.05 & Mann-Whitney \\
\hline $6 G$ & WT fed vs food deprived, cell body & ns & 0.2016 & 0.05 & Mann-Whitney \\
\hline $6 G$ & WT fed vs food deprived, axon & ns & 0.4170 & 0.05 & Mann-Whitney \\
\hline $6 \mathrm{H}$ & WT fed vs food deprived & * & 0.0208 & 0.05 & Mann-Whitney \\
\hline $6 \mathrm{H}$ & ist-1 fed vs food deprived & ns & 0.6271 & 0.05 & Mann-Whitney \\
\hline $7 \mathrm{C}$ & WT, Control vs Trained & ** & 0.0022 & 0.05 & Mann-Whitney \\
\hline 7C & $\begin{array}{l}\text { odr-1::FLP; FRT::eat-4::FRT, Control } \\
\text { vs Trained }\end{array}$ & ** & 0.0043 & 0.05 & Mann-Whitney \\
\hline 7C & eat-4(ky5) Control vs Trained & ns & 0.0649 & 0.05 & Mann-Whitney \\
\hline $7 \mathrm{C}$ & $\begin{array}{l}\text { WT Control vs odr-1::FLP; FRT::eat- } \\
\text { 4::FRT Control }\end{array}$ & ** & 0.0041 & 0.05 & Kruskal-Wallis; Dunn's correction \\
\hline $7 \mathrm{C}$ & WT Control vs eat-4(ky5) Control & * & 0.0189 & 0.05 & Kruskal-Wallis; Dunn's correction \\
\hline $7 \mathrm{E}$ & $\begin{array}{l}\text { WT Control vs Trained, odor OFF } \\
\text { response }\end{array}$ & $* \star * *$ & $<0.0001$ & 0.05 & Mann-Whitney \\
\hline $7 \mathrm{E}$ & $\begin{array}{l}\text { ist- } 1 \text { Control vs Trained, odor OFF } \\
\text { response }\end{array}$ & ns & 0.3801 & 0.05 & Mann-Whitney \\
\hline $7 \mathrm{~F}$ & $p k c-1(n j 1)$ Control vs Trained & ns & 0.0649 & 0.05 & Mann-Whitney \\
\hline $7 F$ & $\begin{array}{l}\text { pkc-1(nj1); str-2::pkc-1 Control vs } \\
\text { Trained }\end{array}$ & $* * *$ & 0.0002 & 0.05 & Mann-Whitney \\
\hline $7 \mathrm{~F}$ & $\begin{array}{l}w t ; \text { str-2::pkc-1(gf) Control vs } \\
\text { Trained }\end{array}$ & *** & 0.0002 & 0.05 & Mann-Whitney \\
\hline S1C & $\begin{array}{l}\text { WT Control turn initiated while } \\
\text { traveling towards odor vs WT Control }\end{array}$ & * & 0.0286 & 0.05 & Mann-Whitney \\
\hline
\end{tabular}




\begin{tabular}{|c|c|c|c|c|c|}
\hline S1C & $\begin{array}{l}\text { turn initiated while traveling away } \\
\text { from odor } \\
\text { WT Trained turn initiated while } \\
\text { traveling towards odor vs WT } \\
\text { Trained turn initiated while traveling } \\
\text { away from odor } \\
\text { ist-1(ok2706) Control turn initiated } \\
\text { while traveling towards odor vs ist- } \\
1 \text { (ok2706) Control turn initiated while } \\
\text { traveling away from odor } \\
\text { ist-1(ok2706) Trained turn initiated } \\
\text { while traveling towards odor vs ist- } \\
1 \text { (ok2706) Trained turn initiated while } \\
\text { traveling away from odor }\end{array}$ & ns & $\begin{array}{l}0.0286 \\
0.0286\end{array}$ & 0.05 & $\begin{array}{l}\text { Mann-Whitney } \\
\text { Mann-Whitney }\end{array}$ \\
\hline $\begin{array}{l}\text { S3C } \\
\text { S3C }\end{array}$ & $\begin{array}{l}\text { WT vs ist-1(ok2706) } \\
\text { daf-2c(pe2722) vs daf-2c(pe2722); } \\
\text { ist-1(ok2706) }\end{array}$ & $\begin{array}{l}\text { ns } \\
\text { ns }\end{array}$ & $\begin{array}{l}0.9143 \\
0.3429\end{array}$ & $\begin{array}{l}0.05 \\
0.05\end{array}$ & $\begin{array}{l}\text { Mann-Whitney } \\
\text { Mann-Whitney }\end{array}$ \\
\hline $\begin{array}{l}\text { S3D } \\
\text { S3D }\end{array}$ & $\begin{array}{l}\text { WT vs ist-1(ok2706) } \\
\text { daf-2c(pe2722) vs daf-2c(pe2722); } \\
\text { ist-1(ok2706) }\end{array}$ & $\begin{array}{l}\text { ns } \\
\text { ns }\end{array}$ & $\begin{array}{l}0.1143 \\
0.0571\end{array}$ & $\begin{array}{l}0.05 \\
0.05\end{array}$ & $\begin{array}{l}\text { Mann-Whitney } \\
\text { Mann-Whitney }\end{array}$ \\
\hline S3E & WT vs ist-1(ok2706) & $* *$ & 0.0093 & 0.05 & Wilcoxon, paired \\
\hline $\begin{array}{l}\text { S3E } \\
\text { S3E }\end{array}$ & $\begin{array}{l}\text { ist-1(ok2706) vs daf-2c(pe2722) } \\
\text { ist-1(ok2706) vs daf-2c(pe2722); ist- } \\
\text { 1(ok2706) }\end{array}$ & ns & $\begin{array}{l}<0.0001 \\
0.1127\end{array}$ & $\begin{array}{l}0.05 \\
0.05\end{array}$ & $\begin{array}{l}\text { Kruskal-Wallis; Dunn's correction } \\
\text { Kruskal-Wallis; Dunn's correction }\end{array}$ \\
\hline S3E & $\begin{array}{l}\text { daf-2c(pe2722) vs daf-2c(pe2722); } \\
\text { ist-1(ok2706) }\end{array}$ & * & 0.0161 & 0.05 & Kruskal-Wallis; Dunn's correction \\
\hline S3F & WT vs ist-1(ok2706) & ** & 0.0024 & 0.05 & Wilcoxon, paired \\
\hline $\begin{array}{l}\text { S3F } \\
\text { S3F }\end{array}$ & $\begin{array}{l}\text { ist-1(ok2706) vs daf-2c(pe2722) } \\
\text { ist-1(ok2706) vs daf-2c(pe2722); ist- } \\
\text { 1(ok2706) }\end{array}$ & $* * * *$ & $<0.0001$ & 0.05 & $\begin{array}{l}\text { Kruskal-Wallis; Dunn's correction } \\
\text { Kruskal-Wallis; Dunn's correction }\end{array}$ \\
\hline S3F & $\begin{array}{l}\text { daf-2c(pe2722) vs daf-2c(pe2722); } \\
\text { ist-1(ok2706) }\end{array}$ & ns & 0.9739 & 0.05 & Kruskal-Wallis; Dunn's correction \\
\hline
\end{tabular}

\section{DATA AND SOFTWARE AVALIABILITY}

All datasets and scripts generated during the current study will be made available on Mendeley Data and Github, respectively. 


\section{SUPPLEMENTARY FIGURE LEGENDS}

Figure S1. ist-1 regulates biased random walk chemotaxis during aversive learning

A) C. elegans utilizes a biased-random walk strategy to navigate toward an odor source, in which turning increases as odor decreases. For panels (B) and (C), the angle between the animals' heading direction and the direction of the odor source was determined shortly before each reversal-turn behavior during chemotaxis assays.

B) Event count of reversal-turns for 50 wild-type or 50 ist-1 mutant animals during one chemotaxis session. The angle between animals' heading direction and odor source is binned by an increment of $30^{\circ}$. Animals were food-deprived (control, white bars), or food-deprived with butanone for 90 mins (trained, pink bars).

C) Average frequency of reversal-turns for wild-type (black) or ist-1 mutant (red) animals when they are traveling towards the odor (white bars with black and red borders), or traveling away from the odor (solid black and red bars).

In (B) and (C), wild-type and ist-1 control animals initiated more reversal-turn reorientations when traveling away from the odors, an act of course-correction for chemotaxis. Wild-type animals that were trained with butanone for 90 mins initiated similar frequencies of reversalturns regardless of their heading direction, a finding that correlates with decreased chemotaxis after training. ist-1 animals that were trained with butanone for 90 mins continued to initiate more reversal-turn reorientations when traveling away from the odors $(*$, values differ at $\mathrm{p} \leq$ 0.05). Statistical tests are described in Table S2.

\section{Figure S2. ist-1 promoters and isoforms}

A) Genomic structure of the C. elegans insulin receptor substrate-1 (ist-1) gene and flanking regions. White blocks indicate noncoding regions; black boxes indicate ist- 1 exons.

B) The $9.3 \mathrm{~kb}$ genomic region between the first exon and the next gene upstream from ist-1 drives GFP in the intestine and pharynx, and does not rescue ist-1 aversive learning when driving an ist- $1 b$ cDNA.

C) The $5.3 \mathrm{~kb}$ genomic region between the first exon and second exon of ist- 1 gene drives expression in the AWC, ASE, AUA and BAG neurons, and rescues ist-1 aversive learning when driving an ist-1b cDNA. 
D-E) The $14.8 \mathrm{~kb}$ full genomic region drives expression in (D) AIM, RIG, ASK, ASI, AWC, ASE, AUA, ASJ, RIM, ASG and BAG neurons (Figure 2D) and (E) tail neurons, and rescues ist1 aversive learning when driving an ist- $1 b$ cDNA.

\section{Figure S3. ist-1 phenotypes and interactions with the insulin/IGF pathway in taste learning}

A) Training and testing conditions for taste learning. Associative learning can be performed by pairing food or food deprivation with low $(25 \mathrm{mM})$ or high $(100 \mathrm{mM})$ salt concentrations. In the final salt preference assay, animals choose between low $(35 \mathrm{mM})$ and high $(95 \mathrm{mM})$ concentrations in a salt gradient.

B) Salt preference after pairing food with low salt (light blue bars) or high salt (dark blue bars), or after pairing food deprivation with low salt (light blue bars) or high salt (dark blue bars). Animals prefer salt concentrations experienced with food.

C-F) Salt preference of wild-type, ist-1, daf-2c, and ist-1 daf-2c double mutant animals after different training conditions. Animals were trained for 5 hours.

Error bars indicate S.E.M. *, values differ at $\mathrm{p} \leq 0.05$. $^{* *}$, values differ at $\mathrm{p} \leq 0.01$. ****, values differ at $\mathrm{p} \leq 0.0001$. ns, values are not significantly different. Statistical tests are described in Table S2. 
A

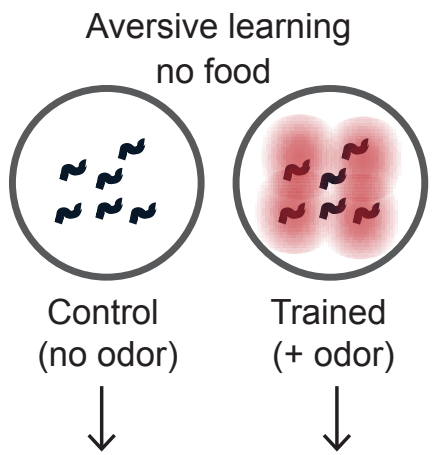

$1: 1000$ butanone

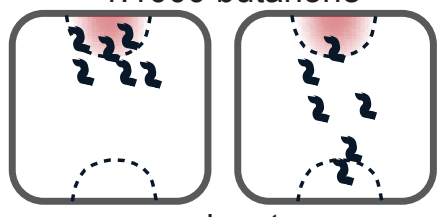

solvent

B

WT

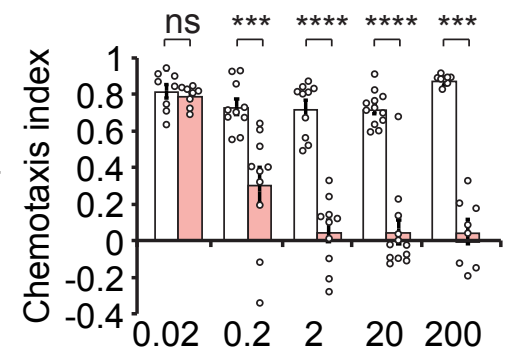

C

${ }^{n+1+1}$

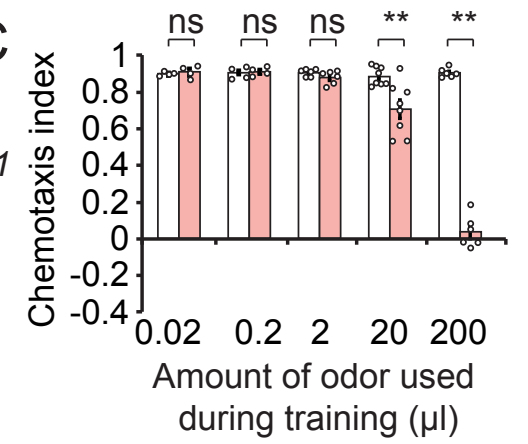

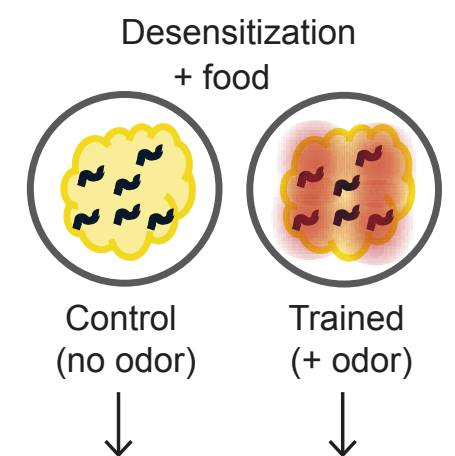

Appetitive learning

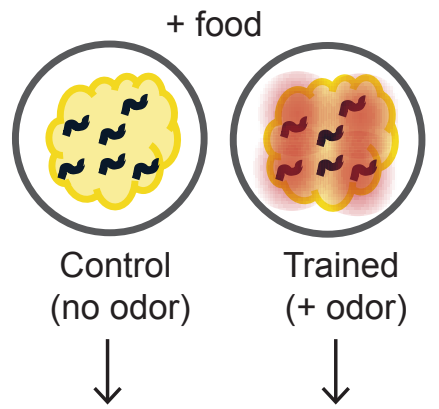

$1: 1000$ butanone

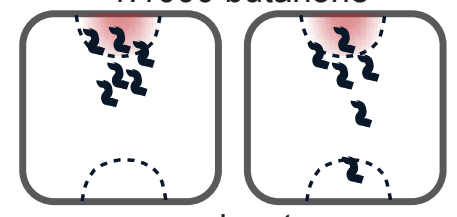

solvent

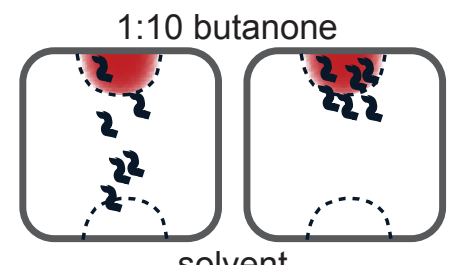

solvent
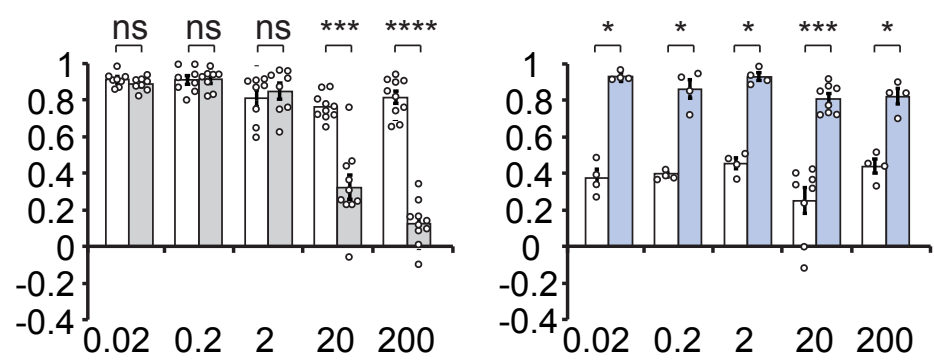

Control

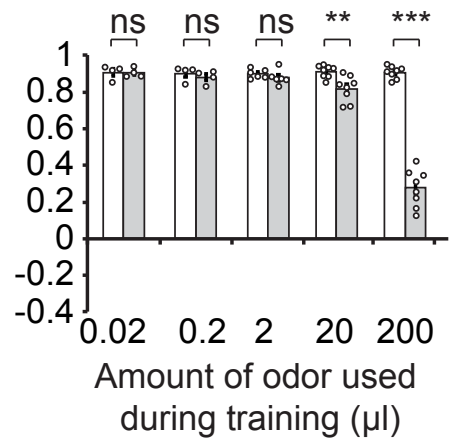

(no odor)

Food

Odor

Trained

(+ odor)

Figure 1. ist-1 mutants are defective in aversive learning 
bioRxiv preprint doi: https://doi.org/10.1101/2022.02.14.480437; this version posted March 1, 2022. The copyright holder for this preprint (which was not certified by peer review) is the author/funder, who has granted bioRxiv a license to display the preprint in perpetuity. It is made available under aCC-BY 4.0 International license.

A

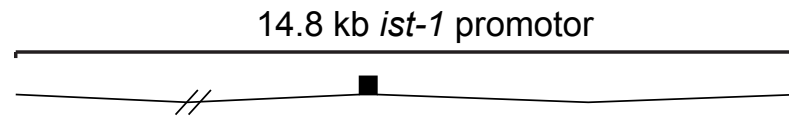
$\mathrm{PH}$ domain

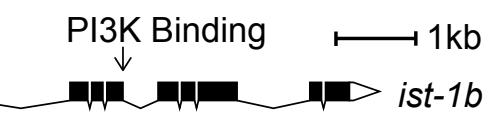

\section{PTB domain}

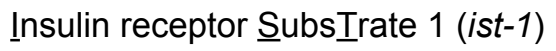

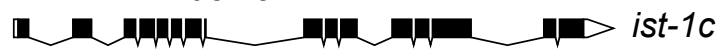

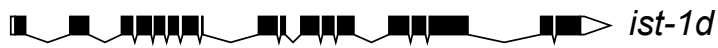

- L

B
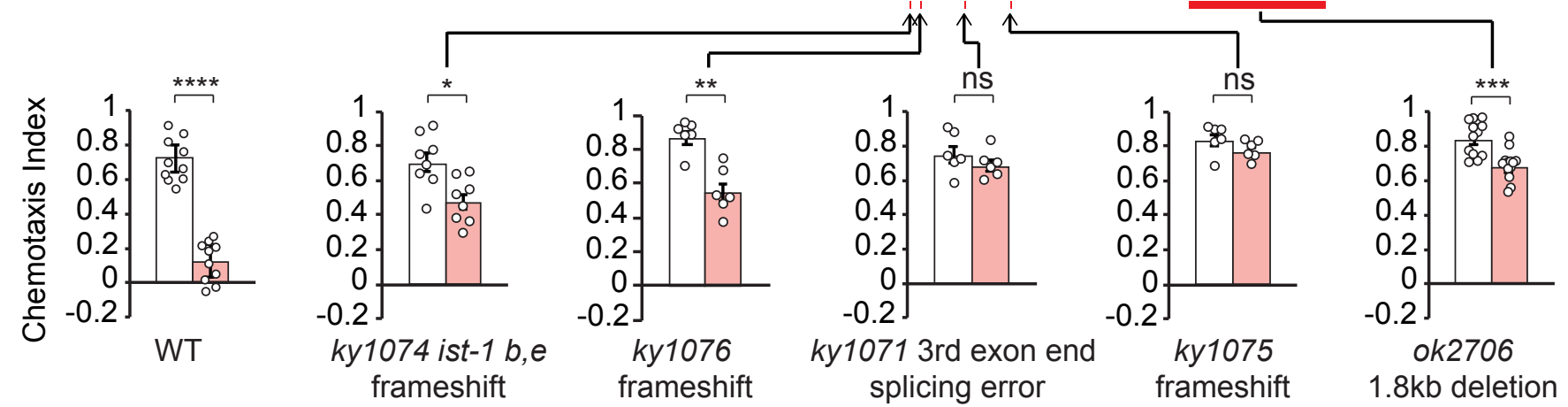

C
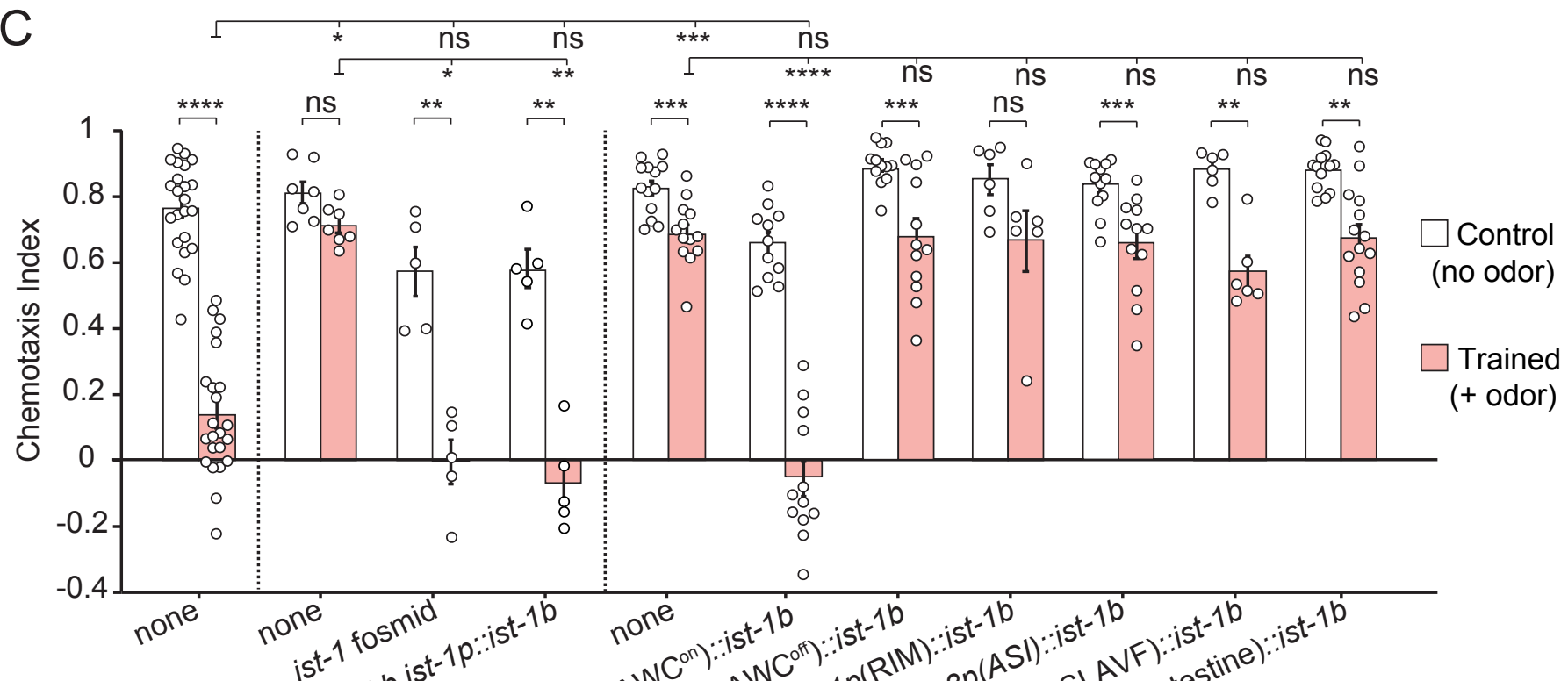

Transgene:

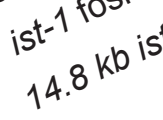

Genotype: $\overline{\text { WT }}$

ist-1(ky1071)

$g c y-28$ (A) $e^{t t-2 p}$

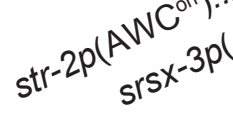
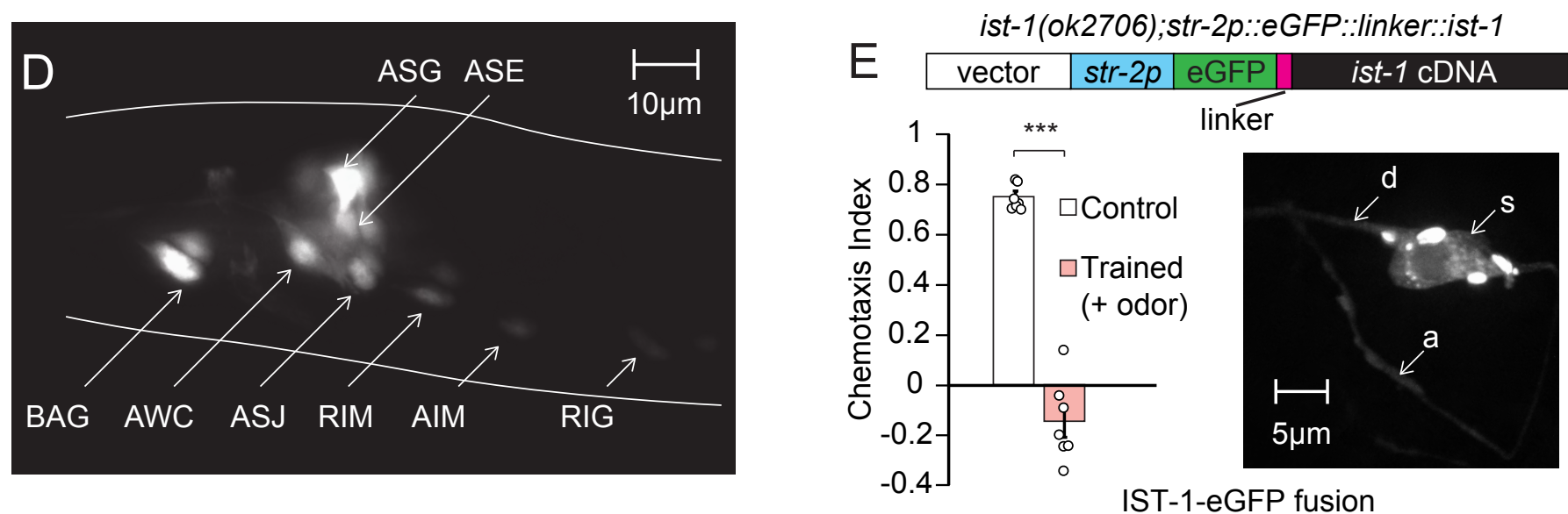

Figure 2. ist-1 is required in $A W C^{O N}$ for butanone aversive learning 
bioRxiv preprint doi: https://doi.org/10.1101/2022.02.14.480437; this version posted March 1, 2022. The copyright holder for this preprint (which was not certified by peer review) is the author/funder, who has gfanted bioRxiv a license to display the preprint in perpetuity. It is made A other available under aCC-BY 0 International license. available under aCC-BY 0 International license.
other

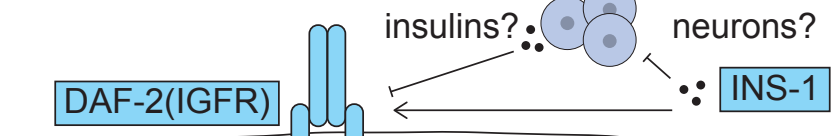

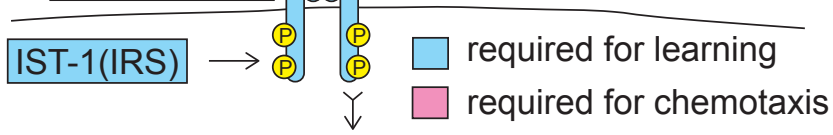
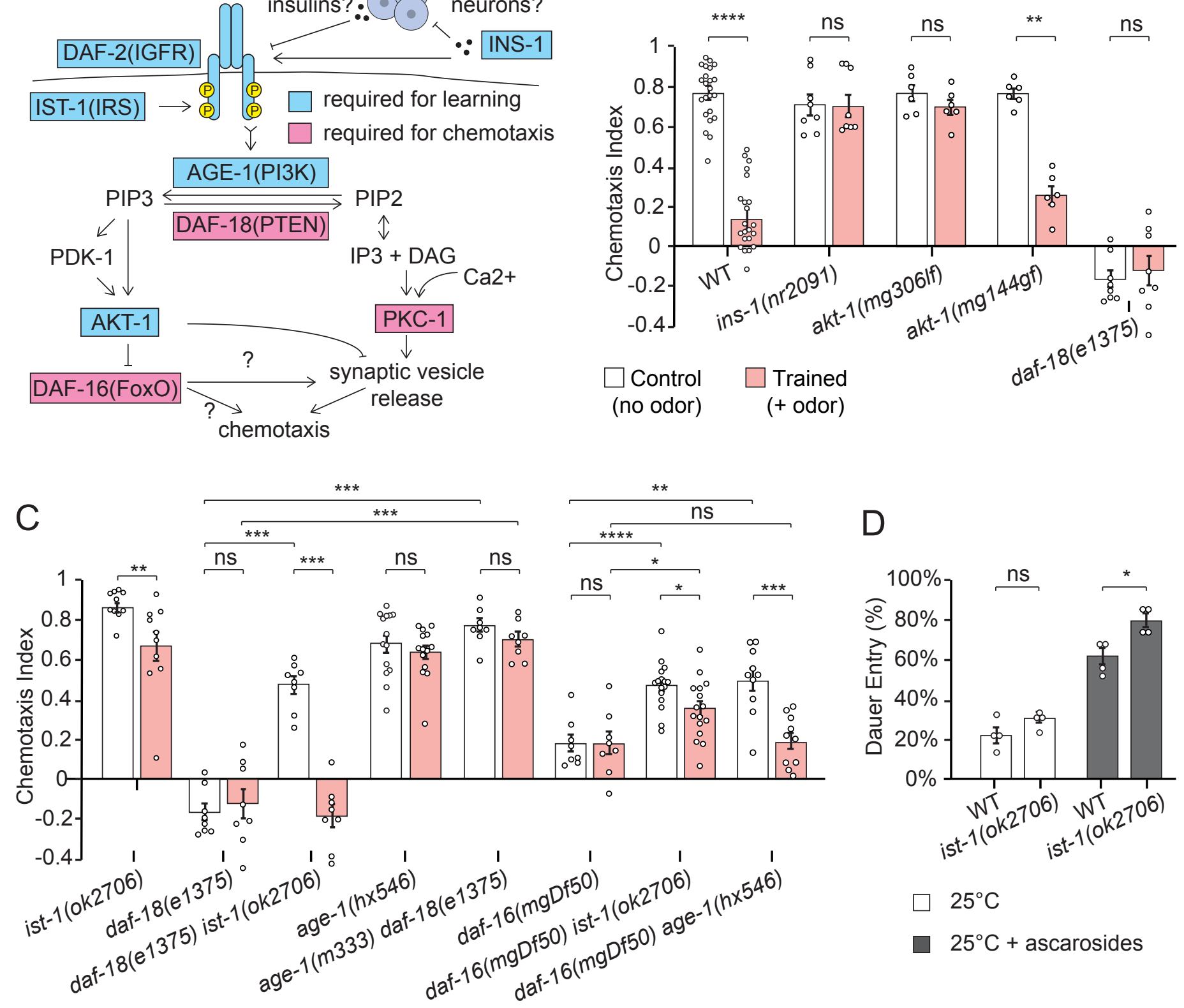

Figure 3. ist-1 interacts with the insulin/IGF signaling pathway in aversive learning 
bioRxiv preprint doi: https://doi.org/10.1101/2022.02.14.480437; this version posted March 1, 2022. The copyright holder for this preprint (which was not certified by peer review) is the author/funder, who has granted bioRxiv a license to display the preprint in perpetuity. It is made available under aCC-BY 4.0 International license.

A

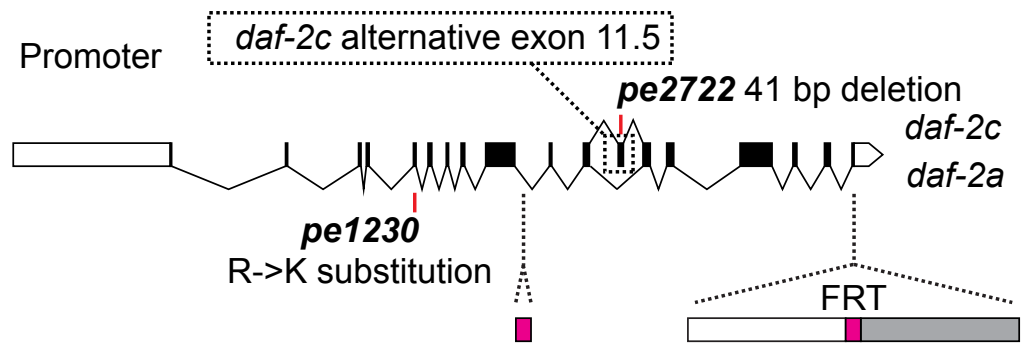

daf-2 conditional allele:

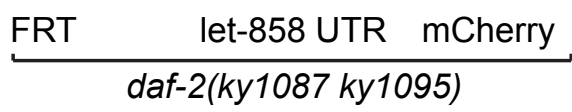

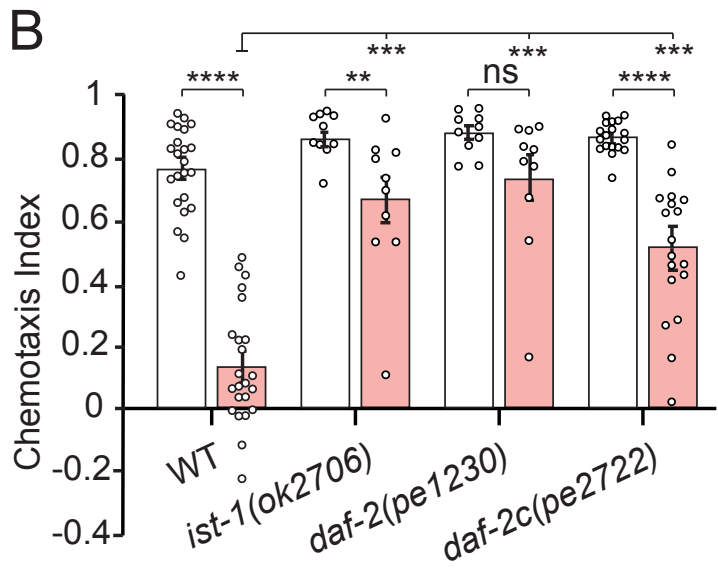

C daf-2 cell-specific rescue

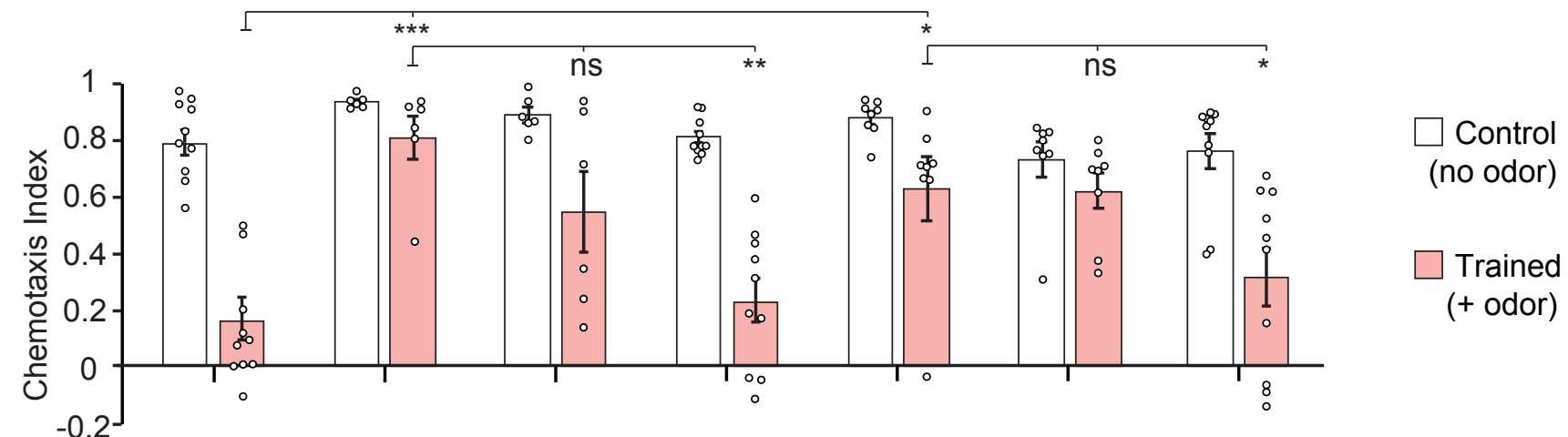

Transgene: none none str-2p:: str-2p:: none str-2p:: str-2p:: daf-2a daf-2c daf-2a daf-2c

Genotype: WT

daf-2(pe1230)

daf-2(pe2722)

D daf-2 cell-specific knock-out with conditional allele

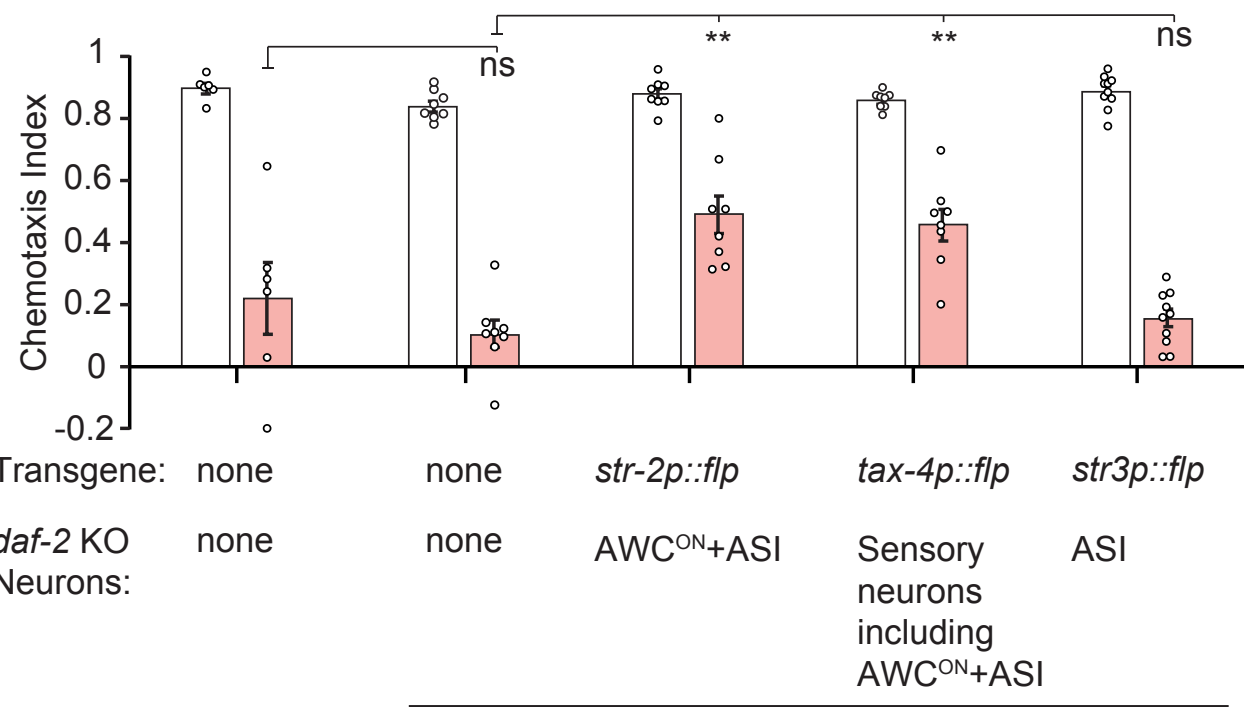

Genotype: WT

daf-2(ky1087 ky1095)

Figure 4. The DAF-2 Insulin/IGF receptor is required in AWCON for aversive learning 
bioRxiv preprint dol: https://doi.org/10.1101/2022.02.14.480437; this version posted March $1,2022$. The copyright holder for this preprint (which was not certified by peer review) is the author/funder, who has granted bioRxiv a license to display the preprint in perpetuity. It is made available under aCC-BY 4.0 International license.

A $[95 \mathrm{~mm} \mathrm{NaCl1}$

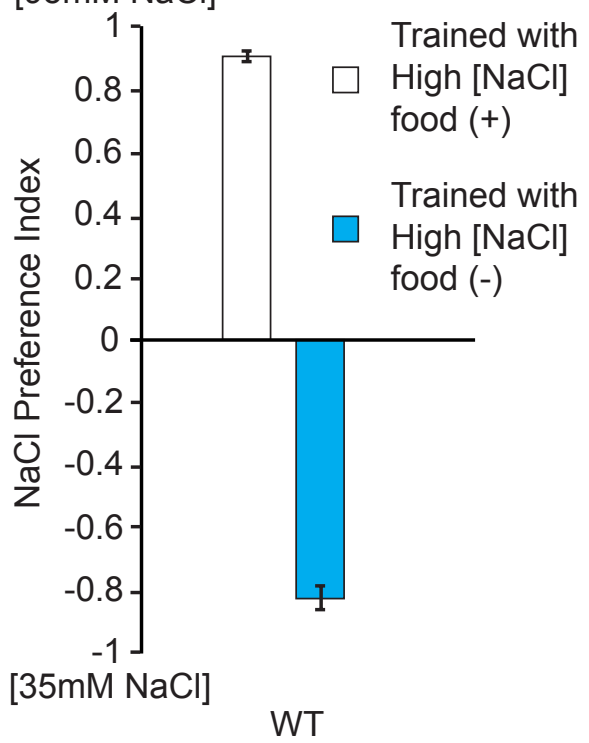

B Trained with High [NaCl], food (-)

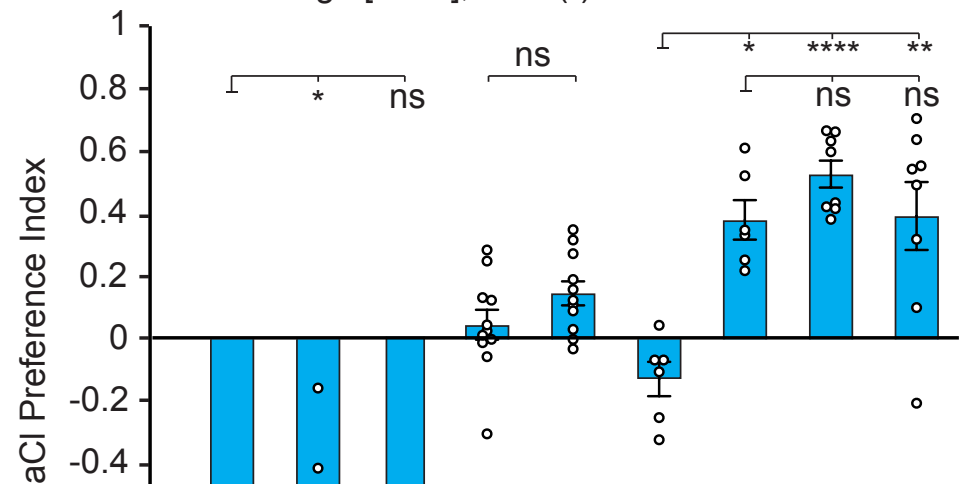

Figure 5. ist-1 in ASER interacts with the insulin/IGF pathway in taste avoidance learning 
A DAF-2a-mVenus fusion (str2p::daf-2a::mVenus) \begin{tabular}{|c|c|c|c|}
\hline vector & str-2p & daf-2a cDNA mVenus \\
\hline
\end{tabular}
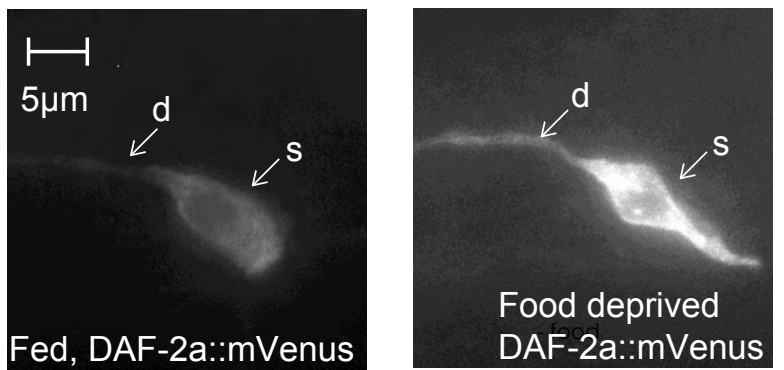

D DAF-2c-mVenus fusion (str2p:::daf-2c::mVenus) \begin{tabular}{|c|c|c|c|}
\hline vector & str-2 $p$ & daf-2c cDNA & mVenus \\
\hline
\end{tabular}

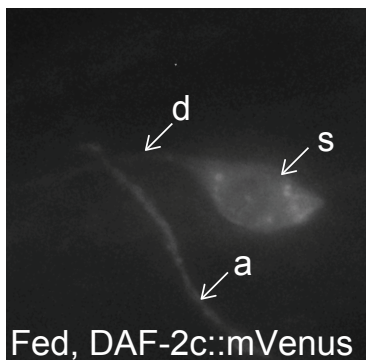
exon 11.5
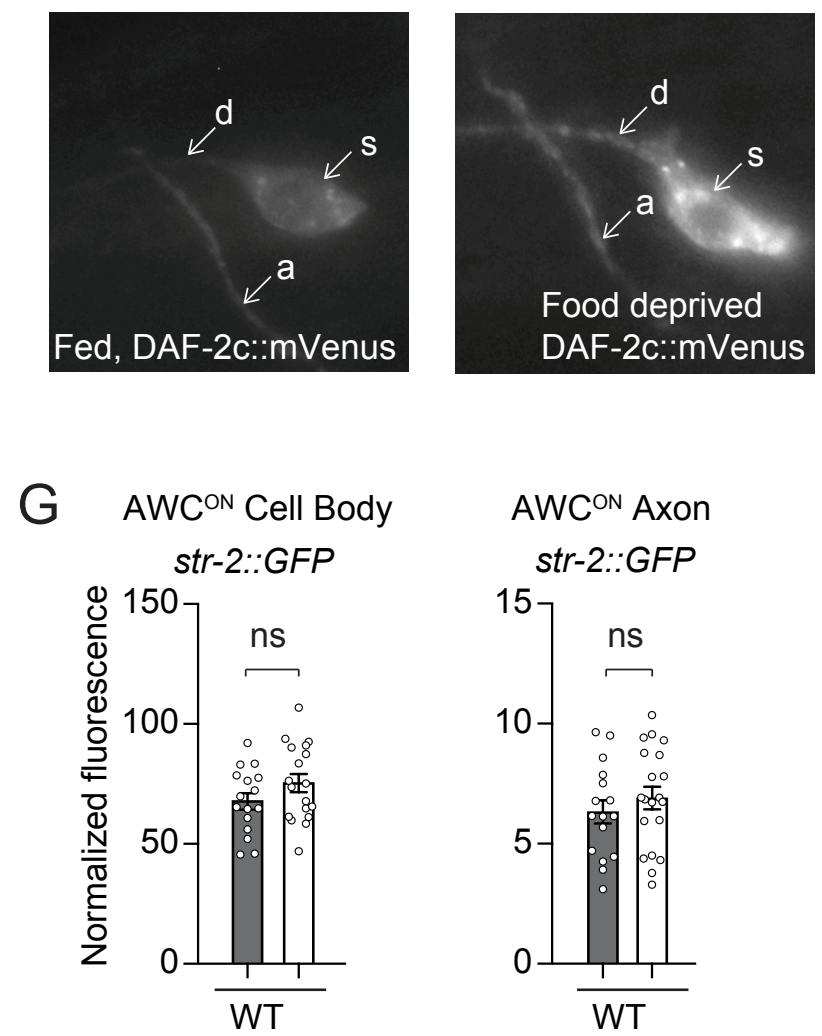

E $\quad \begin{aligned} & \text { AWCON Cell Body } \\ & \text { str-2::daf-2c::mVenus }\end{aligned}$

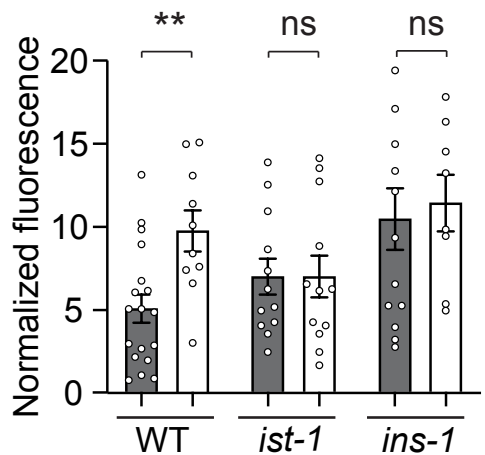

F str-2::daf-2c::mVenus

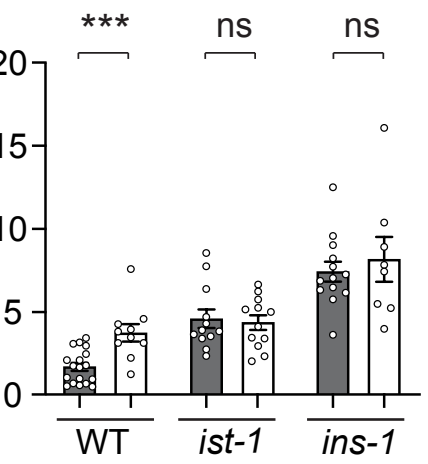

B $\quad$ AWC ${ }^{O N}$ Cell Body
str-2::daf-2a::mVenus

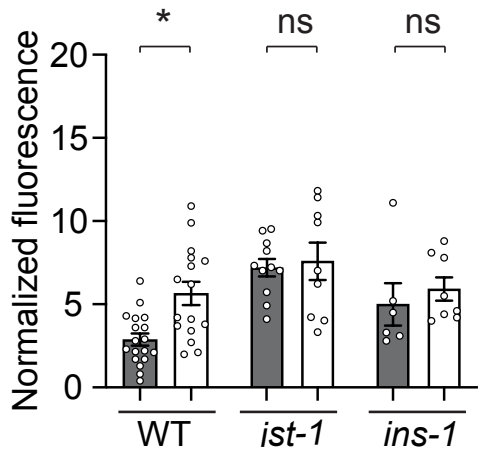
C $\begin{gathered}\mathrm{AWC}^{\mathrm{ON}} \text { Axon } \\ \text { str-2::daf-2a::mVenus }\end{gathered}$

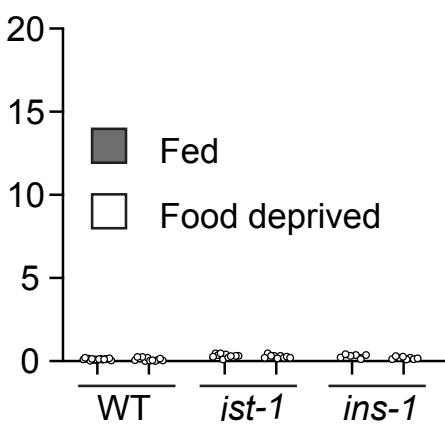

H ASER Axon

gcy-5::daf-2c::mVenus

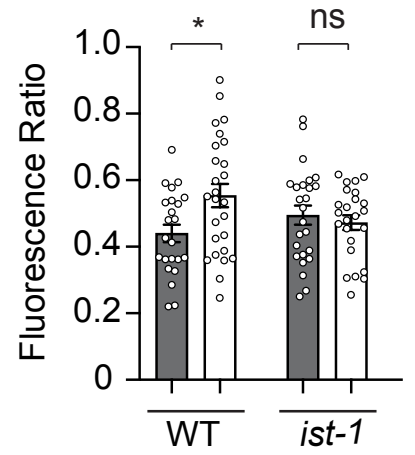

Figure 6. DAF-2 is regulated by nutritional state, ist-1, and ins-1 
bioRxiv preprint doi: https://doi.org/10.1101/2022.02.14.480437; this version posted March 1, 2022. The copyright holder for this preprint (which was not certified by peer review) is the author/funder, who has granted bioRxiv a license to display the preprint in perpetuity. It is made available under aCC-BY 4.0 International license.

A
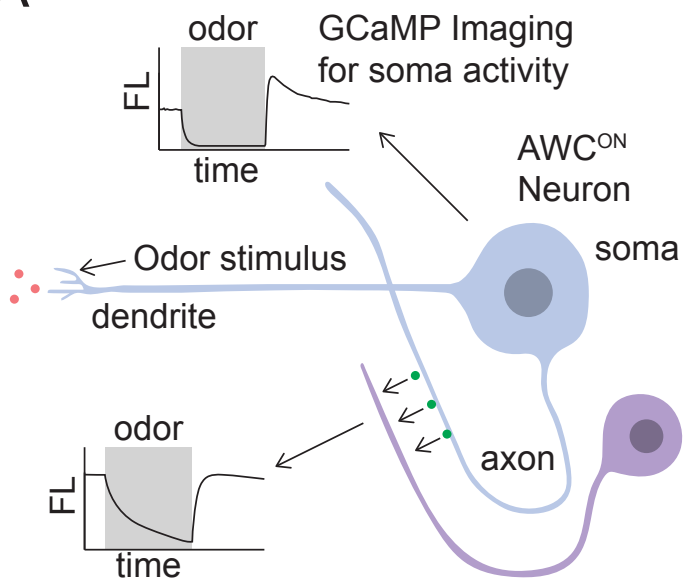

pHluorin Imaging for synaptic glutamate release
Target Neurons

C

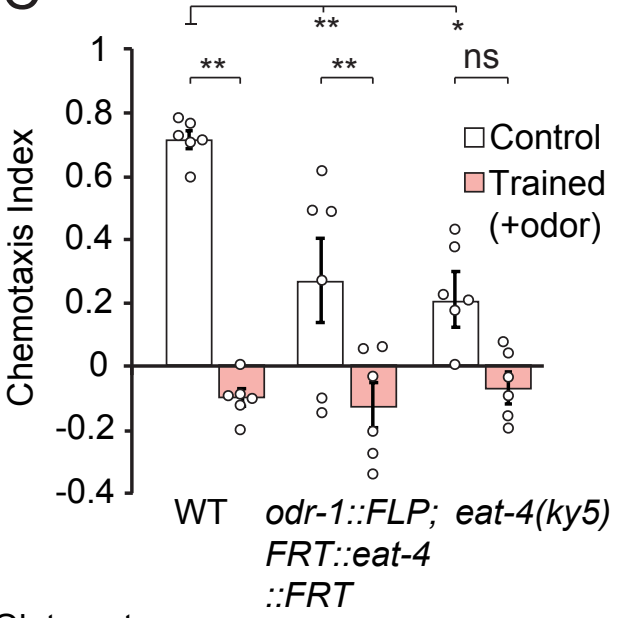

Glutamate $\because F R T$

knockout in - AWC All cells

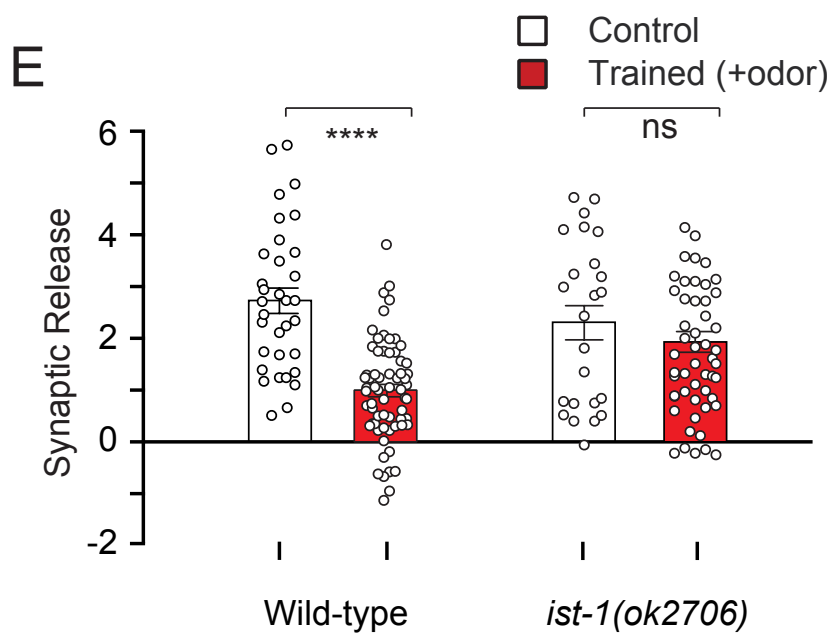

Quantification of synaptic release

B GCaMP Imaging

Wild-type Control Trained (+odor)

[Butanone] (buffer) $10^{-8} \mathrm{M} \quad 10^{-7} \mathrm{M} \quad 10^{-6} \mathrm{M} \quad 10^{-5} \mathrm{M} \quad 10^{-4} \mathrm{M} \quad 10^{-3} \mathrm{M}$

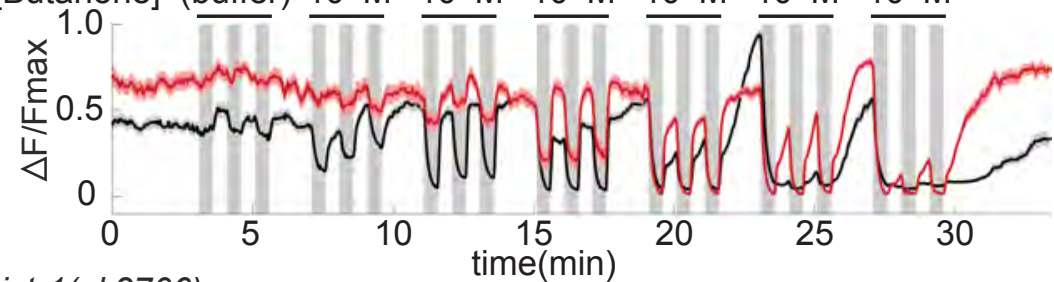

ist-1(ok2706)

[Butanone] (buffer) $10^{-8} \mathrm{M} \quad 10^{-7} \mathrm{M} \quad 10^{-6} \mathrm{M} \quad 10^{-5} \mathrm{M} \quad 10^{-4} \mathrm{M} \quad 10^{-3} \mathrm{M}$

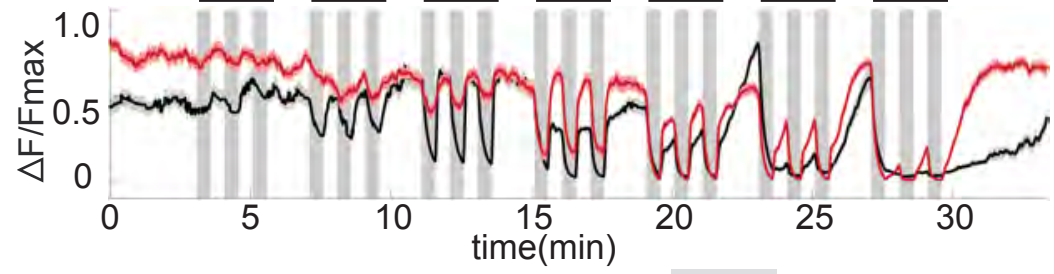

$10^{-5} \mathrm{M}$ butanone

D pHluorin Imaging
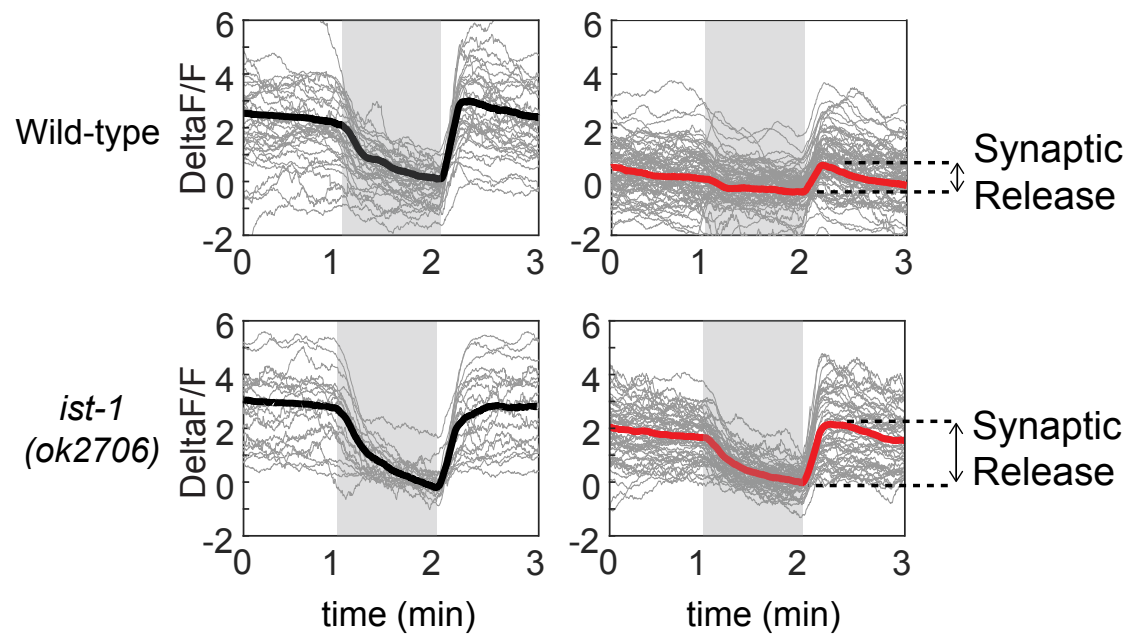

F

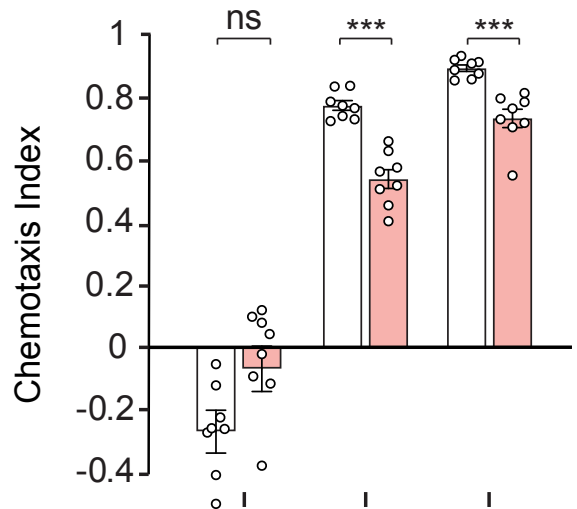

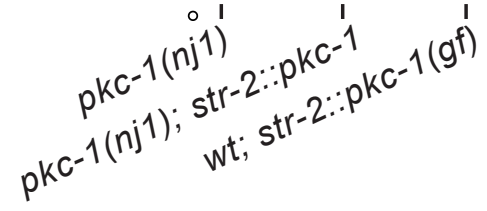

Figure 7. Aversive learning suppresses synaptic odor responses in AWC ${ }^{O N}$ 
A

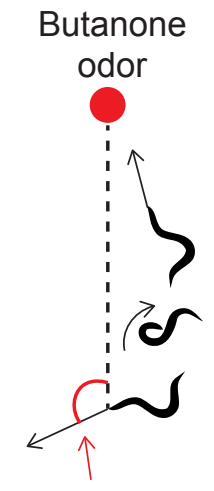

Relative head angle to odor before the initiation of a reversal-turn
B Wild-type
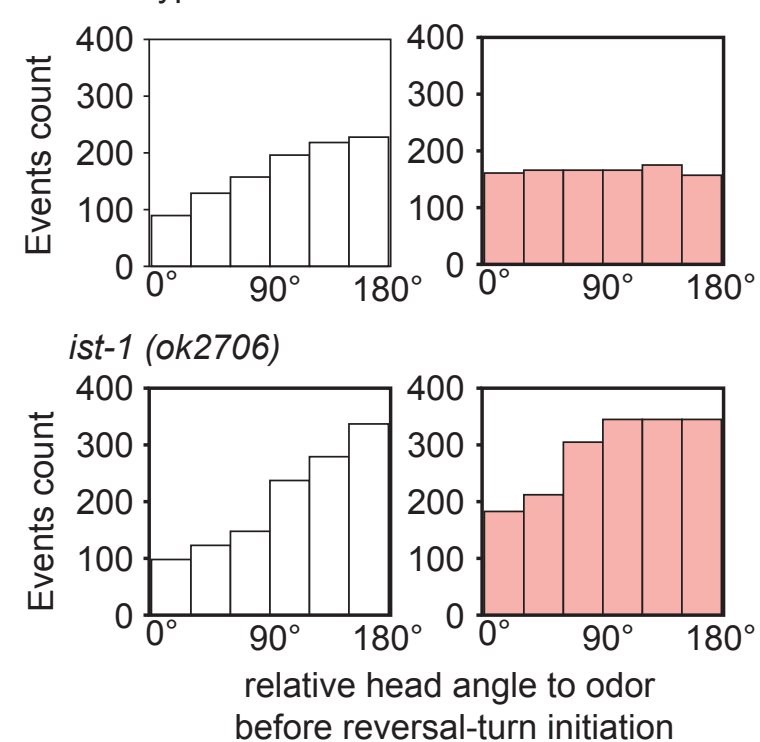

$\square$ Control

$\square$ Trained (+odor)
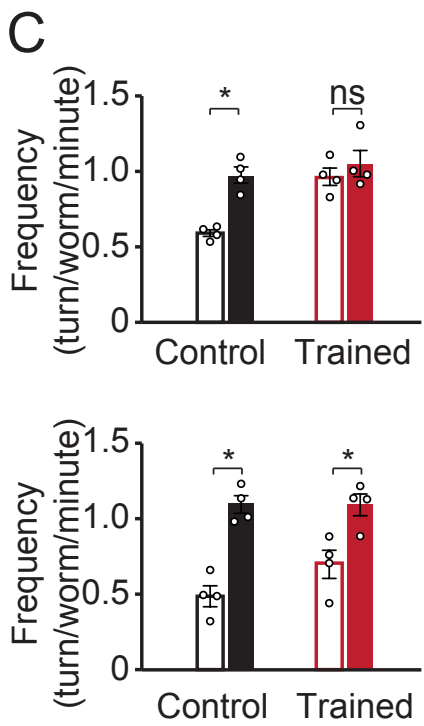

口पTurn initiated towards odor $\left(<90^{\circ}\right)$

a Turn initiated away from odor $\left(>90^{\circ}\right)$

Figure S1. ist-1 regulates biased random walk chemotaxis during aversive learning 
bioRxiv preprint doi: https://doi.org/10.1101/2022.02.14.480437; this version posted March 1, 2022. The copyright holder for this preprint (which was not certified by peer review) is the author/funder, who has granted bioRxiv a license to display the preprint in perpetuity. It is made available under aCC-BY 4.0 International license.

\section{A}

ist-1_14.8kb promoter::GFP ist-1_9.3kb promoter::GFP ist-1_5.3kb promoter::GFP $5 \mathrm{~kb}$ Niml Mn ist- $1 b$

B

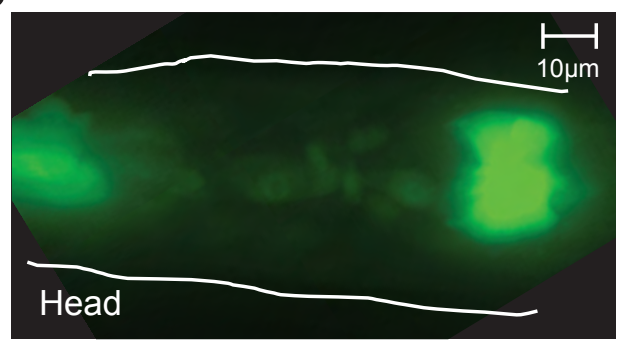

ist-1_9.3kb promoter::GFP

Expression: intestine and pharynx

Rescue learning with ist-1b cDNA: No

$\mathrm{D}$

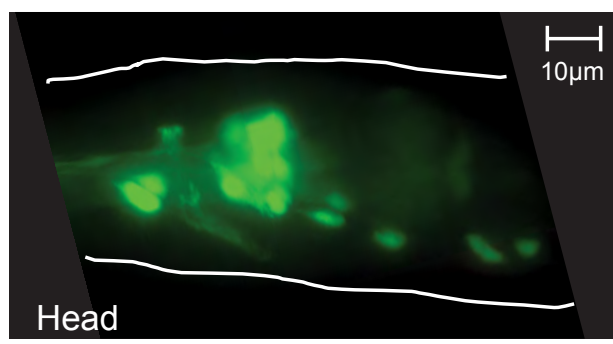

ist-1_14.8kb promoter::GFP

Expression: AIM, RIG, ASK, ASI, AWC, ASE, AUA, ASJ, RIM, ASG, BAG

Rescue learning with ist- $1 b$ cDNA: Yes
C

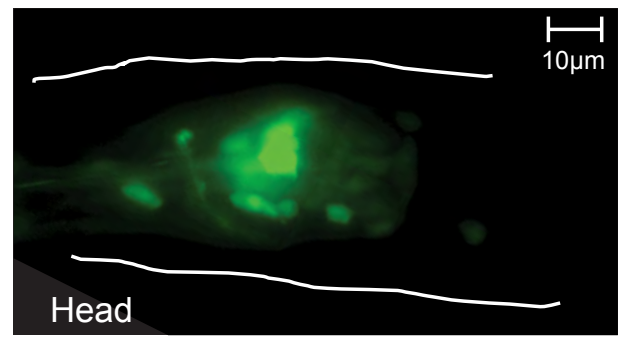

ist-1_5.3kb promoter::GFP

Expression: AWC, ASE, AUA, BAG

Rescue learning with ist-1b $c D N A$ : Yes

$E$

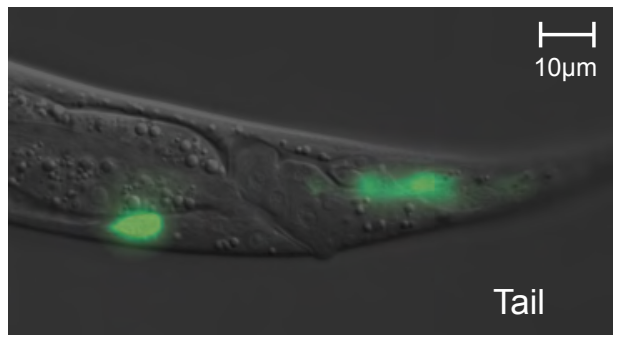

ist-1_14.8kb promoter::GFP

Expression: some tail neurons

Figure S2. ist-1 promoters and isoforms 
bioRxiv preprint doi: https://doi.org/10.1101/2022.02.14.480437; this version posted March 1, 2022. The copyright holder for this preprint (which was not certified by peer review) is the author/funder, who has granted bioRxiv a license to display the preprint in perpetuity. It is made available under aCC-BY 4.0 International license.

A Fed conditioning Low $[\mathrm{NaCl}]$ [25mM]

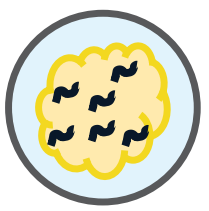

+ food

$\mathrm{NaCl}$ Preference assay
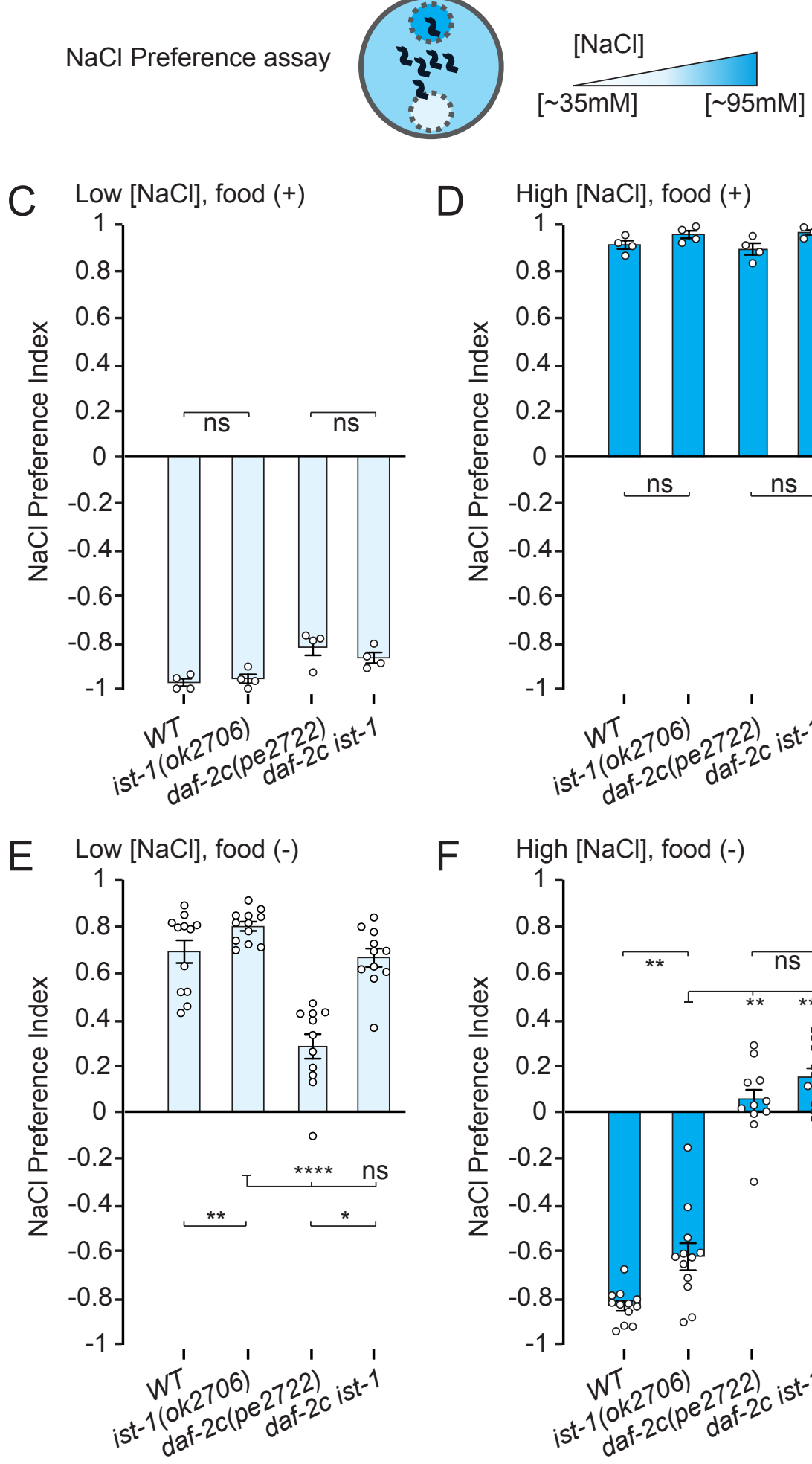

Starved conditioning

Low $[\mathrm{NaCl}] \quad$ High $[\mathrm{NaCl}]$

[25mM] [100mM]
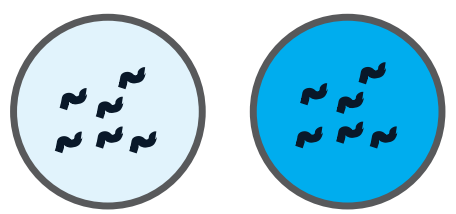

no food
F High $[\mathrm{NaCl}]$, food (-)

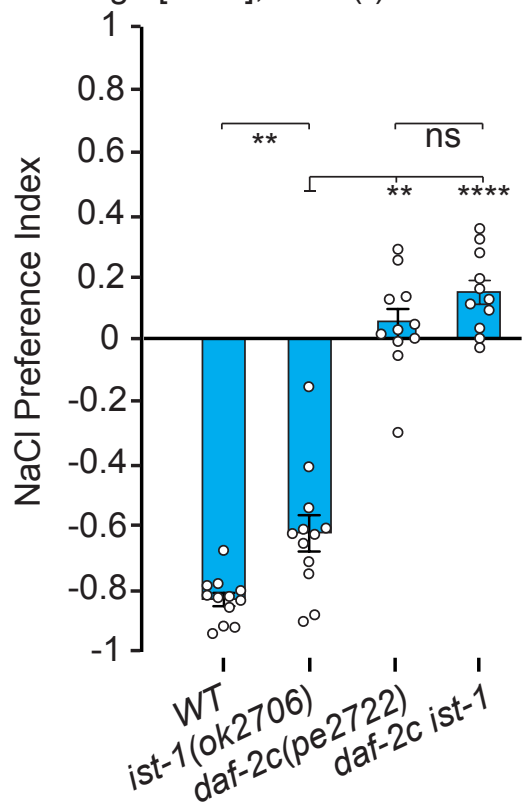

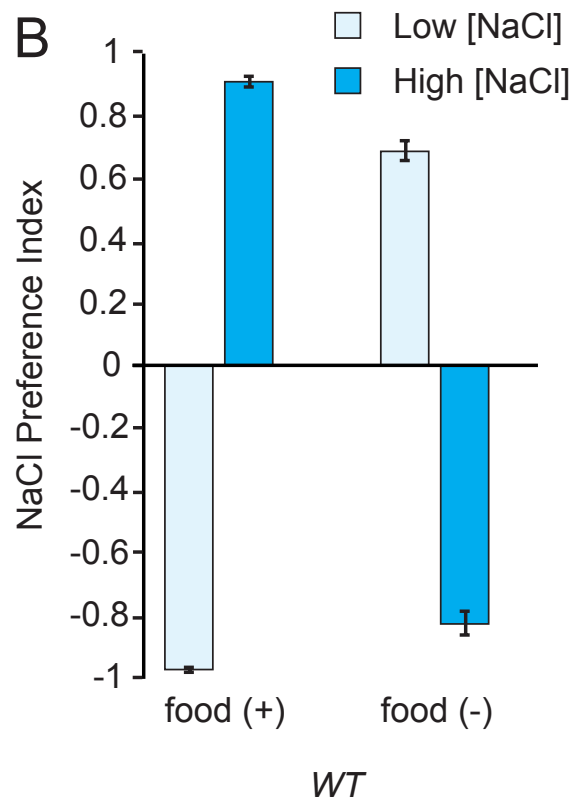

Figure S3. ist-1 phenotypes and interactions with the insulin/IGF pathway in taste learning 